\author{
Universidade de São Paulo \\ Instituto de Física
}

\title{
Utilização de técnicas de análise de franjas para a avaliação de dimensões de lesões na pele
}

\author{
Marcia Tiemi Saito
}

Orientador: Profa. Dra. Elisabeth Mateus Yoshimura

Dissertação de mestrado apresentada ao Instituto de Física para a obtenção do título de Mestre em Ciências

Banca Examinadora:

Profa. Dra. Elisabeth Mateus Yoshimura (Instituto de Física da Universidade de São Paulo)

Prof. Dr. Mikiya Muramatsu (Instituto de Física da Universidade de São Paulo)

Prof. Dr. Antonio Carlos Loureiro Lino (Instituto Agronômico de Campinas) 
Aos meus pais,

Shigueru Saito e Hiroko Tsuchiya,

que me ensinaram as coisas mais importantes nessa vida. 
"Quem sabe pode muito,

mas quem ama pode muito mais."

(Chico Xavier) 


\section{Agradecimentos}

A Deus por só trazer coisas boas em minha vida.

Aos meus pais, pelo amor, pelo carinho, pelo apoio em todos os momentos da minha vida, pela educação que me deram e a tudo que me ensinaram.

À minha irmã e toda a minha família, pelo carinho, apoio e amizade.

Aos meus amigos espirituais, que sempre me guiam e me intuem nos momentos precisos.

Ao meu companheiro e amigo Fernando Gabriel Benitez Jara, pelo apoio, compreensão e pela força que me dá.

À minha orientadora Elisabeth Mateus Yoshimura, por contribuir na minha formação e pelo exemplo de cientista e professora que ela é.

Ao Prof. Francisco F. Palacios, sem a sua ajuda este trabalho não seria nada.

Ao Prof. Mikiya Muramatsu, por me permitir utilizar o Laboratório de Óptica.

Ao técnico do Laboratório de Óptica Diogo Soga, pelas contribuições neste trabalho, pela sua disposição e empenho em ajudar, e pela sua amizade.

Aos funcionários da Oficina Central do IFUSP, que com tanta dedicação e empenho me ajudaram a construir o suporte para a tomada de dados no hospital.

Ao doutor José Angelo Lauletta Lindoso, que me recebeu com tanto carinho e me permitiu tomar dados dos seus pacientes.

Ao Prof. Antonio C. L. Lino, por contribuir na fase inicial deste trabalho.

Ao Marcelo, pela sua amizade e por me ajudar a construir as amostras.

Ao meu amigo-irmão André Luiz Ramos, pelo seu apoio, amor e amizade desde os tempos de iniciação científica.

A todos os meus amigos e colegas dos laboratórios de Dosimetria e de Óptica, pelos bons momentos que passamos juntos neste período.

A todos os meus amigos estrangeiros do IFUSP, pela sua amizade, pelas risadas e pelos bons momentos que passamos juntos, sem vocês esse período teria sido muito chato.

Aos meus amigos do CEFET-SP e a todos os outros amigos, que sempre me apoiaram e fazem a minha vida mais feliz.

Aos meus companheiros do $\mathrm{CA}$, que, assim como eu, acreditam e trabalham para tornar o IFUSP, a USP e o mundo lugares um pouco melhores.

Ao Instituto de Física da USP e à CAPES pelo apoio financeiro. 


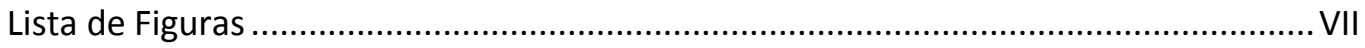

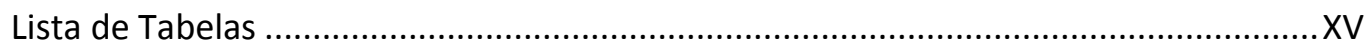

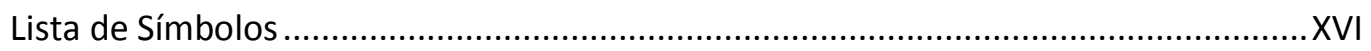

Lista de Abreviaturas ........................................................................................

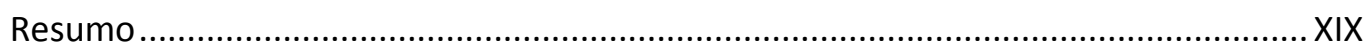

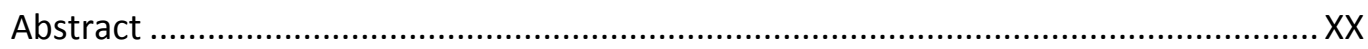

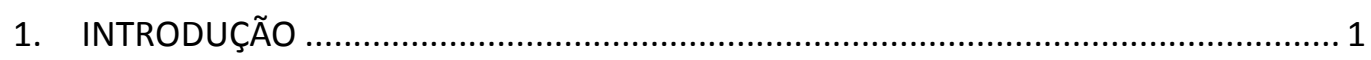

1.1 Medição das dimensões de lesões na pele ........................................................ 1

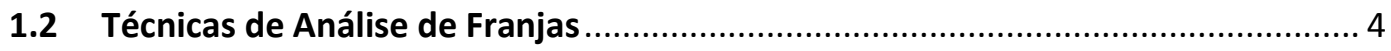

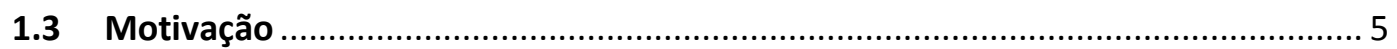

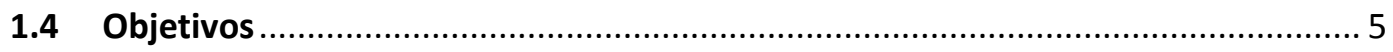

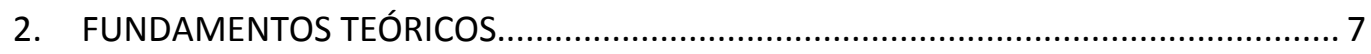

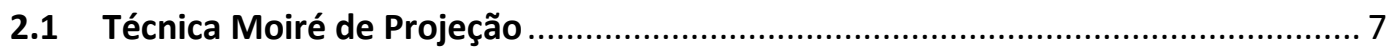

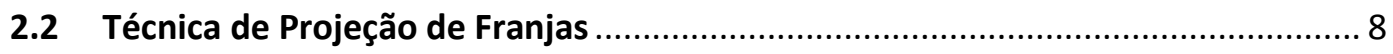

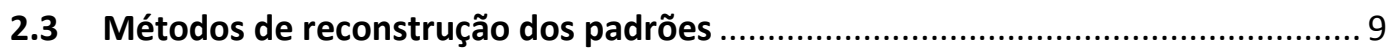

2.3.1 Método de Deslocamento de Fase ............................................................... 11

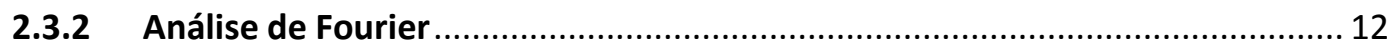

2.3.3 Método de Projeção Ortogonal ..................................................................... 14

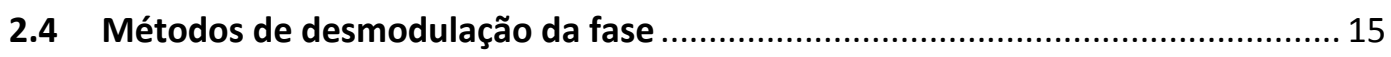

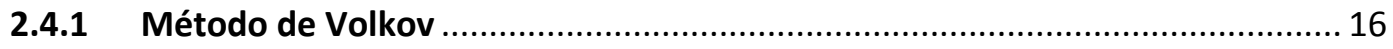

2.5 Métodos de remoção dos portadores de frequência........................................... 17 
2.5.1 Técnica de remoção linear por ajuste de um plano

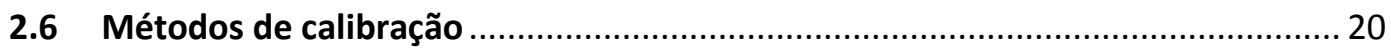

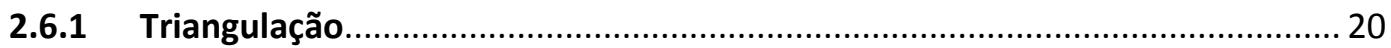

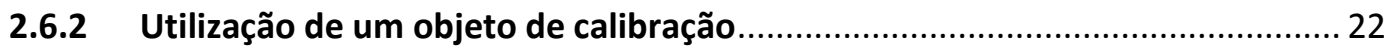

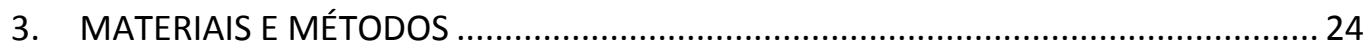

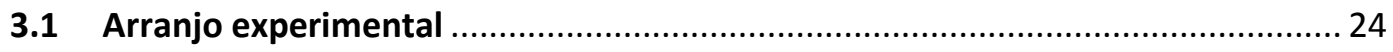

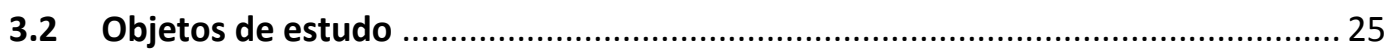

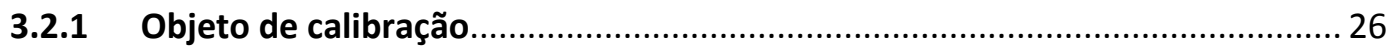

3.2.2 Objetos com topografia de análise mais simples ......................................... 26

3.2.3 Objetos com topografia de análise mais complexa......................................26

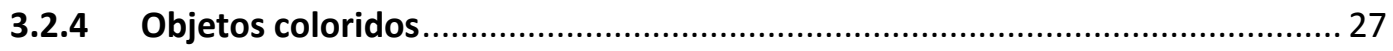

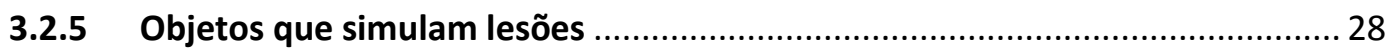

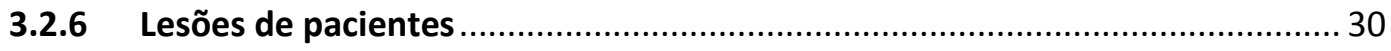

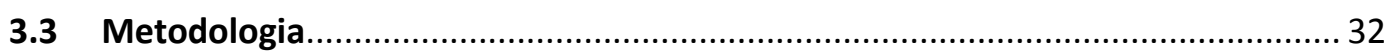

3.3.1 Medidas das dimensões dos objetos com paquímetro.................................... 32

3.3.2 Tomada de dados com a Técnica Moiré de Projeção ....................................... 33

3.3.3 Análise dos dados da Técnica Moiré de Projeção ........................................... 34

3.3.4 Tomada de dados com a Técnica de Projeção de Franjas ..................................37

3.3.5 Análise dos dados da Técnica de Projeção de Franjas ................................... 38

3.3.6 Comparação com as medidas obtidas com o paquímetro e estimativa das incertezas 40

3.3.7 Obtenção dos mapas de intensidade

4. CALIBRAÇÃO E TESTE. 
4.1 Calibração do arranjo experimental

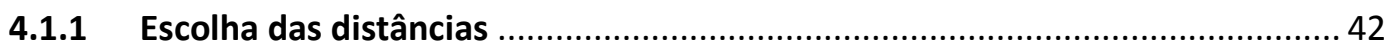

4.1.2 Escolha do período espacial das franjas ...................................................... 42

4.1.3 Escolha da cor das franjas com as amostras coloridas ................................. 45

4.1.4 Escolha do brilho e contraste da projeção para as amostras coloridas............ 47

4.2 Comparação entre a Técnica de Moiré de Projeção e a Projeção de Franjas....... 49

4.3 Comparação entre o Método de Deslocamento de Fase e o Método de Projeção Ortogonal.

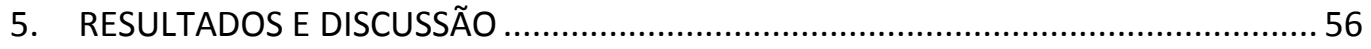

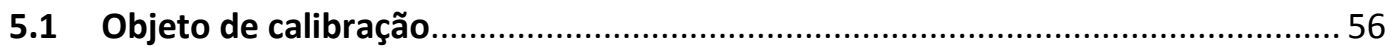

5.2 Objetos de topografias de análise mais simples ............................................... 58

5.3 Objetos de topografia de análise mais complexa ...............................................6

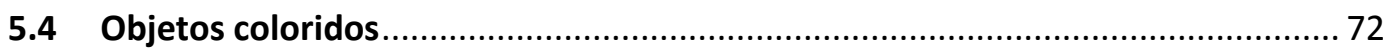

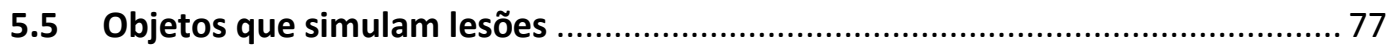

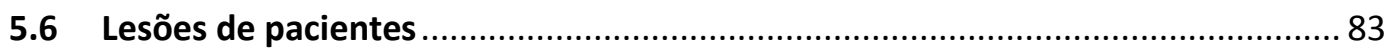

5.7 Sugestão de um protocolo de procedimento para a utilização da técnica na medida de lesões na pele. .89

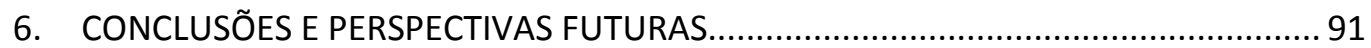

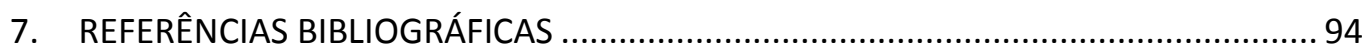

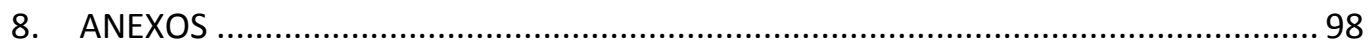

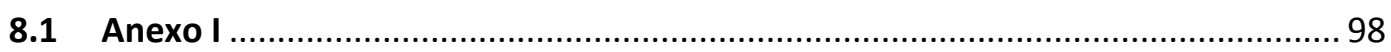




\section{Lista de Figuras}

Figura 1: Exemplo de úlcera de pressão (fonte: NPUAP, 2013)

Figura 2: Foto da perna de um paciente que sofreu safenectomia e implante de pontes de safena, cuja cicatriz apresenta deiscência (Foto: MC Chavantes - Incor/FMUSP).

Figura 3: Exemplificação da Técnica de Projeção de Franjas (fonte: Miao et al., 2004). ....... 4

Figura 4: Superposição de duas estruturas periódicas, formando um padrão moiré. ............ 7

Figura 5: Esquema de um sistema para Técnica Moiré de Projeção (modificado de Yeras, 2004).

Figura 6: Esquema de um sistema para a Técnica de Projeção de Franjas (fonte: Yeras, 2004).

Figura 7: Método de Análise de Fourier: (a) se seleciona um dos termos de primeira ordem, que contém a informação a respeito do objeto, isolando-o. (b) move-se esse termo para o centro do espectro (fonte: Quan et al., 2007).

Figura 8: (Esquerda) Espectro de Fourier de um objeto obtido com a Técnica de Projeção Ortogonal. (Direita) Seleção de um dos termos de primeira ordem, após a subtração dos espectros das franjas ortogonais, para a remoção do portador de frequência (fonte: Tavares e Vaz, 2006)

Figura 9: (a) MDT de um modelo em formato de peixe. (b) Plano de referência. (c) Após a remoção dos portadores de frequência. 18

Figura 10: (Esquerda) Iluminação de uma superfície com luz de intensidade senoidal. (Direita) Mudança no período espacial de observação das franjas devido à mudança de altura na superfície (fonte: Hobson et al., 1997)

Figura 11: Esquema do arranjo experimental utilizado.

Figura 12: Suporte construído para reproduzir o arranjo experimental da Figura 11 em um ambiente hospitalar. 25

Figura 13: Objeto e calibração. 26 
Figura 14: Objetos de topografias de análise simples.

Figura 15: Objetos de topografia de análise mais complexa. ................................................ 27

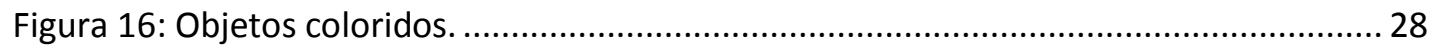

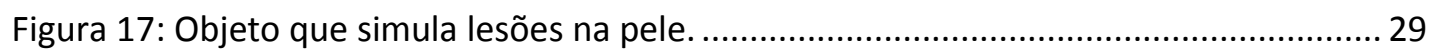

Figura 18: Simulação de uma lesão confeccionada em uma mão de borracha. ....................229

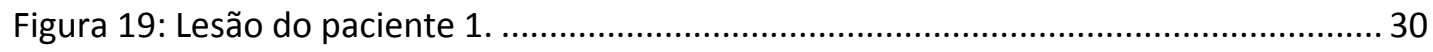

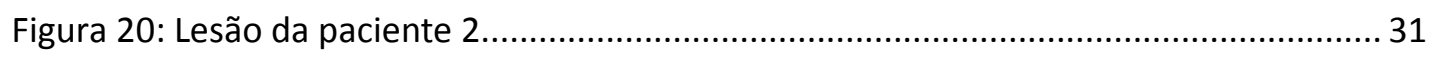

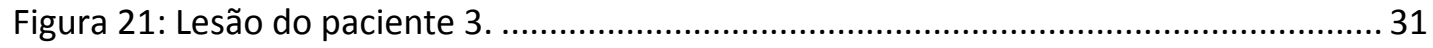

Figura 22: Objeto rígido com uma escala em papel milimetrado acoplada, usado como plano de referência.

Figura 23: Linhas ao longo das quais foram medidas as alturas do objeto em relação a um plano de referência para o objeto de calibração.

Figura 24: Gráficos da posição no eixo $z$ em função da posição ao longo da linha $x$ (esquerda) e ao longo da linha y (direita) do objeto de calibração.

Figura 25: Quatro grades com a mesma densidade de franjas, cada uma deslocada de 1/4 do período em relação à anterior, projetadas no plano de referência. 34

Figura 26: Uma das grades projetada sobre o objeto 1. 34

Figura 27: Duas grades com a mesma densidade de franjas, uma ortogonal à outra, projetadas no plano de referência. 34

Figura 28: Duas grades com a mesma densidade de franjas, uma ortogonal à outra, projetadas no objeto 1 .

Figura 29: Subtração das imagens com as quatro grades deslocadas de $1 / 4$ do período da com uma das grades projetada no objeto 1, para a análise com a Técnica Moiré de Projeção com Deslocamento de Fase. 35 
Figura 30: As quatro imagens da Figura 29, após a aplicação do filtro gaussiano, para a obtenção do padrão moiré.

Figura 31: Subtração das imagens das grades ortogonais projetadas no plano de referência das suas respectivas imagens com a grade projetada no objeto 1, para a análise com a Técnica Moiré com Projeção Ortogonal.

Figura 32: Etapas para a análise dos dados obtidos com a Técnica Moiré de Projeção com Deslocamento de Fase.

Figura 33: Etapas para a análise dos dados obtidos com a Técnica Moiré com Projeção Ortogonal.

Figura 34: Quatro grades com a mesma densidade de franjas, cada uma deslocada de 1/4 do período em relação à anterior, projetadas no objeto 1 .

Figura 35: Etapas para a análise dos dados obtidos com a Técnica de Projeção de Franjas com Deslocamento de Fase. 39

Figura 36: Etapas para a análise dos dados obtidos com a Técnica de Projeção de Franjas com Projeção Ortogonal. 40

Figura 37: (Esquerda) Linhas traçadas ao longo dos principais eixos das regiões de interesse do objeto 1. (Direita) Comparação dos perfis obtidos com a Técnica de Projeção de Franjas com Deslocamento de Fase e o medido com o paquímetro, ao longo da linha 2y do objeto 1.41

Figura 38: Variação do número de franjas de 80 a 130, de 10 em 10 franjas, em uma imagem de $1000 \times 600$ pixels e projeção sobre o objeto 1. As imagens adquiridas possuíam $280 \times 960$ pixels.

Figura 39: Linhas traçadas em uma parte plana do objeto, com (a) 90 e (c) 130 franjas projetadas. Perfis de intensidade luminosa em níveis de cinza ao longo das linhas traçadas, para (b) 90 e (d) 130 franjas projetadas. 44

Figura 40: MDT obtido com um período espacial de franjas $p=(0,33 \pm 0,01) \mathrm{cm} /$ franja. .45

Figura 41: Espectro de absorção da melanina e da hemoglobina (fonte: Wang et al., 2010). 
Figura 42: Perfis das franjas preto e branco e ciano e vermelho ao longo da linha amarela, para as amostras de pele escura (acima) e pele média (abaixo), respectivamente. 46

Figura 43: Perfis, ao longo da linha amarela, das franjas preto e branco projetadas sobre o objeto de cor pele clara, com contraste do projetor fixo igual a 50 e brilhos iguais a 25 (acima) e 95 (abaixo).

Figura 44: Perfis, ao longo da linha amarela, das franjas preto e branco projetadas sobre o objeto de cor pele clara, com brilho do projetor fixo igual a 65 e contrastes iguais a 20 (acima) e 80 (abaixo).

Figura 45: Mapa de fases moduladas (esquerda) e MDT (direita) obtidos com a Técnica Moiré de Projeção com Deslocamento de Fase, para o objeto 1.

Figura 46: MDT 3D obtido com a Técnica Moiré de Projeção com Deslocamento de Fase, para o objeto 1 . 50

Figura 47: Mapa de fases moduladas (esquerda) e MDT (direita) obtidos com a Técnica de Projeção de Franjas com Deslocamento de Fase, para o objeto 1. 50

Figura 48: MDT 3D obtido com a Técnica de Projeção de Franjas com Deslocamento de Fase, para o objeto 1 50

Figura 49: MDTs do objeto 1 obtidos com a Técnica Moiré de Projeção (esquerda) e com a Técnica de Projeção de Franjas (direita), ambas com Deslocamento de Fase.

Figura 50: Mapa de fases moduladas (esquerda) e MDT (direita) obtidos com a Técnica de Projeção de Franjas com Projeção Ortogonal, para o objeto 1. 53

Figura 51: MDT 3D obtido com a Técnica de Projeção de Franjas com Projeção Ortogonal, para o objeto 1 . 54

Figura 52: MDTs do objeto 1 obtidos com a Técnica de Projeção de Franjas com Deslocamento de Fase (esquerda) e com Projeção Ortogonal (direita). 54

Figura 53: Espectro de Fourier do objeto 1, obtido com a Técnica de Projeção de Franjas com Projeção Ortogonal. 55 
Figura 54: (a) Mapa de fases moduladas do objeto de calibração. (b) MDT. (c) comparação do perfil obtido com a Técnica de Projeção de Franjas e o paquímetro ao longo da linha x e (d) da linha $y$

Figura 55: MDT 3D (esquerda) e mapa de intensidades (direita) obtidos para o objeto de calibração. .57

Figura 56: (a) Mapa de fases moduladas do objeto 1. (b) MDT. (c) Comparação do perfil obtido com a Técnica de Projeção de Franjas e o paquímetro ao longo da linha 1x, (d) da linha $1 y,(e)$ da linha $2 x$ e (f) da linha $2 y$. 58

Figura 57: (a) Mapa de fases moduladas do objeto 2. (b) MDT. (c) Comparação do perfil obtido com a Técnica de Projeção de Franjas e o paquímetro ao longo da linha x e (d) da linha y. 59

Figura 58: (a) Mapa de fases moduladas do objeto 3. (b) MDT. (c) Comparação do perfil obtido com a Técnica de Projeção de Franjas e o paquímetro ao longo da linha $x$ e (d) da linha y....... 59

Figura 59: MDT 3D (esquerda) e mapa de intensidades (direita) obtidos para o objeto 1. . 61

Figura 60: MDT 3D (esquerda) e mapa de intensidades (direita) obtidos para o objeto 2. . 62

Figura 61: MDT 3D (esquerda) e mapa de intensidades (direita) obtidos para o objeto 3. . 62

Figura 62: (a) Mapa de fases moduladas do objeto 4. (b) MDT. (c) comparação do perfil obtido com a Técnica de Projeção de Franjas e o paquímetro ao longo da linha x e (d) da linha y........ .66

Figura 63: (a) Mapa de fases moduladas do objeto 5. (b) MDT. (c) comparação do perfil obtido com a Técnica de Projeção de Franjas e o paquímetro ao longo da linha x e (d) da linha y....... 66

Figura 64: (a) Mapa de fases moduladas do objeto 6. (b) MDT. (c) comparação do perfil obtido com a Técnica de Projeção de Franjas e o paquímetro ao longo da linha x e (d) da linha y. 67 
Figura 65: (a) Mapa de fases moduladas do objeto 7. (b) MDT. (c) comparação do perfil obtido com a Técnica de Projeção de Franjas e o paquímetro ao longo da linha x e (d) da linha y.

Figura 66: (a) Mapa de fases moduladas do objeto 8. (b) MDT. (c) comparação do perfil obtido com a Técnica de Projeção de Franjas e o paquímetro ao longo da linha x e (d) da linha y. 68

Figura 67: (a) Mapa de fases moduladas do objeto 9. (b) MDT. (c) comparação do perfil obtido com a Técnica de Projeção de Franjas e o paquímetro ao longo da linha x e (d) da linha y. .68

Figura 68: MDT 3D (esquerda) e mapa de intensidades (direita) obtidos para o objeto 4. . 69

Figura 69: MDT 3D (esquerda) e mapa de intensidades (direita) obtidos para o objeto 5. . 70 Figura 70: MDT 3D (esquerda) e mapa de intensidades (direita) obtidos para o objeto 6. . 70 Figura 71: MDT 3D (esquerda) e mapa de intensidades (direita) obtidos para o objeto 7. . 70 Figura 72: MDT 3D (esquerda) e mapa de intensidades (direita) obtidos para o objeto 8. . 71 Figura 73: MDT 3D (esquerda) e mapa de intensidades (direita) obtidos para o objeto 9. . 71

Figura 74: (a) Mapa de fases moduladas do objeto pele clara. (b) MDT. (c) comparação do perfil obtido com a Técnica de Projeção de Franjas e o paquímetro ao longo da linha $x$ e (d) da linha $y$.

Figura 75: (a) Mapa de fases moduladas do objeto pele média. (b) MDT. (c) comparação do perfil obtido com a Técnica de Projeção de Franjas e o paquímetro ao longo da linha $x$ e (d) da linha $y$.

Figura 76: (a) Mapa de fases moduladas do objeto pele escura. (b) MDT. (c) comparação do perfil obtido com a Técnica de Projeção de Franjas e o paquímetro ao longo da linha x e (d) da linha $y$. 74

Figura 77: (a) Mapa de fases moduladas do objeto vermelho. (b) MDT. (c) comparação do perfil obtido com a Técnica de Projeção de Franjas e o paquímetro ao longo da linha $x$ e (d) da linha $y$. .75 
Figura 78: MDT 3D (esquerda) e mapa de intensidades (direita) obtidos para o objeto pele clara. .75

Figura 79: MDT 3D (esquerda) e mapa de intensidades (direita) obtidos para o objeto pele média

Figura 80: MDT 3D (esquerda) e mapa de intensidades (direita) obtidos para o objeto pele escura.

Figura 81: MDT 3D (esquerda) e mapa de intensidades (direita) obtidos para o objeto vermelho. .76

Figura 82: Mapa de fases moduladas (acima) e mapa de intensidades (abaixo) para o objeto lesões. .78

Figura 83: (a) MDT da lesão 1 do objeto lesões. (b) MDT 3D. (c) comparação do perfil obtido com a Técnica de Projeção de Franjas e o paquímetro ao longo da linha $x$ e (d) da linha y......

Figura 84: (a) MDT da lesão 2 do objeto lesões. (b) MDT 3D. (c) comparação do perfil obtido com a Técnica de Projeção de Franjas e o paquímetro ao longo da linha x e (d) da linha y .79

Figura 85: (a) MDT da lesão 3 do objeto lesões. (b) MDT 3D. (c) comparação do perfil obtido com a Técnica de Projeção de Franjas e o paquímetro ao longo da linha x e (d) da linha y. .79

Figura 86: (a) Mapa de fases moduladas da lesão confeccionada em mão de borracha. (b) MDT. (c) comparação do perfil obtido com a Técnica de Projeção de Franjas e o paquímetro ao longo da linha $x$ e (d) da linha y 80

Figura 87: MDT 3D (esquerda) e mapa de intensidades (direita) obtidos para a lesão confeccionada em mão de borracha.

Figura 88: (a) Mapa de fases moduladas da lesão do paciente 1. (b) MDT. (c) perfil obtido com a Técnica de Projeção de Franjas ao longo da linha x.

Figura 89: MDT 3D (esquerda) e mapa de intensidades (direita) obtidos para a lesão do paciente 1 
Figura 90: (a) Mapa de fases moduladas da lesão do paciente 2. (b) MDT. (c) perfil obtido com a Técnica de Projeção de Franjas ao longo da linha x. 85

Figura 91: MDT 3D (esquerda) e mapa de intensidades (direita) obtidos para a lesão do paciente 2 86

Figura 92: (a) Mapa de fases moduladas da lesão do paciente 3. (b) MDT. (c) perfil obtido com a Técnica de Projeção de Franjas ao longo da linha x. .87

Figura 93: MDT 3D (esquerda) e mapa de intensidades (direita) obtidos para a lesão do paciente 3 87 


\section{Lista de Tabelas}

Tabela 1: Estadiamento da úlcera de pressão recomendado pelo National Pressure Ulcer Advisory Panel (NPUAP). (fonte: Ferreira et al., 2008).

Tabela 2: Classificação das cores dos objetos coloridos, de acordo com a escala Pantone ${ }^{\circledR}$.

Tabela 3: Classificação das cores dos objetos que simulam lesões, de acordo com a escala Pantone ${ }^{\circledR}$ 29

Tabela 4: Máximas discrepâncias entre as medidas dos perfis obtidas com a Técnica de Projeção de Franjas e com o paquímetro para os objetos de topografia de análise simples. ... 63

Tabela 5: Máximas discrepâncias entre as medidas dos perfis obtidas com a Técnica de Projeção de Franjas e com o paquímetro para os objetos de topografia de análise mais complexa.

Tabela 6: Máximas discrepâncias entre as medidas dos perfis obtidas com a Técnica de Projeção de Franjas e com o paquímetro para os objetos coloridos e para os que simulam lesões. 82 


\section{Lista de Símbolos}

$A(x, y)$ : intensidade média, quantifica a iluminação de fundo

$B(x, y)$ : intensidade modulada, quantifica da visibilidade das franjas

C: coeficiente de calibração da imagem

$C\left(u-f_{0}, v\right):$ um dos termos de primeira ordem no espectro da Análise de Fourier

$d$ : distância entre a câmera e o projetor

$\delta_{n}$ : Deslocamento de fase introduzido no Método de Deslocamento de Fase

$\Delta \phi$ : variação na fase do padrão projetado

$\Delta h$ : variação de altura em relação ao plano de referência

$\operatorname{Er}\left(f_{x}, f_{y}, \phi_{c, 0}\right)$ : função erro da função dos portadores de fase

$F:$ Transformada de Fourier direta

$F^{-1}$ : Transformada de Fourier inversa

$f_{0}$ : portador de frequência

$\phi(x, y)$ : fase desmodulada, a ser determinada

$\phi_{m}(\vec{r})$ : fase modulada

$\phi_{c, \text { exp }}$ : valor da fase obtida experimentalmente no plano de referência

$G\left(\frac{2 \pi}{p} x\right):$ função periódica qualquer

$g_{1}(x, y)$ : padrão de franjas senoidal projetado no objeto na Análise de Fourier

$g_{2}(x, y)$ : segundo padrão de franjas, ortogonal a $g_{1}(x, y)$, projetado no objeto no Método de Projeção Ortogonal 
$G_{1}(u, v):$ Transformada de Fourier de $g_{1}(x, y)$

$G_{2}(u, v):$ Transformada de Fourier de $g_{2}(x, y)$

$h(x, y)$ : altura do objeto em cada ponto $(\mathrm{x}, \mathrm{y})$ da imagem

$I(x, y)$ : intensidade luminosa em cada ponto $(\mathrm{x}, \mathrm{y})$ da imagem

$I_{n}(x, y)$ : intensidade luminosa introduzida para casa $\delta_{n}$ no Método de Deslocamento de Fase

$L$ : distância entre a CCD e o plano de referência

$\lambda:$ comprimento de onda

$p$ : período espacial da função/intensidade luminosa do padrão

$p^{\prime}$ : período espacial da função/intensidade luminosa do padrão na superfície plana

$p^{\prime \prime}$ : período espacial da função/intensidade luminosa do padrão observado a um ângulo $\theta_{v}$

$\vec{q}\left(q_{x}, q_{y}, q_{z}\right)$ : vetor que opera no espaço recíproco da imagem

$\theta_{i}$ : ângulo de iluminação

$\theta_{v}$ : ângulo de visualização/observação do padrão

$\vec{r}(x, y, z)$ : vetor que opera no espaço real da imagem

$\sigma_{h}$ : incerteza na altura

$\sigma_{p}:$ incerteza do paquímetro

$\sigma_{e m}:$ incerteza da escala milimetrada

$\psi(\vec{r})$ : função escalar bidimensional, com as frequências corrigidas pelo Método de Volkov 


\section{Lista de Abreviaturas}

CCD: dispositivo de carga acoplada (charge-coupled device)

FFT: Transformada de Fourier rápida (Fast Fourier Transform)

FM: Fáscia muscular

INPM: Instituto Nacional de Pesos e Medidas

LED: diodo emissor de luz (Light Emitting Diode)

MDT: Modelo Digital Topográfico

MEMS: Sistemas microeletrônicos

OE: Objeto de estudo

Pantone $^{\circledR}$ : escala comercial de classificação de cores para um sistema de reprodução

PR: Plano de referência

R: Rede

RGB: sistema de cores formado por vermelho (Red), verde (Green) e azul (Blue)

RO: Rede de observação

RP: Rede de projeção

SO: Sistema de observação

SP: Sistema de projeção

SVGA: resolução do projetor (Super Video Graphics Array)

TCS: Tecido celular subcutâneo 


\section{Resumo}

A medida precisa de dimensões de lesões crônicas e o acompanhamento do processo de cicatrização são essenciais durante o tratamento. Porém, os métodos utilizados atualmente para esse fim são invasivos e imprecisos. Por outro lado, as técnicas de análise de franjas são métodos óticos amplamente explorados para a obtenção de topografias de objetos, pela análise da deformação de um padrão periódico de franjas projetado sobre a superfície deles. Dessa forma, a utilização dessas técnicas surge como uma interessante alternativa para a obtenção da topografia e das dimensões das lesões.

Com o intuito de desenvolver uma técnica de análise de franjas capaz de medir dimensões de lesões na pele de forma não invasiva, rápida, exata e de baixo custo, comparou-se a Técnica Moiré de Projeção e a Técnica de Projeção de Franjas, chegando-se a conclusão de que a segunda era a mais adequada para o propósito. Assim, projetaram-se quatro padrões de franjas, deslocados de $1 / 4$ do período entre si, sobre a superfície do objeto de estudo e, através da análise das imagens, obteve-se um mapa com as fases dos padrões moduladas pela presença do objeto. Em seguida, esse mapa foi desmodulado para a obtenção das fases reais. Para a calibração desse mapa e obtenção das dimensões do objeto, utilizou-se um objeto de calibração de dimensões conhecidas, cujas imagens foram obtidas e analisadas nas mesmas condições que as imagens do objeto de estudo.

Para a validação da técnica, obteve-se a topografia de vários objetos, que simulavam diferentes características das lesões, e compararam-se os resultados obtidos com as dimensões conhecidas deles. As limitações encontradas para a técnica se referem à presença de sombra e brilho na imagem e a variações abruptas na topografia dos objetos. A incerteza obtida para a técnica com o arranjo experimental utilizado foi de $3 \mathrm{~mm}$.

Uma vez validada a técnica e estudadas suas limitações, foram feitas medidas das dimensões de lesões em pacientes e verificou-se que é possível a utilização da técnica de análise de franjas para esse fim. Assim, pôde-se estabelecer uma sugestão de protocolo para a medição de dimensões de lesões no ambiente clínico, utilizando a análise de franjas. 


\begin{abstract}
Measuring chronic wound dimensions and evaluating the healing process are very important procedures during the treatment; however, the methods currently used for this are invasive and inaccurate. On the other hand, the fringe analysis techniques are optical methods, widely explored to obtain the 3D topography of an object. It consists in analyzing the deformation of a periodic fringe pattern projected on an object surface. Thereby, the fringe analysis techniques are an interesting alternative to obtain wound dimensions and topography.

In order to develop a fringe analysis technique that can measure wound dimensions using a non-invasive, fast, accurate and low-cost method, the Moire Projection and the Fringe Projection Techniques were compared, with the conclusion that the second one was the most suitable for the proposal. This way, four fringe patterns are projected on the object surface, each one displaced of $1 / 4$ of the period. Through the images analysis, a wrapped phase map, with the phases modulated by the object topography, was obtained. This map is unwrapped to obtain the actual phases. To calibrate this map and obtain the object dimensions, a calibration object with known dimensions was used. Its images were obtained and analyzed in the same conditions as the studied object.

To validate the technique, the topography of different objects, which simulated wound characteristics, were obtained, and the results were compared with the known dimensions. The limitations of this technique are due to the presence of shadow and bright light in the image and to abrupt variations in the object topographies. The uncertainty of the technique obtained with this experimental setup was of $3 \mathrm{~mm}$.

Once the technique was validated and its limitations were studied, measurements of patient's wound dimensions were made and it was verified that the utilization of the fringe analysis technique for this application is feasible. Thus, it was possible to develop a suggestion of procedure protocol to use the technique for measuring wound dimensions in the clinic environment.
\end{abstract}




\section{INTRODUÇÃO}

\subsection{Medição das dimensões de lesões na pele}

Lesões crônicas, como as úlceras por pressão ou úlceras de decúbito, são uma das causas mais comuns de morbidade e até mesmo mortalidade em pacientes, com incidências nos hospitais que variam de 1\% a 29\% [Haghpanah et al., 2006].

A úlcera por pressão, como a mostrada na Figura 1, é definida como a área de morte celular que se desenvolve quando um tecido é comprimido por um período de tempo capaz de provocar isquemia local, a qual prejudica a perfusão da região e a oxigenação celular por compressão. Essa importante comorbidade acomete pacientes submetidos a prolongados períodos de internação hospitalar, especialmente, nas unidades de terapia intensiva e pode apresentar diferentes estadiamentos, como mostrado na Tabela 1 [Ferreira et al., 2008; NPUAP, 2013].

O tratamento, para os estadiamentos mais avançados, costuma ser primeiramente o desbridamento do tecido necrótico da lesão, seguido de tratamento específico para cada caso buscando o fechamento da lesão, o que pode ocorrer através de métodos para o estímulo do tecido de granulação, retalho cutâneo, laserterapia, entre outros.

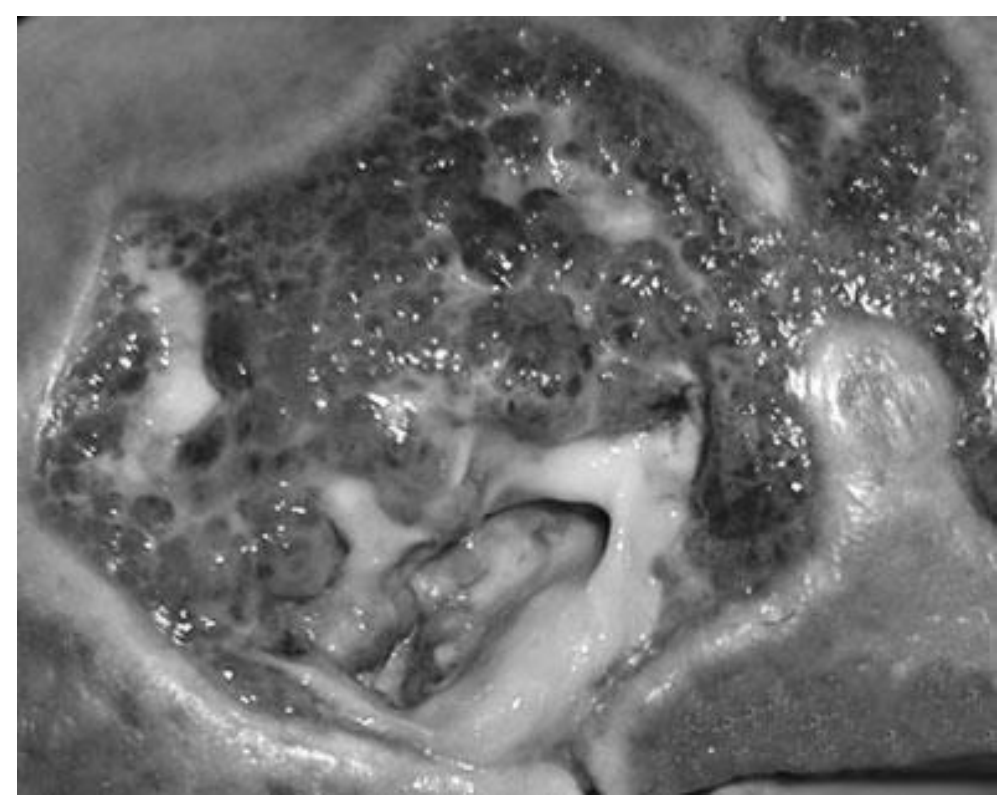

Figura 1: Exemplo de úlcera de pressão (fonte: NPUAP, 2013). 
Tabela 1: Estadiamento da úlcera de pressão recomendado pelo National Pressure Ulcer Advisory Panel (NPUAP). (fonte: Ferreira et al., 2008).

\begin{tabular}{|c|l|}
\hline Estadiamento & Descrição \\
\hline I & $\begin{array}{l}\text { Pele intacta; presença de eritema mantido. } \\
\text { Pode haver alteração na temperatura e } \\
\text { pigmentação ao redor da área }\end{array}$ \\
\hline II & $\begin{array}{l}\text { Lesão parcial da pele: epiderme e porção } \\
\text { superior da derme. Apresenta-se como uma } \\
\text { abrasão, bolha ou cratera rasa. }\end{array}$ \\
\hline III & $\begin{array}{l}\text { Lesão total da pele: epiderme e toda } \\
\text { extensão da derme, pode acometer tecido } \\
\text { celular subcutâneo (TCS) e fáscia muscular (FM) }\end{array}$ \\
\hline IV & $\begin{array}{l}\text { Lesão total da pele, TCS, FM, atingindo } \\
\text { músculos, ossos e estruturas de suporte } \\
\text { (tendões e articulações) }\end{array}$ \\
\hline
\end{tabular}

Outra importante situação onde as lesões crônicas estão presentes é quando o paciente é submetido a uma cirurgia e possui, ao mesmo tempo, outras morbidades (como diabetes, hipertensão, obesidade) que dificultam o processo de cicatrização, produzindo inclusive deiscências, como no caso do paciente da Figura 2.

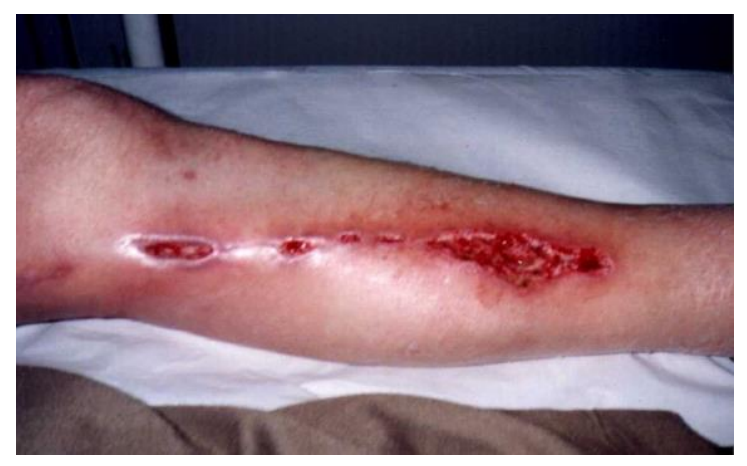

Figura 2: Foto da perna de um paciente que sofreu safenectomia e implante de pontes de safena, cuja cicatriz apresenta deiscência (Foto: MC Chavantes - Incor/FMUSP).

Em todos esses casos, a medida precisa das dimensões da lesão e o acompanhamento do processo de cicatrização, são essenciais durante o tratamento.

Para o acompanhamento do processo de cicatrização, muitas vezes se utilizam métodos histológicos, como a biópsia, que depende da retirada de amostras da lesão. Trata-se de um método capaz de oferecer informações a respeito do estado do processo 
de cicatrização e formação tecidual, porém possui a desvantagem de ser um método invasivo [Edsberg, 2007].

Já os métodos utilizados atualmente na prática clínica para avaliar as dimensões de lesões na pele e acompanhar a sua evolução no processo de cicatrização apresentam diversos problemas, sendo em sua maioria invasivos e imprecisos ou, então, ficam limitados à medida apenas da área superficial da lesão. Alguns desses métodos são descritos em Haghpanah et al. (2006), Humbert et al. (2004), Lagan et al. (2000) e Cooper (1991), e são resumidos abaixo:

a. Métodos lineares manuais:

- Uso de réguas ou grades de plástico graduadas: com contato direto, mede-se o comprimento vertical e a largura horizontal máximos, podendo-se estimar a área superficial;

- Cotonetes e hastes de ponta estéreis: introduzem-se esses elementos na lesão do paciente para estimar a profundidade;

b. Métodos lineares eletrônicos:

- Através de imagens digitais: fotografa-se a lesão, com uma escala conhecida aparecendo na imagem, posicionada no mesmo plano da lesão. Com essa imagem se pode estimar a área superficial da lesão;

c. Métodos para medir área e volume:

- Sondas ou sistemas de coordenadas (consistindo de três réguas acopladas): introduzem-se esses dispositivos na lesão e medem-se as dimensões internas, possibilitando estimar o volume desta;

- Moldes de alginato: introduz-se o alginato na lesão e espera-se que se forme o molde rígido, retira-se esse molde e mede-se o seu volume pesando-o ou verificando o deslocamento causado em recipiente graduado com água;

Dessa forma, devido à importância em medir com exatidão as dimensões das lesões, para o acompanhamento desse importante fator no processo de cicatrização, e à necessidade de se encontrar métodos mais confiáveis e menos invasivos para realizar 
essas medidas, as técnicas de análise de franjas surgem com uma boa alternativa, capazes de avaliar com exatidão o formato, a profundidade e o volume das lesões na pele, de forma não invasiva, precisa e de baixo custo.

\subsection{Técnicas de Análise de Franjas}

As técnicas de análise de franjas como a Técnica Moiré de Projeção e a Técnica de Projeção de Franjas são técnicas ópticas conhecidas capazes de medir o posicionamento e a deformação de objetos, perfis de superfície, topografia dos objetos em três dimensões, entre outras grandezas físicas, sem contato e sem destruir a amostra [Rajshekhar e Rastogi, 2012]. Elas têm sido largamente exploradas nos últimos anos, em diversas áreas, e consistem basicamente em projetar um padrão periódico de franjas sobre a superfície de um objeto (como exemplificado na Figura 3), fotografá-lo e, a partir da observação da deformação desses padrões de acordo com a topografia do objeto, calcular as informações a respeito da superfície em 3D.
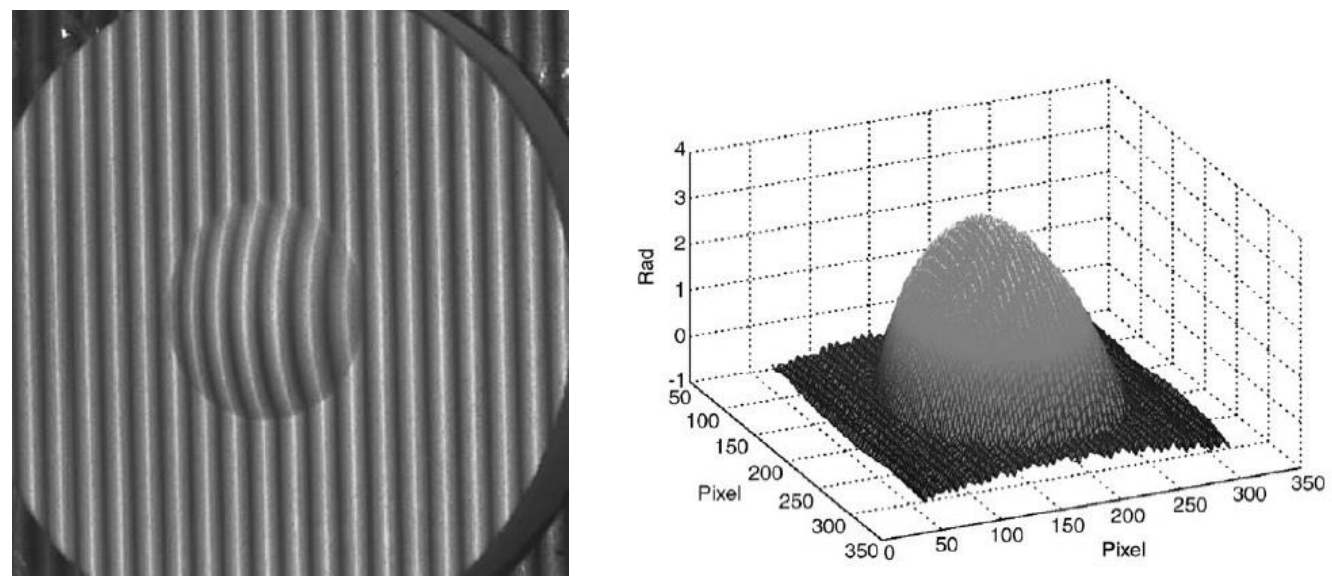

Figura 3: Exemplificação da Técnica de Projeção de Franjas (fonte: Miao et al., 2004).

Suas aplicações vão desde a análise da topografia de objetos de dimensões da ordem de micrometros, como os componentes de sistemas microeletrônicos (MEMS), até a obtenção da topografia de painéis, da ordem de 2,5 m x 0,45 m [Gorthi e Rastogi, 2010]. Essas técnicas têm sido aplicadas nas áreas industrial e científica, na análise de vibrações [Zhang e Su, 2005], detecção de deformações em superfícies [Zhang e Su, 2002], análise de corrosão [Huang et al., 1999], análises biométricas como o reconhecimento facial [Zhou et al., 2009], na área agrônoma, na análise de superfície de folhas e órgãos vegetais [Martínez et al., 2012; Lino, 2008], na área biomédica na reconstrução 3D intraoral dental [Chen e Huang, 2005; Yeras, 2003], medida da forma corporal [Lilley et al., 2000], detecção 
de escoliose [Yeras, 2004], entre outras. Suas principais vantagens são a alta resolução, a ausência de contato para a obtenção das topografias, a simplicidade e baixo custo.

Em trabalho anterior, Ferraq et al. (2007) mostrou é possível a utilização da Técnica de Projeção de Franjas, por exemplo, para a avaliação da profundidade de lesões induzidas na pele humana ex vivo. Porém, ainda não foram realizados estudos detalhados sobre a utilização dessa técnica na determinação do volume de lesões e suas limitações, e tampouco foram feitos estudos sobre a aplicabilidade desta na medida de dimensões de lesões in vivo.

\subsection{Motivação}

Conforme visto anteriormente, a medida de dimensões de lesões com exatidão é de extrema importância para avaliar a eficácia do tratamento no processo de cicatrização. Porém, os métodos utilizados atualmente na prática clínica para a medida das dimensões das lesões são invasivos e imprecisos ou, então, se limitam apenas à medida da área superficial da lesão.

Por outro lado, as técnicas de análise de franjas são técnicas ópticas largamente exploradas nos últimos anos para a obtenção da topografia de objetos em três dimensões, tendo as vantagens de ser uma técnica de alta resolução, com ausência de contato, simples e de baixo custo.

Dessa forma, a motivação desse trabalho é desenvolver a aplicabilidade das técnicas de análise de franjas na medida de dimensões de lesões na pele, de modo a buscar uma técnica que permita a avaliação dessas dimensões de forma confiável, precisa, não invasiva e de baixo custo.

\subsection{Objetivos}

O objetivo geral desse trabalho é desenvolver a aplicação de uma técnica de análise de deformação de franjas, com o intuito de utilizá-la na rotina clínica, para a avaliação das dimensões de lesões na pele e sua evolução durante o processo de cicatrização, além de estudar as suas limitações. 
Os objetivos específicos deste trabalho consistem em:

- Montar um arranjo experimental e estudar os melhores parâmetros (periodicidade do padrão de franjas, distâncias ótimas, brilho e contraste da projeção, entre outros) para obter imagens em um ambiente clínico;

- Comparar duas técnicas diferentes de análise de franjas (Moiré de Projeção e Projeção de Franjas), para escolher uma e desenvolver sua aplicabilidade na medição de dimensões de lesões;

- Comparar dois métodos diferentes de reconstrução dos padrões (Deslocamento de Fase e Projeção Ortogonal);

- Explorar a possibilidade de projetar franjas coloridas com o intuito de obter melhor contraste entre as franjas e as superfícies dos objetos de estudo;

- Estudar as limitações e a precisão possíveis de atingir com a técnica;

- Sugerir um protocolo de procedimento para a utilização da técnica na medida de dimensões de lesões na pele. 


\section{FUNDAMENTOS TEÓRICOS}

\subsection{Técnica Moiré de Projeção}

O fenômeno moiré [Costa et al., 2008; Patorski, 1993] pode ser observado na superposição de duas ou mais estruturas periódicas ou quase periódicas quaisquer, formando um novo padrão periódico, o chamado padrão moiré, conforme mostrado na Figura 4. O termo "moiré" é um termo francês para "aparência de ondas ou ondulatória" e se refere à superposição de duas peças de seda, que apresentam movimento relativo entre si, produzindo franjas. Esses padrões de franjas podem dar informação a respeito da superfície, da topografia, do formato e inclinação de objetos regulares e irregulares, e podem ser obtidos por diversas técnicas como:

- Moiré Intrínseco: o padrão moiré é formado pela superposição de um padrão periódico acoplado fisicamente ao objeto e outro presente no sistema de observação;

- Moiré de Reflexão: o padrão moiré é formado pela superposição de um padrão periódico refletido pela superfície do objeto e outro presente no sistema de observação;

- Moiré de Sombra: o padrão moiré é formado pela superposição do padrão periódico em si e sua sombra;

- Moiré de Projeção: o padrão moiré é formado pela superposição da projeção do padrão periódico com outro presente no sistema de observação.

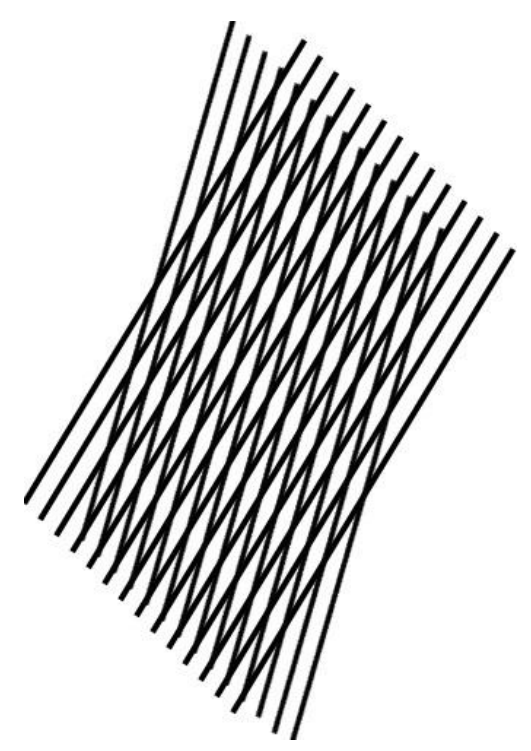

Figura 4: Superposição de duas estruturas periódicas, formando um padrão moiré. 


\section{Moiré de Projeção}

A Técnica Moiré de Projeção [Lino, 2008; Yeras, 2004] é feita de acordo com o esquema mostrado na Figura 5, onde se projeta uma rede (RP) no objeto de estudo (OE) através do sistema de projeção (SP), essa rede é superposta com outra rede (RO) presente no sistema de observação (SO).

O padrão originado fornece informações a respeito da topografia do objeto em relação a um plano de referência (PR).

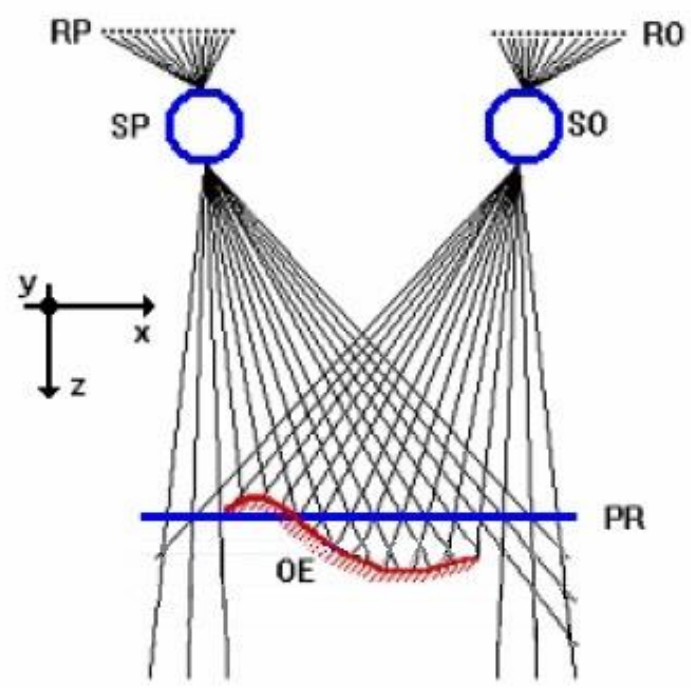

Figura 5: Esquema de um sistema para Técnica Moiré de Projeção (modificado de Yeras, 2004).

\subsection{Técnica de Projeção de Franjas}

A Técnica de Projeção de Franjas consiste em projetar um padrão de franjas periódico sobre um objeto e observar a deformação desse padrão, que ocorre devido à topografia do objeto. Através dessa deformação, é possível extrair informações a respeito da superfície, da topografia, do formato e inclinação do objeto [Michalski et al., 1986]. Historicamente, essa técnica surgiu do desenvolvimento e aprimoramento da Técnica Moiré de Projeção, mas atualmente é classificada em outra categoria por já possuir uma estrutura sólida, formulação independente e por não se basear na superposição de padrões [Rajshekhar e Rastogi, 2012; Yeras, 2004; Gasvik, 2002].

Nessa técnica, uma rede (R) é projetada por um sistema de projeção (SP) sobre o objeto de estudo (OE), as imagens são captadas por um sistema de observação (SO) e a 
topografia do objeto é medida em relação a um plano de referência (PR), conforme o esquema mostrado na Figura 6.

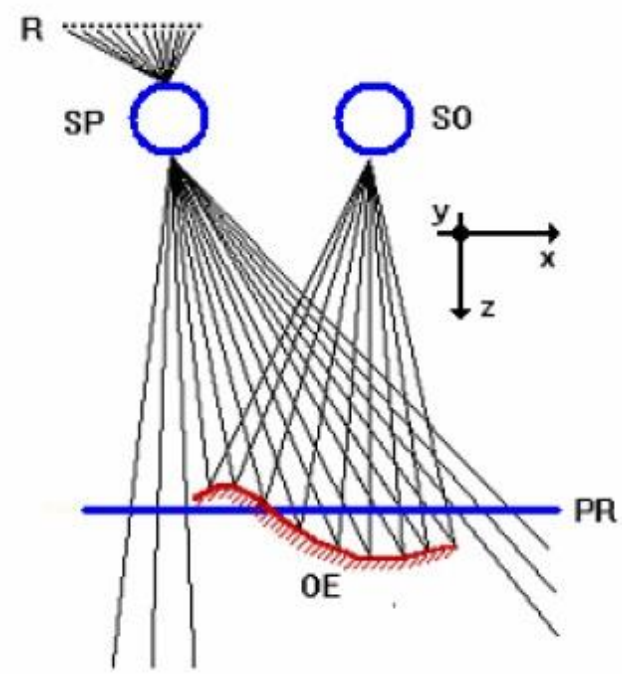

Figura 6: Esquema de um sistema para a Técnica de Projeção de Franjas (fonte: Yeras, 2004).

\subsection{Métodos de reconstrução dos padrões}

A intensidade luminosa, ao longo da direção $x$ indicada nas Figuras 5 e 6, que atravessa a rede óptica ou que é projetada, nas técnicas de análise de franjas, pode ser descrita pela seguinte equação [Rajshekhar e Rastogi, 2012; Yeras, 2004]:

$$
I=I_{0}\left[\frac{1}{2}+\frac{1}{2} G\left(\frac{2 \pi}{p} x\right)\right]
$$

$$
\begin{gathered}
\text { onde, } G\left(\frac{2 \pi}{p} x\right): \text { função periódica qualquer } \\
p: \text { período espacial da função }
\end{gathered}
$$

As franjas periódicas resultantes, ao serem projetadas na superfície do objeto, sofrerão uma modulação na sua fase descrita por:

$$
I=A(x, y)+B(x, y) G\left(\frac{2 \pi}{p} x+\phi(x, y)\right)
$$

$A(x, y)$ : é a intensidade média e quantifica a iluminação de fundo

$B(x, y)$ : é a intensidade modulada e quantifica da visibilidade das franjas 
$\phi(x, y)$ : é a fase modulada, a ser determinada.

Expandindo a função $G\left(\frac{2 \pi}{p} x\right)$, em série de Fourier, temos:

$$
I(x, y)=\left[A(x, y)+B(x, y) \sum_{n=-\infty}^{\infty} a_{n} \cos \left(\frac{2 \pi n}{p} x+\phi(x, y)\right)\right]
$$

No caso das técnicas de projeção como o Moiré de Projeção e a Projeção de Franjas, pode-se escolher a forma da função $G\left(\frac{2 \pi}{p} x\right)$ a ser projetada e opta-se por uma função do tipo senoidal ou cossenoidal, para facilitar a análise, e a intensidade luminosa modulada pela presença do objeto passa a ser descrita por:

$$
I(x, y)=A(x, y)+B(x, y) \cos \phi(x, y)
$$

Para interpretar os padrões obtidos, existem duas categorias de métodos:

- $\quad$ Métodos de intensidades;

- $\quad$ Métodos de fase;

Os métodos de intensidades fornecem a intensidade em cada ponto da imagem e suas modulações, através dos termos $A(x, y)$ e $B(x, y)$ da equação (2). As modulações, representadas por mudanças nas posições relativas dos máximos e mínimos de intensidade, são devidas à presença do objeto de estudo, e são relacionadas com as alturas desse objeto em relação ao plano de referência.

Já os métodos de fase se baseiam no fato de que cada ponto $(x, y)$ da superfície do objeto está relacionado a uma altura $h(x, y)$, através de uma variação na fase $\phi(x, y)$. A modulação e a desmodulação da informação luminosa permitem a determinação da variação na fase, com a qual é possível calcular as magnitudes das variações de altura da superfície do objeto.

Neste trabalho utilizaremos somente métodos de fase, e, dentre os diversos métodos existentes, estudaremos somente os métodos de Deslocamento de Fase e de Projeção Ortogonal. 


\subsubsection{Método de Deslocamento de Fase}

Pela expressão (4) da intensidade luminosa projetada, nota-se que existem três incógnitas $A(x, y), B(x, y)$ e $\phi(x, y)$, sendo necessário no mínimo um sistema de três equações para determinar essas incógnitas.

No Método de Deslocamento de Fase [Miao et al., 2007], essas três equações podem ser obtidas introduzindo-se deslocamentos de fase conhecidos na distribuição de intensidade luminosa dada por (4), de forma que a expressão para o perfil de iluminação modulado pela presença do objeto passa a ser dada por:

$$
I_{n}(x, y)=A(x, y)+B(x, y) \cos \left[\phi(x, y)+\delta_{n}\right]
$$

$\delta_{n}$ : Deslocamento de fase introduzido

sendo $n$ o índice referente aos diversos deslocamentos de fase que serão introduzidos (no mínimo três).

No padrão luminoso gerado, $I_{n}(x, y)$ e $\delta_{n}$ são conhecidos, bastando realizar no mínimo três medições para resolver o sistema de três incógnitas. Usualmente, por questões de praticidade, utiliza-se a chamada Técnica de Quatro Passos [Soga, 2000], em que são projetados quatro padrões de franjas senoidais na superfície do objeto, cada um deslocado de $1 / 4$ do período $(\delta=0, \pi / 2, \pi, 3 \pi / 2)$, de forma que as distribuições de intensidades com esse deslocamento de fase entre cada padrão pode ser descrito pelas seguintes equações:

$$
\begin{aligned}
& I_{1}(x, y)=A(x, y)+B(x, y) \cos \phi(x, y) \\
& I_{2}(x, y)=A(x, y)+B(x, y) \cos \lfloor\phi(x, y)+\pi / 2\rfloor \\
& I_{3}(x, y)=A(x, y)+B(x, y) \cos [\phi(x, y)+\pi] \\
& I_{4}(x, y)=A(x, y)+B(x, y) \cos \lfloor\phi(x, y)+3 \pi / 2\rfloor
\end{aligned}
$$

Para cada projeção é capturada uma imagem, e com as informações de cada pixel $(x, y)$ se resolve esse sistema de quatro equações. Assim, é possível obter o mapa de 
intensidades a partir das variáveis $A(x, y)$ e $B(x, y)$, e a fase $\phi(x, y)$ em cada ponto $(x, y)$ da imagem através da seguinte equação:

$$
\phi(x, y)=\operatorname{arctg}\left[\frac{I_{4}(x, y)-I_{2}(x, y)}{I_{1}(x, y)-I_{3}(x, y)}\right]
$$

No entanto, a fase obtida da equação (10) estará limitada ao intervalo de $-\pi$ a $\pi$, correspondente ao valor principal da função arco tangente, o que faz com que o mapa com os valores modulados das fases possua uma ambiguidade (descontinuidades artificiais), sempre que a fase real for, em módulo, superior a $\pi$. Com algoritmos específicos de desmodulação, se pode obter o Modelo Digital Topográfico (MDT), com as fases da imagem, sem a ambiguidade da função arco tangente.

\subsubsection{Análise de Fourier}

Um padrão de franjas senoidal projetado no objeto é descrito pela equação [Takeda et al., 1982]:

$$
g_{1}(x, y)=a(x, y)+b(x, y) \cos \left[2 \pi f_{0} x+\phi(x, y)\right]
$$

onde $a(x, y)$ e $b(x, y)$ representam distribuições não uniformes da refletividade da superfície do objeto, $f_{0}$ é o portador de frequência, inverso ao período espacial $p$ (Equação 1), e $\phi(x, y)$ é a modulação na fase resultante devido à presença do objeto.

Por conveniência, esse padrão de franjas pode ser reescrito por:

$$
g_{1}(x, y)=a(x, y)+c(x, y) \exp \left[2 \pi i f_{0} x\right]+c^{*}(x, y) \exp \left[-2 \pi i f_{0} x\right]
$$

onde:

$$
c(x, y)=\frac{b(x, y) \exp [i \phi(x, y)]}{2}
$$

$\mathrm{e}^{*}$ representa o complexo conjugado.

Assim, a transformada de Fourier de $g_{1}(x, y)$ será dada por:

$$
G_{1}(u, v)=A(u, v)+C\left(u-f_{0}, v\right)+C *\left(u+f_{0}, v\right)
$$


Uma vez que $a(x, y), b(x, y)$ e $\phi(x, y)$ variam lentamente comparado com as variações introduzidas pelo portador de frequência $f_{0}$, o espectro de Fourier da equação (14) será separado pelo portador de frequência $f_{0}$, conforme mostrado na Figura 7. Então, se seleciona um dos termos de primeira ordem no espectro resultante, que contém a informação a respeito da topografia do objeto, digamos $C\left(u-f_{0}, v\right)$, isola-se esse termo com a janela do filtro centrada em $f_{0}$ e move-se para o centro do espectro, removendo o portador de frequência $f_{0}$, conforme mostrado na Figura 7. De forma que o espectro resultante seja:

$$
G(u, v)=C(u, v)
$$

Fazendo a transformada de Fourier inversa, obtém-se:

$$
g(x, y)=c(x, y)=\frac{b(x, y) \exp [i \phi(x, y)]}{2}
$$

E o mapa de fases moduladas será dado por:

$$
\phi(x, y)=\operatorname{arctg}\left[\frac{\operatorname{Im}(c(x, y))}{\operatorname{Re}(c(x, y))}\right]
$$

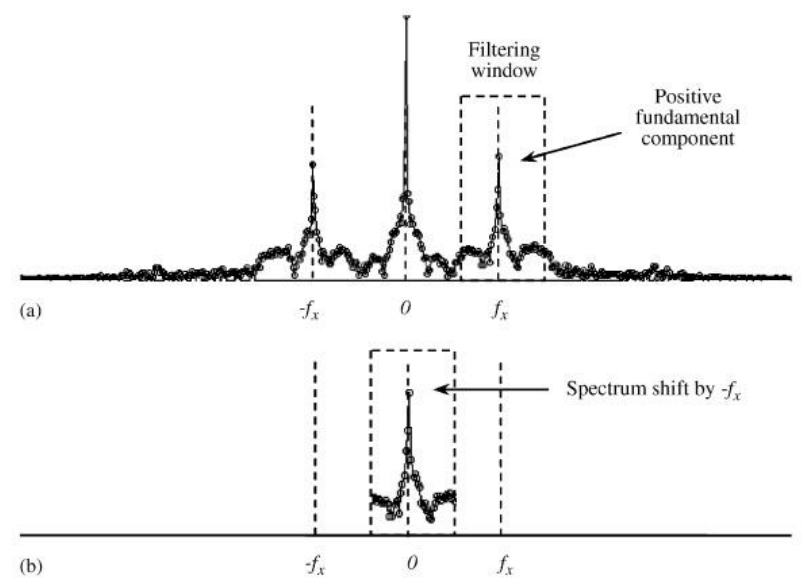

Figura 7: Método de Análise de Fourier: (a) se seleciona um dos termos de primeira ordem, que contém a informação a respeito do objeto, isolando-o. (b) move-se esse termo para o centro do espectro (fonte: Quan et al., 2007). 


\subsubsection{Método de Projeção Ortogonal}

O Método de Projeção Ortogonal [Tavares e Vaz, 2006] é um método baseado na análise de Fourier e consiste, basicamente, de um aprimoramento desse método.

Nele, um segundo padrão de franjas, com franjas ortogonais ao primeiro, é projetado sobre o objeto e pode ser descrito por:

$$
g_{2}(x, y)=a(x, y)+c(x, y) \exp \left[2 \pi i f_{0} y\right]+c *(x, y) \exp \left[-2 \pi i f_{0} y\right]
$$

A sua transformada de Fourier será:

$$
G_{2}(u, v)=A(u, v)+C\left(u, v-f_{0}\right)+C^{*}\left(u, v+f_{0}\right)
$$

A fase $\phi(x, y)$, que depende da altura do objeto em cada ponto $(x, y)$, permanece inalterada, assim como $a(x, y)$ e $b(x, y)$, caso o contraste e o brilho das duas imagens permaneçam constantes e a variação da iluminação de fundo seja controlada. Pelas equações (14) e (18), fica evidente que, com essas hipóteses, o componente de ordem zero $A(u, v)$ é idêntico nos dois espectros.

Subtraindo os dois espectros, temos:

$$
G_{1}(u, v)-G_{2}(u, v)=C\left(u-f_{0}, v\right)-C\left(u, v-f_{0}\right)+C^{*}\left(u+f_{0}, v\right)-C^{*}\left(u, v+f_{0}\right)
$$

Em (19), observa-se que o componente de ordem zero é totalmente eliminado do espaço de frequências, e que o espectro resultante possui valores positivos e negativos. Esse espectro é, então, manipulado de forma a eliminar os valores negativos, resultando em um espectro que contenha somente os termos:

$$
C\left(u-f_{0}, v\right)+C *\left(u+f_{0}, v\right)
$$

A seguir, conforme a filtragem usual do método de transformada de Fourier, selecionase um dos termos de primeira ordem no espectro resultante, isola-se esse termo com a janela do filtro centrada em $f_{0}$ e este foi movido para o centro do espectro, removendo o portador de frequência $f_{0}$, como mostrado na Figura 8 , desta forma o mapa de fases moduladas será novamente obtido pela equação (16). 

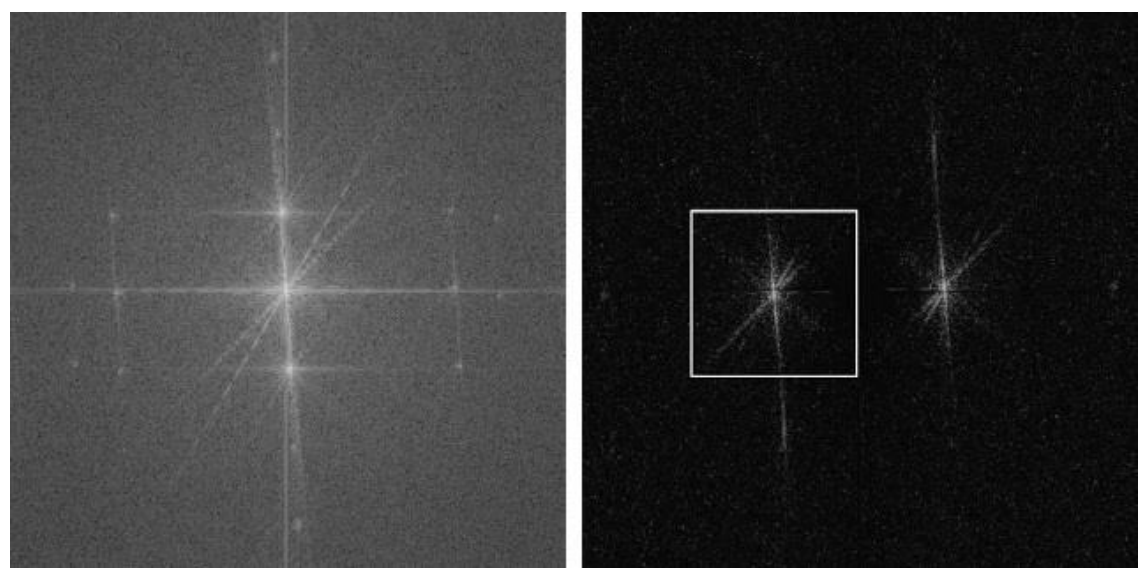

Figura 8: (Esquerda) Espectro de Fourier de um objeto obtido com a Técnica de Projeção Ortogonal. (Direita) Seleção de um dos termos de primeira ordem, após a subtração dos espectros das franjas ortogonais, para a remoção do portador de frequência (fonte: Tavares e Vaz, 2006).

A fase obtida pela equação (16), assim como no Método de Deslocamento de Fase, estará limitada no intervalo entre $-\pi$ e $\pi$, correspondente ao valor principal da função arco tangente, sendo necessária a aplicação de algoritmos específicos de desmodulação da fase para a obtenção do MDT, com as fases da imagem sem a ambiguidade da função arco tangente.

Como o Método de Projeção Ortogonal é um aprimoramento da análise de Fourier, neste trabalho, estudaremos somente este e o Método de Deslocamento de Fase.

\subsection{Métodos de desmodulação da fase}

Como vimos na seção anterior, nos métodos de reconstrução dos padrões, o mapa de fases obtido possui uma ambiguidade (descontinuidades artificiais), por proporcionar apenas o valor principal da função arco tangente, limitado ao intervalo entre $-\pi$ e $\pi$. Para retirar essa ambiguidade e obter o MDT, é necessária a aplicação de algoritmos específicos de desmodulação da fase.

O método tradicional (sequencial) de desmodulação da fase consiste em comparar as fases dos pixels adjacentes na imagem e adicionar ou subtrair $2 \pi$, até que a fase relativa entre os dois pixels vizinhos esteja no intervalo entre $-\pi$ e $\pi$ [Gorthi e Rastogi, 2010], trata-se de um processo simples caso o mapa de fases moduladas seja ideal. No entanto, as medidas reais apresentam sombras, descontinuidades nas franjas, brilho na imagem, 
ruídos, entre outros problemas, que podem dificultar esse processo ou torná-lo dependente do caminho.

Para lidar com esses problemas, existem diversos algoritmos de desmodulação como o método de expansão mínima [Ching et al., 1992], mínimos quadrados com gradiente conjugado pré-condicionado [Kaufmann et al., 1998], método de Volkov, entre outros.

Muitos algoritmos proporcionam bons resultados, porém, possuem algumas desvantagens como a necessidade de tomar muitas imagens, serem feitos em várias etapas, necessidade de comparação com muitos pixels adjacentes na imagem, exigência de um tempo computacional longo, entre outras.

Neste trabalho utilizaremos o Método de Volkov [Volkov e Zhu, 2003], que possui a vantagem de ser feito em uma única etapa, com mínimo núcleo de pixels para a realização do cálculo teórico de $2 \times 1$ pixels na imagem, ser baseado em Transformadas de Fourier (de modo a não atuar diretamente no mapa de fases, mas em seu espaço de frequências). Tudo isso torna o procedimento pouco sensível a ruídos, independente do caminho, rápido e robusto.

\subsubsection{Método de Volkov}

A fase modulada $\phi_{m}(\vec{r})$ é definida pelo valor principal da função arco tangente $-\pi<\phi_{m}(\vec{r})<\pi$. Tradicionalmente, para obter a verdadeira fase $\phi(\vec{r})$, que pode estar fora do intervalo principal, aplica-se o processo de desmodulação dado por (20), onde $n(\vec{r})$ é a função experimental que descreve o ruído na imagem. A expressão (20) é válida para qualquer $\vec{r}(x, y, z)$ pertencente à imagem.

$$
\phi_{m}(\vec{r})+2 \pi k(\vec{r})=\phi(\vec{r})+n(\vec{r})
$$

O método de Volkov [Volkov e Zhu, 2003] parte das propriedades das Transformadas de Fourier direta $(F)$ e inversa $\left(F^{-1}\right)$ (equações (21) e (22)), onde $\vec{r}$ e $\vec{q}$ são vetores que operam no espaço real e recíproco. O método assume uma única hipótese: a de que os saltos de fase não excedem $2 \pi /$ pixel.

$$
\begin{aligned}
& \nabla[\exp (2 \pi i \vec{q} \cdot \vec{r})]=2 \pi i \vec{q}[\exp (2 \pi i \vec{q} \cdot \vec{r})] \\
& \nabla \psi(\vec{r})=2 \pi i F^{-1}\{F[\psi(\vec{r})] \vec{q}\}
\end{aligned}
$$


Primeiramente, aplica-se o operador $F$ na equação (22) e faz-se o produto escalar com as componentes do vetor $\vec{q}\left(q_{x}, q_{y}, q_{z}\right)$, que representa as frequências teóricas, sem ruídos. Esse processo corrige as frequências da imagem com ruídos, para as frequências teóricas do mapa de fases moduladas. Assim, obtemos uma nova expressão para a função escalar $\psi(\vec{r})$ real ou complexa no espaço bidimensional, dada por:

$$
\psi(\vec{r})=\operatorname{Re}\left\{\frac{1}{2 \pi i} F^{-1}\left[\frac{F\left(\partial_{x} \psi\right) q_{x}+F\left(\partial_{y} \psi\right) q_{y}}{q_{\perp}^{2}}\right]\right\}
$$

onde $q_{x}$ e $q_{y}$ são as projeções no espaço do vetor $q_{\perp}$, cujo módulo é definido como $q_{\perp}^{2}=q_{x}^{2}+q_{y}^{2} \neq 0$.

Como a integração apresentada na equação (23) é feita no espaço recíproco (de $\vec{q}$ ), a solução é independente do caminho e teoricamente imune a ruídos no espaço real da imagem.

Caso, no mapa de $\nabla_{\perp} \phi_{m}(\vec{r})$, seja feita uma correção adequada dos falsos pixels (pixels onde ocorrem saltos nos quais a relação $2 \pi /$ pixel para a fase não é válida), pode-se assumir que $\partial_{x} \psi(\vec{r}) \cong \partial_{x} \phi_{m}(\vec{r})$ e $\partial_{y} \psi(\vec{r}) \cong \partial_{y} \phi_{m}(\vec{r})$ e, assim, saber as componentes $\partial_{x} \psi(\vec{r})$ e $\partial_{y} \psi(\vec{r})$ da função $\nabla_{\perp} \psi(\vec{r})$, a partir da qual se obtém $\psi(\vec{r})$.

Uma vez obtida $\psi(\vec{r})$, aplica-se a relação (24) para obter a o mapa de fases desmodulado.

$$
\psi(\vec{r})=\phi(\vec{r})+n(\vec{r})
$$

\subsection{Métodos de remoção dos portadores de frequência}

Em geral, após o processo de desmodulação da fase, o mapa de fases contém a soma da fase relacionada à topografia do objeto e a fase relacionada aos portadores de frequência, sendo necessária a remoção desta última, para estimar corretamente a altura de cada ponto da superfície do objeto em relação ao plano de referência, conforme mostrado na Figura 9. Mesmo no caso da utilização dos métodos baseados na Análise de Fourier, que tentam remover esses portadores, ainda podem sobrar alguns resquícios da fase relacionada eles, principalmente quando os termos de primeira ordem e de ordem zero são muito próximos. 
A existência desses portadores causa, no mapa de fases, um formato aproximado de uma rampa superposta com a fase relacionada à topografia do objeto. Isso ocorre, pois, a fase com os portadores de frequência possui mais pontos com fases moduladas do que a sem, e o processo de desmodulação da fase resulta em fases com uma sequência linear [Li et al., 1998].

Para remover os portadores de fase, existem diversas técnicas lineares como o deslocamento do espectro, a inclinação média, o ajuste de um plano, e técnicas não lineares como a subtração de referência, o mapeamento de fase, expansão em séries, entre outros [Quan et al., 2007]. Neste trabalho se utilizará a técnica de remoção linear por ajuste de um plano.
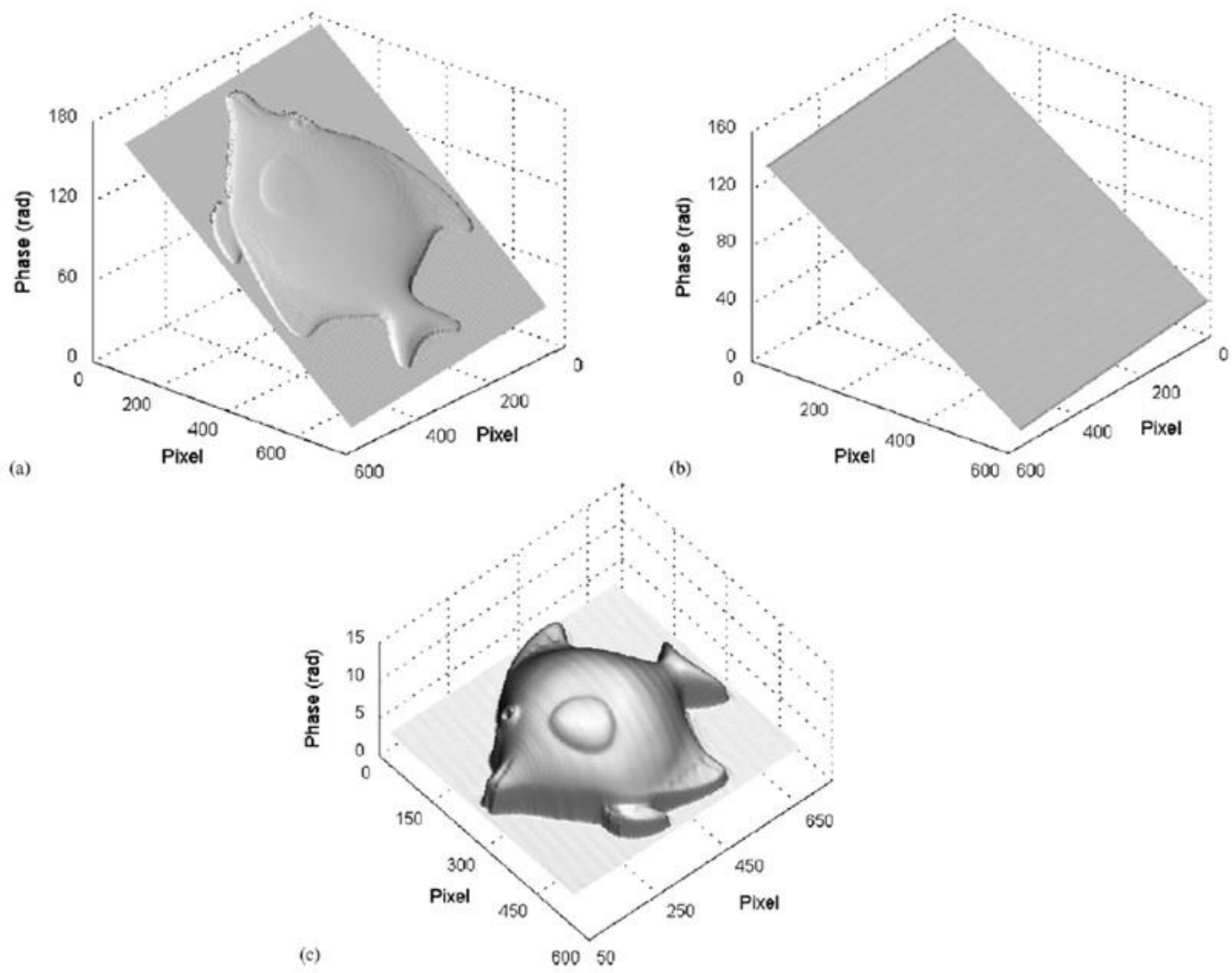

Figura 9: (a) MDT de um modelo em formato de peixe. (b) Plano de referência. (c) Após a remoção dos portadores de frequência. 


\subsubsection{Técnica de remoção linear por ajuste de um plano}

A técnica de remoção linear por ajuste de um plano [Quan et al., 2007] é aplicável para a remoção dos portadores de fase, baseada na análise espacial da imagem, e sua precisão é independente da distribuição de fase relacionada ao formato do objeto.

Se os portadores de fase estão em uma direção arbitrária, a sua frequência aproximada em primeira ordem pode ser descrita por:

$$
f(x, y)=f_{x} x+f_{y} y
$$

onde $f_{x}$ e $f_{y}$ são as frequências espaciais dos portadores medidas nas direções $x$ e $y$, respectivamente.

Nesse caso, é necessário deslocar a componente fundamental de frequência por $-f_{x}$ na direção $x$ e $-f_{y}$ na direção $y$. E, para isso, é necessário encontrar a frequência nas direções $x$ e $y$.

Essas variáveis podem ser calculadas ajustando-se um plano, com o cálculo baseado no método de mínimos quadrados. Esse plano pode ser expresso por:

$$
\phi_{c}(x \cdot y)=2 \pi f_{x} x+2 \pi f_{y} y+\phi_{c, 0}
$$

onde $\phi_{c}$ é a função dos portadores de fase e $\phi_{c, 0}$ é o valor da fase inicial. A função do erro é definida como o quadrado das diferenças entre a função dos portadores de fase e as fases obtidas experimentalmente:

$$
\operatorname{Er}\left(f_{x}, f_{y}, \phi_{c, 0}\right)=\sum_{(x, y) \in U}\left[2 \pi f_{x} x+2 \pi f_{y} y+\phi_{c, 0}-\phi_{c, \exp }(x, y)\right]^{2}
$$

onde $\phi_{c, \text { exp }}$ é o valor da fase obtida experimentalmente no plano de referência.

Tomando-se a primeira derivada de $E r$ com relação a $f_{x}, f_{y}$ e $\phi_{c, 0}$ e igualando-as a zero, se obtém um sistema de três equações, do qual as variáveis $f_{x}, f_{y}$ e $\phi_{c, 0}$ podem ser calculadas. Em seguida, a função 2D dos portadores de fase que minimiza o erro pode ser calculada e removida, subtraindo-a da distribuição de fase total. 
Nesse método, para realizar esse processo de ajuste, é necessária a medida dos valores de fase no plano de referência onde é colocado o objeto, uma vez que o valor de fase nesse plano contém apenas a componente dos portadores de frequência, sem a componente relacionada ao formato do objeto. No entanto, não é preciso fazer a medida do plano de referência separadamente do objeto, uma única medida pode ser feita fazendo o ajuste apenas ao plano de fundo do objeto, escolhendo, no mapa de fases moduladas, somente os pontos da região correspondente ao plano de referência.

\subsection{Métodos de calibração}

A última etapa importante para a obtenção das dimensões reais do objeto é a calibração. Ela é necessária, pois as fases obtidas no mapa de fases desmodulado, referentes ao eixo $z$ das Figuras 5 e 6, que são relacionadas à altura do objeto em cada ponto da superfície, estarão na escala de ângulos (em radianos) e a distância entre os pontos da superfície do objeto (referentes ao plano xy das Figuras 5 e 6) estarão na escala de pixels, sendo necessária a conversão para uma escala de distâncias espaciais.

A calibração da distância entre os pontos da superfície do objeto é simples, basta que na imagem do objeto apareça uma escala ou outro objeto de dimensões espaciais bem conhecidas, e a conversão da escala de pixels para uma escala em centímetros, por exemplo, é feita linearmente.

Já para efetuar a calibração das alturas em cada ponto da topografia do objeto, existem diversos métodos, entre eles estão o método da triangulação [Hobson et al., 1997] e a utilização de um objeto de dimensão conhecida. A seguir, são apresentados esses dois métodos.

\subsubsection{Triangulação}

Trata-se de um método absoluto determinado unicamente pelos parâmetros do arranjo experimental e os que descrevem a relação entre os valores de fase obtidos e as alturas em cada ponto $(x, y)$ na topografia do objeto em relação ao plano de referência. Esse método estabelece essa relação entre a distribuição de fases no mapa de fases moduladas e as coordenadas geométricas $3 D$ do objeto por simples princípio de triangulação. 
Suponha que uma superfície plana é iluminada, em um ângulo $\theta_{i}$, com uma luz de intensidade senoidal, como mostrado na Figura 10, e fotografada em um ângulo $\theta_{v}$. Se a intensidade de luz tem um período espacial (distância entre o início de uma franja ao início da seguinte) $p$, então o seu período $p^{\prime}$, na superfície plana é dado por:

$$
p^{\prime}=\frac{p}{\cos \left(\theta_{i}\right)}
$$
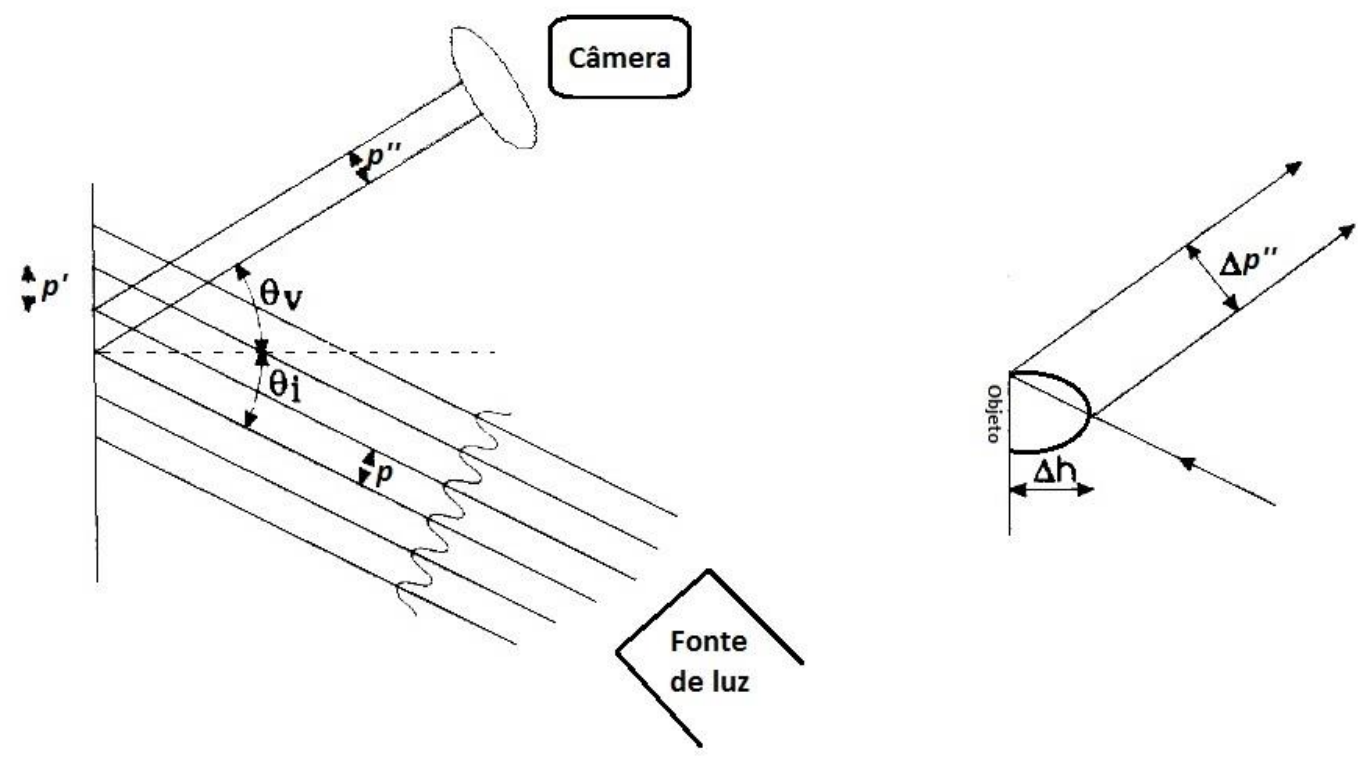

Figura 10: (Esquerda) Iluminação de uma superfície com luz de intensidade senoidal. (Direita) Mudança no período espacial de observação das franjas devido à mudança de altura na superfície (fonte: Hobson et al., 1997).

A luz observada pela câmera terá uma variação de intensidade com período dado por:

$$
p^{\prime \prime}=p^{\prime} \cos \left(\theta_{v}\right)=\frac{p \cos \left(\theta_{v}\right)}{\cos \left(\theta_{i}\right)}
$$

Agora suponha que a superfície se mova de uma distância $\Delta h$, devido a presença de um objeto, conforme mostrado na Figura 10(b). Haverá uma mudança $\Delta p^{\prime \prime}$ na posição da luz observada, o que é equivalente a um deslocamento de fase de $\Delta \phi$ dado por:

$$
\Delta \phi=2 \pi \frac{\Delta p^{\prime \prime}}{p^{\prime \prime}}
$$

E a distância $\Delta p^{\prime \prime}$ e o deslocamento de fase $\Delta \phi$ serão dados por (32): 


$$
\begin{array}{r}
\Delta p^{\prime \prime}=\Delta h\left[\operatorname{tg}\left(\theta_{i}\right)+\operatorname{tg}\left(\theta_{v}\right)\right] \cos \left(\theta_{v}\right) \\
\Delta \phi=\frac{2 \pi \Delta h\left[\operatorname{tg}\left(\theta_{i}\right)+\operatorname{tg}\left(\theta_{v}\right)\right] \cos \left(\theta_{i}\right)}{p}
\end{array}
$$

Essa equação (32) indica que a variação de altura $\Delta h$ em um ponto da superfície pode ser obtida da avaliação da mudança ocorrida na fase $\Delta \phi$ do padrão de luz senoidal, que foi projetado na superfície do objeto. Com a lente da câmera perpendicular ao plano do objeto de estudo, $\theta_{v}$ é zero, e a variação de altura é dada por:

$$
\Delta h=\frac{p \Delta \phi}{2 \pi \sin \left(\theta_{i}\right)}=\mathrm{C} \Delta \phi
$$

onde C é a constante de calibração da imagem dada por:

$$
\mathrm{C}=\frac{p}{2 \pi \sin \left(\theta_{i}\right)}
$$

\subsubsection{Utilização de um objeto de calibração}

No método de triangulação apresentado anteriormente, $\Delta h$ é uma função das coordenadas $(x, y)$ da imagem e é determinada pelos parâmetros óticos do arranjo experimental. No entanto, na prática, é muito difícil medir com exatidão os parâmetros do sistema e ainda mais difícil determinar o período das franjas, pois ele não se mantém constante ao longo da imagem, devido a não perpendicularidade exata da projeção, entre outros fatores.

Por isso, outro método de calibração que pode ser mais eficiente é a utilização conjunta da equação (33) e de um objeto de calibração cujas dimensões são conhecidas, para obter o coeficiente $C$ da equação (34), que será utilizado para calibrar as imagens dos objetos de estudo.

Para isso, obtêm-se imagens de um objeto de dimensões conhecidas e topografia simples, que pode facilmente ser obtida pelas técnicas de análise de franjas, faz-se o processamento dessas imagens até obter o MDT. Em seguida, utilizam-se os parâmetros do arranjo experimental medidos e a expressão (33), para a obtenção de uma primeira estimativa para o coeficiente $C$ de calibração do sistema. Finalmente, fazem-se ajustes finos em C, de forma a obter o coeficiente que proporciona o melhor ajuste dos dados 
obtidos com as técnicas de análise de franjas ao formato do objeto medido com outro método direto ou bem estabelecido, como o paquímetro, por exemplo.

O coeficiente resultante será utilizado para calibrar as imagens dos outros objetos de estudo, desde que essas imagens sejam obtidas nas mesmas condições experimentais.

A triangulação juntamente com a utilização de um objeto de calibração será o método utilizado neste trabalho para a calibração das imagens. 


\section{MATERIAIS E MÉTODOS}

\subsection{Arranjo experimental}

O arranjo experimental utilizado consiste de um projetor do tipo data show, utilizado para a projeção das franjas, uma câmera CCD, que captura as imagens, ambos conectados a um computador para o processamento das imagens, e um plano de referência onde se apoia o objeto em estudo. Esse arranjo está esquematizado na Figura 11, onde $L$ é a distância entre a CCD e o plano de referência, $d$ é a distância entre a câmera e o projetor e $\theta_{i}$ é o ângulo entre a projeção da imagem e a sua captura.

Os parâmetros experimentais para as medidas feitas em laboratório, dos objetos de estudo, foram $L=(44,5 \pm 0,5) \mathrm{cm}$ e $d=(9,1 \pm 0,5) \mathrm{cm}$. Esses parâmetros foram escolhidos após alguns testes descritos mais adiante.

A câmera CCD usada nos experimentos é monocromática, com resolução de 1280x960 pixel, modelo DMK 41BU02.H, da marca The Imaging Source, e foi acoplada a uma lente macro 12,5 - $75 \mathrm{~mm}$ F1.8. O projetor usado é um projetor LED RGB, com resolução SVGA (858x600), lentes $2-17,7$ mm, modelo Mini Projetor Joybee GP1, da marca BenQ.

Em todas as aquisições de dados, tomou-se o cuidado de não saturar a câmera CCD, escolhendo a abertura mais adequada para a lente.

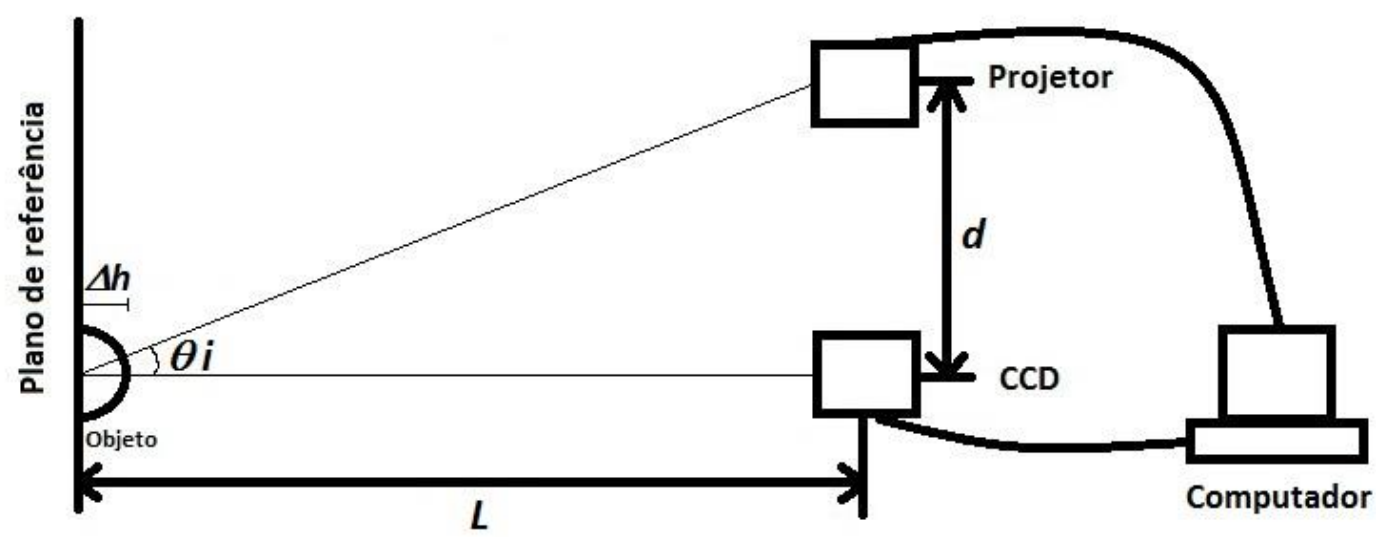

Figura 11: Esquema do arranjo experimental utilizado.

Para a tomada de dados realizada em hospital, foi construído um suporte portátil, que possibilitava a reprodução do arranjo experimental da Figura 11, conforme as 
necessidades e possibilidades de um ambiente hospitalar. Esse suporte é mostrado na Figura 12, onde a câmera CCD e o projetor, conectados a um computador portátil, são acoplados a uma haste, que possibilita ajustes verticais, de altura, e horizontais, de posicionamento. Os pés desse suporte possuem rodízios e foram projetados para que possam ser alocados embaixo da cama do paciente, proporcionar um melhor ajuste do posicionamento da câmera e do projetor e, ao mesmo tempo, não causar vibração no arranjo, o que prejudicaria as medidas.

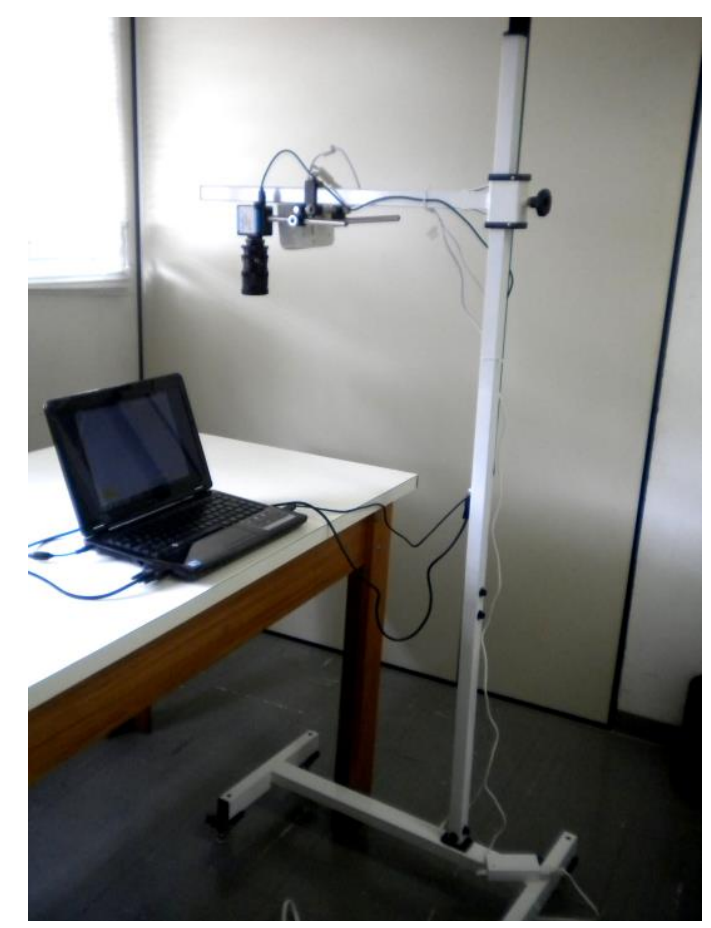

Figura 12: Suporte construído para reproduzir o arranjo experimental da Figura 11 em um ambiente hospitalar.

\subsection{Objetos de estudo}

Com o intuito de validar a técnica de projeção de franjas para depois aplicá-la na medida das dimensões de lesões na pele, foram estudados primeiramente objetos de cor branca e topografias de análise simples, para, em seguida, estudar objetos com topografias de análise mais complexa. Após essa etapa, estudaram-se objetos coloridos, cujas cores simulavam os diferentes tons de pele e as cores das feridas.

Por fim, foram medidas lesões de pacientes. Em todos os casos foi necessária a utilização de um objeto de calibração. 


\subsubsection{Objeto de calibração}

O objeto de calibração era um objeto com uma topografia simples, facilmente obtida pela técnica, e dimensões da ordem de centímetros, tratava-se de um cilindro de latão cortado perpendicularmente à base, pintado com tinta acrílica branca, conforme mostrado na Figura 13.

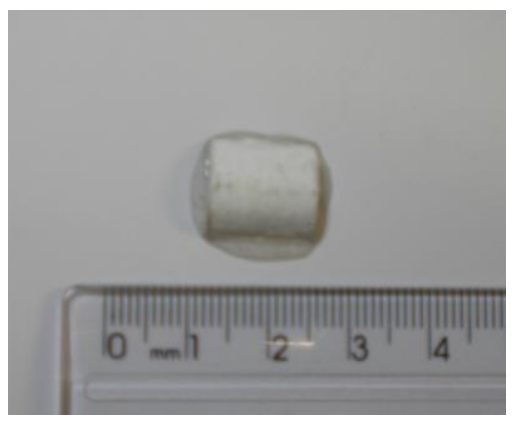

Figura 13: Objeto e calibração.

\subsubsection{Objetos com topografia de análise mais simples}

Os objetos com topografia de análise mais simples foram construídos em parafina e pintados com tinta acrílica branca, possuíam topografias suaves, que não geravam sombra utilizando o arranjo experimental descrito anteriormente, e não possuíam saliências ou bordas abruptas em sua geometria. Esses objetos são mostrados na Figura 14.

Objeto 1

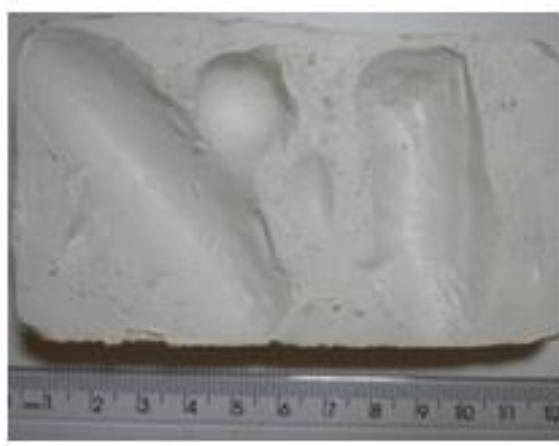

Objeto 2

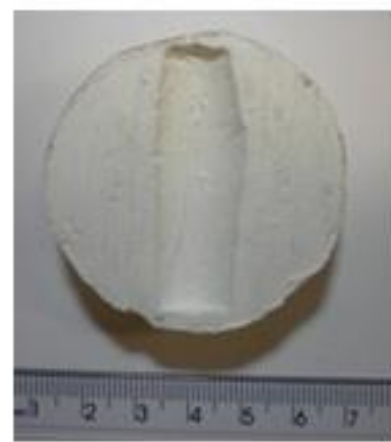

Objeto 3

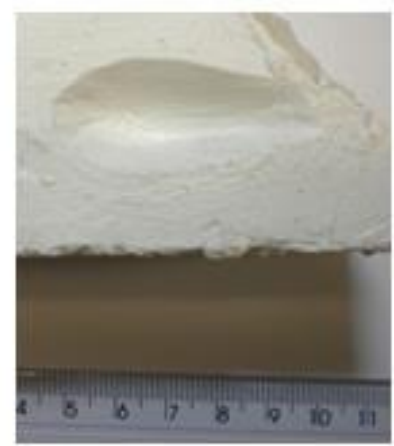

Figura 14: Objetos de topografias de análise simples.

\subsubsection{Objetos com topografia de análise mais complexa}

Os objetos com topografia de análise mais complexa também foram construídos a partir de diversos materiais moldáveis como parafina, resinas, madeira, entre outros, e pintados com tinta acrílica branca, alguns possuíam topografias que geravam sombra e/ou 
tinham saliências ou bordas abruptas em sua geometria. Esses objetos são mostrados na Figura 15.

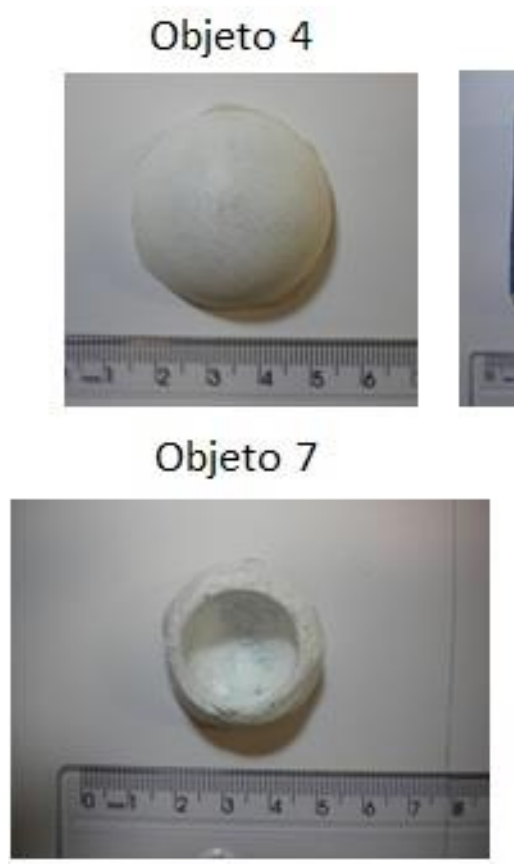

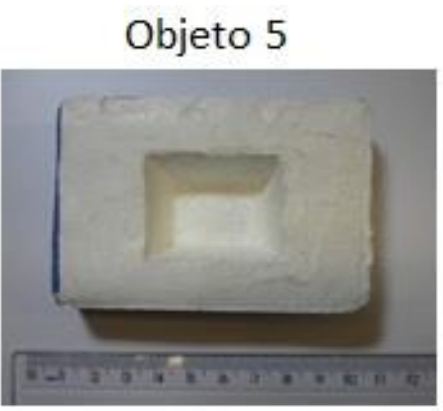

Objeto 8

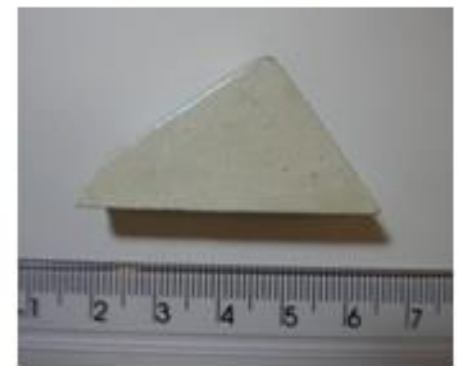

Objeto 6

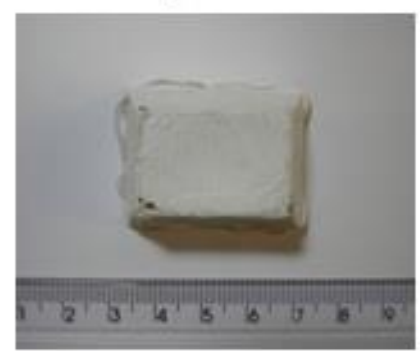

Objeto 9

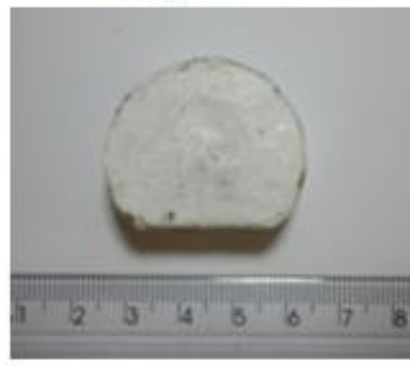

Figura 15: Objetos de topografia de análise mais complexa.

\subsubsection{Objetos coloridos}

Os objetos coloridos foram construídos em parafina e pintados com tinta acrílica de cores que simulavam diferentes tonalidades de pele e as cores das lesões, e são mostrados na Figura 16. As cores dos objetos que simulavam diferentes tonalidades de pele foram classificadas de acordo com o inventário cromático Humanae [Dass, 2012], baseado na escala Pantone ${ }^{{ }^{1}}$, já o objeto vermelho, cuja cor simulava a de uma lesão, teve a cor classificada de acordo com a escala Pantone ${ }^{\circledR}$ em si [Source, 2013]. Essas classificações são mostradas na Tabela 2.

As topografias desses objetos eram de análise simples, pois não geravam sombra e não tinham saliências ou bordas abruptas em sua geometria.

${ }^{1}$ A escala Pantone ${ }^{\circledR}$ é uma escala comercial padronizada, que classifica cores para um sistema de reprodução, e é largamente utilizada na indústria gráfica. A lista de números de cor e valores da Pantone ${ }^{\circledR}$ é considerada propriedade intelectual da empresa. 
Tabela 2: Classificação das cores dos objetos coloridos, de acordo com a escala Pantone ${ }^{\circledR}$.

\begin{tabular}{|l|cc|}
\hline \multirow{2}{*}{\begin{tabular}{|} 
Objetos \\
coloridos
\end{tabular}} & Objeto & Classificação Pantone ${ }^{\circledR}$ \\
\cline { 2 - 3 } & Pele clara & $62-6 \mathrm{C}$ \\
\cline { 2 - 3 } & Pele média & $76-6 \mathrm{C}$ \\
\cline { 2 - 3 } & Pele escura & $322-7 \mathrm{C}$ \\
\cline { 2 - 3 } & Vermelho & 180 \\
\hline
\end{tabular}
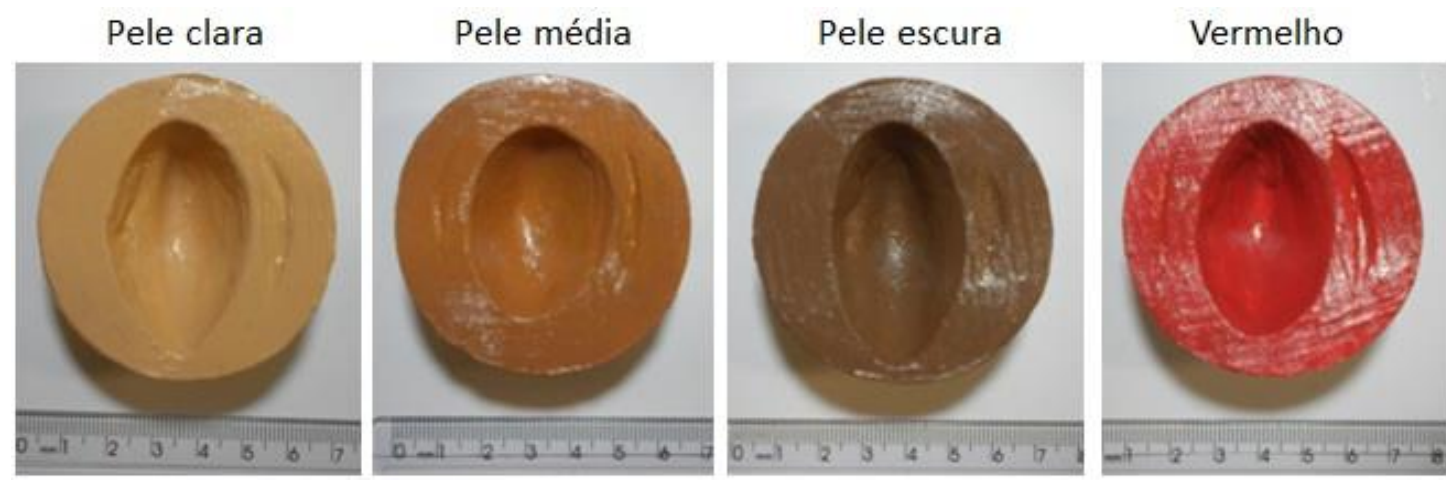

Figura 16: Objetos coloridos.

\subsubsection{Objetos que simulam lesões}

Foi também construído um objeto que simulava três lesões na pele, com cores e formatos diferentes; estas lesões foram nomeadas como lesão 1, 2 e 3, conforme mostrado na Figura 17. Esse objeto também foi construído em parafina e pintado com tinta acrílica, e suas cores foram classificadas da mesma forma que as cores dos objetos monocromáticos, que também são mostradas na Tabela 3. A topografia dessas lesões possuía uma análise um pouco mais complexa que a topografia dos objetos monocromáticos, pois possuíam regiões que geravam sombra.

Por fim, foi confeccionada uma lesão em uma mão de borracha, conforme mostrada na Figura 18, a fim de simular uma lesão em uma superfície não plana. A mão e a lesão foram pintadas com tinta acrílica, cujas cores também estão classificadas na Tabela 3. Esse objeto também foi empregado para testar o suporte portátil, e os parâmetros experimentais utilizados foram $L=(46,0 \pm 0,5) \mathrm{cm}$ e $d=(9,0 \pm 0,5) \mathrm{cm}$. 


\section{Objeto lesões}

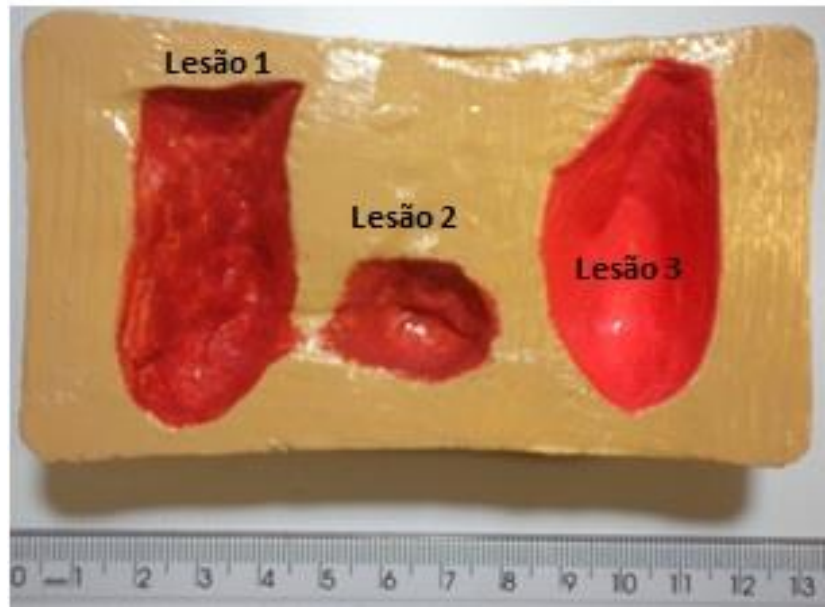

Figura 17: Objeto que simula lesões na pele.

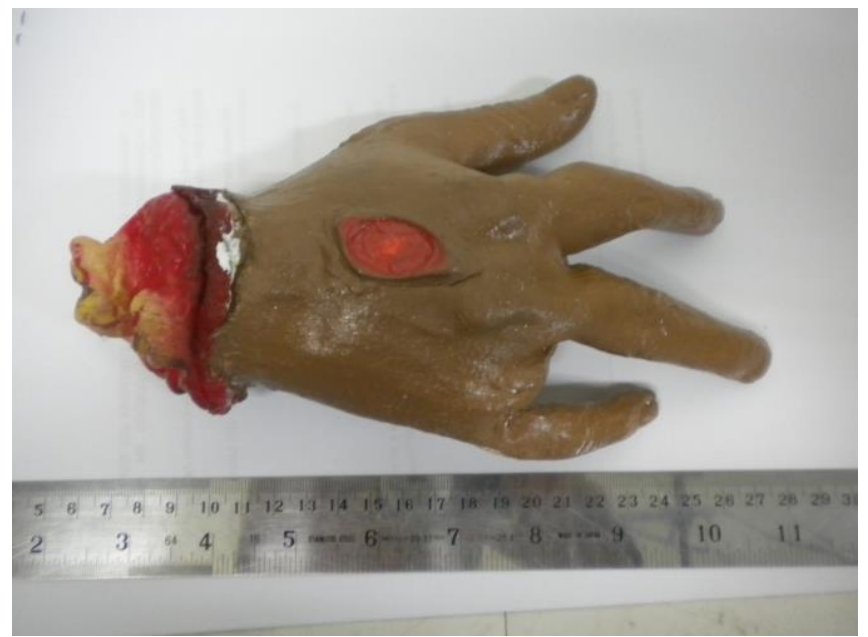

Figura 18: Simulação de uma lesão confeccionada em uma mão de borracha.

Tabela 3: Classificação das cores dos objetos que simulam lesões, de acordo com a escala Pantone ${ }^{\circledR}$.

\begin{tabular}{|c|cc|}
\hline \multicolumn{1}{|c|}{} & \multicolumn{1}{|c|}{ Objeto } & Classificação Pantone $^{\circledR}$ \\
\hline \multirow{2}{*}{$\begin{array}{c}\text { Objeto } \\
\text { Lesões }\end{array}$} & Pele & $61-6 C$ \\
\cline { 2 - 3 } & Lesão 1 & 1797 \\
\cline { 2 - 3 } & Lesão 2 & 180 \\
\cline { 2 - 3 } & Lesão 3 & 178 \\
\hline \multirow{2}{*}{ Lesão em mão } & Pele & $65-4 C$ \\
\cline { 2 - 3 } de borracha & Lesão & 180 \\
\hline
\end{tabular}




\subsubsection{Lesões de pacientes}

Também foram feitas medidas de lesões em pacientes, que estavam em tratamento no Hospital Emílio Ribas, em São Paulo, concordaram em colaborar com a pesquisa e serem fotografados, e preencheram o Termo de Consentimento Livre e Esclarecido, cujo modelo está no Anexo I desta dissertação.

Nessas medidas, foi utilizado um objeto de calibração para cada paciente. Esses objetos foram esterilizados previamente, com álcool etílico hidratado $70^{\circ}$ INPM, para evitar contaminação. Nas lesões que já possuíam certo grau de cicatrização, não estavam abertas e o paciente permitiu, o objeto de calibração foi fotografado apoiado sobre a lesão, cuja superfície de apoio foi considerada como o plano de referência. Já nas lesões que estavam abertas, foi solicitado que o paciente segurasse o objeto de calibração bem próximo ao plano da lesão, sem tocá-la, e esta altura foi considerada como sendo o plano de referência para as medidas.

O paciente 1, 74 anos, sexo masculino, pele branca, apresentava um quadro de Leishmaniose cutânea, sua lesão já vinha sendo tratada há três meses e estava localizada no braço direito. No dia da medição, ela apresentava uma crosta de pele necrosada, que se elevava acima da pele saudável, conforme mostrado na Figura 19.

Os parâmetros experimentais para a medida dessa lesão foram $L=(50 \pm 0,5) \mathrm{cm}$ e $d=(9,5 \pm 0,5) \mathrm{cm}$.

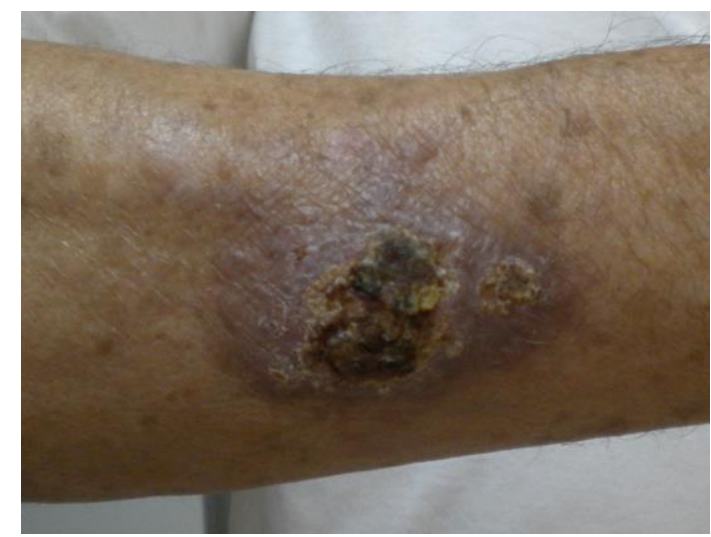

Figura 19: Lesão do paciente 1.

A paciente 2, 71 anos, sexo feminino, pele amarela, também apresentava um quadro de Leishmaniose cutânea, sua lesão havia surgido há dois meses e estava localizada na 
mão direita. No dia da medição, uma parte da lesão estava necrosada e outra parte aberta apresentava pus, parte da lesão se elevava acima da pele saudável e parte possuía certa profundidade abaixo da pele saudável, conforme mostrado na Figura 20.

Os parâmetros experimentais para a medida dessa lesão foram $L=(53 \pm 0,5) \mathrm{cm}$ e $d=(9,5 \pm 0,5) \mathrm{cm}$.

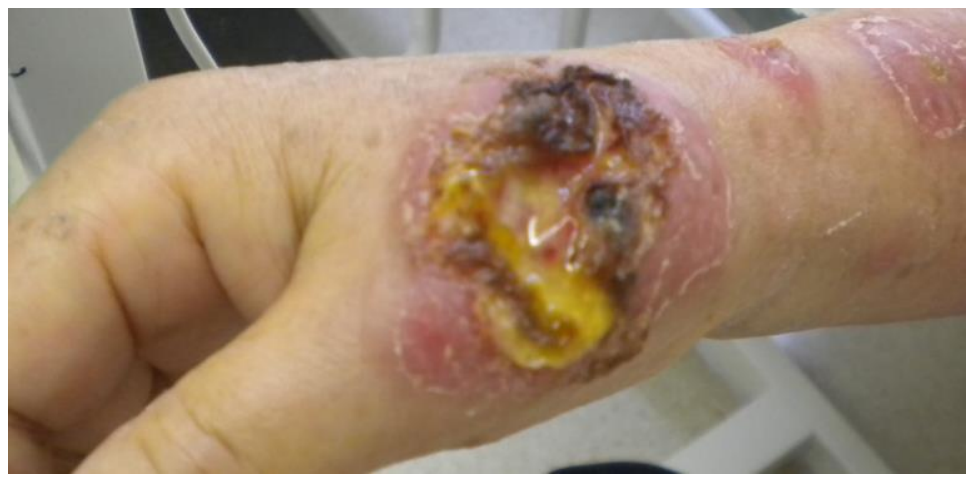

Figura 20: Lesão da paciente 2.

O paciente 3, 70 anos, sexo masculino, pele branca, ainda não havia sido diagnosticado, porém a suspeita é que ele apresentava um quadro de carcinoma espinocelular. Sua lesão estava localizada na perna esquerda e, no dia da medição, apresentava uma crosta avermelhada, que se elevava um pouco acima da pele saudável, conforme mostrado na Figura 21.

Os parâmetros experimentais para a medida dessa lesão foram $L=(50,7 \pm 0,5) \mathrm{cm} \mathrm{e}$ $d=(9,5 \pm 0,5) \mathrm{cm}$.

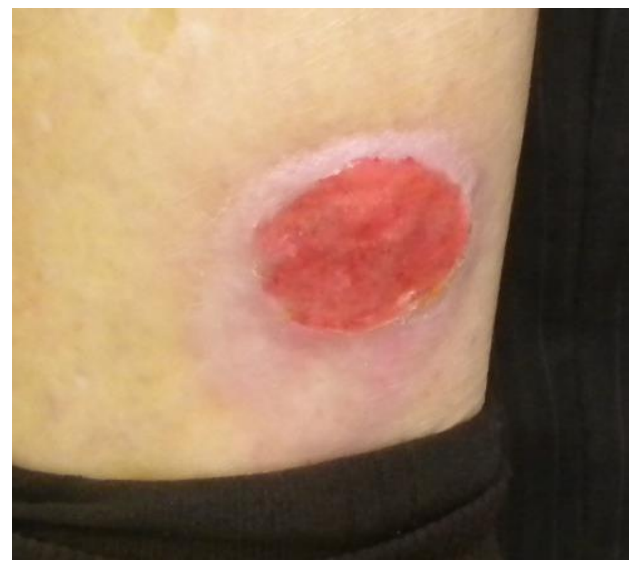

Figura 21: Lesão do paciente 3. 
Em nenhum dos pacientes foi possível realizar medidas das dimensões das lesões com os métodos tradicionais de medida (métodos diretos) para efeitos de comparação, pois não era rotina do hospital fazer medida de profundidade ou volume das lesões, somente medida das dimensões superficiais, e não se pretendia modificar a rotina do acompanhamento. De forma que, neste trabalho, somente serão feitas comparações com as topografias conhecidas e possíveis de ser visualizadas nas fotografias (Figuras 19, 20 e 21).

\subsection{Metodologia}

\subsubsection{Medidas das dimensões dos objetos com paquímetro}

Para comparação e validação dos resultados obtidos com a Técnica de Projeção de Franjas em laboratório, foram medidas as dimensões dos objetos de estudo com um paquímetro de 0,05 $\mathrm{mm}$ de precisão.

Para isso utilizou-se um objeto rígido, de espessura de $(0,360 \pm 0,005) \mathrm{cm}$ com uma escala em papel milimetrado acoplada (mostrado na Figura 22), como plano de referência, a partir do qual todas as medidas de perfil de profundidade foram feitas.

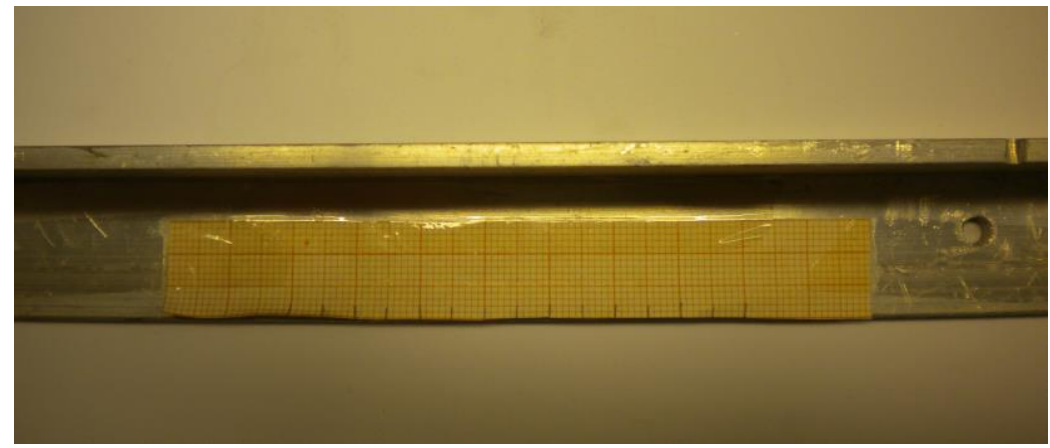

Figura 22: Objeto rígido com uma escala em papel milimetrado acoplada, usado como plano de referência.

As dimensões de cada objeto medidas com o paquímetro foram plotadas em gráficos da altura em função da posição do paquímetro ao longo de retas posicionadas nos principais eixos do objeto, conforme mostrado nas Figuras 23 e 24 e as incertezas dessas medidas foram avaliadas combinando-se as incertezas do paquímetro com a incerteza da escala do papel milimetrado acoplado ao plano de referência, de acordo com a equação:

$$
\sigma_{h}^{2}=\sigma_{p}^{2}+\sigma_{e m}^{2}
$$


onde $\sigma_{h}$ é a incerteza na altura, $\sigma_{p}=0,05 \mathrm{~mm}$ é a incerteza do paquímetro e $\sigma_{e m}=0,5 \mathrm{~mm}$ foi considerada a incerteza da escala milimetrada.

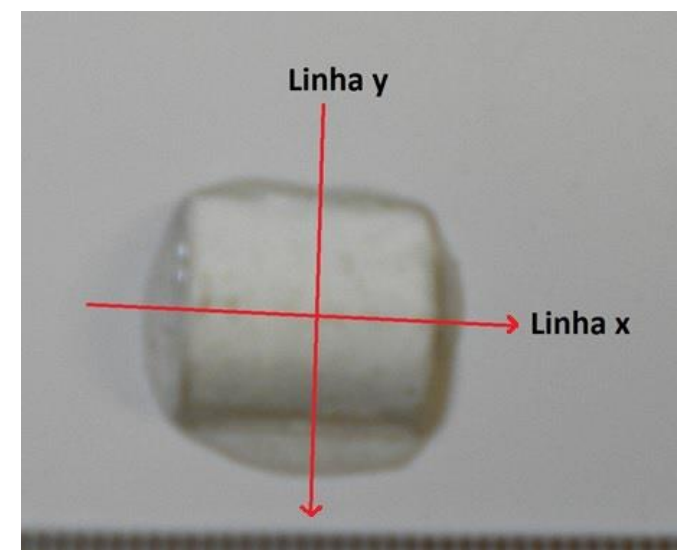

Figura 23: Linhas ao longo das quais foram medidas as alturas do objeto em relação a um plano de referência para o objeto de calibração.
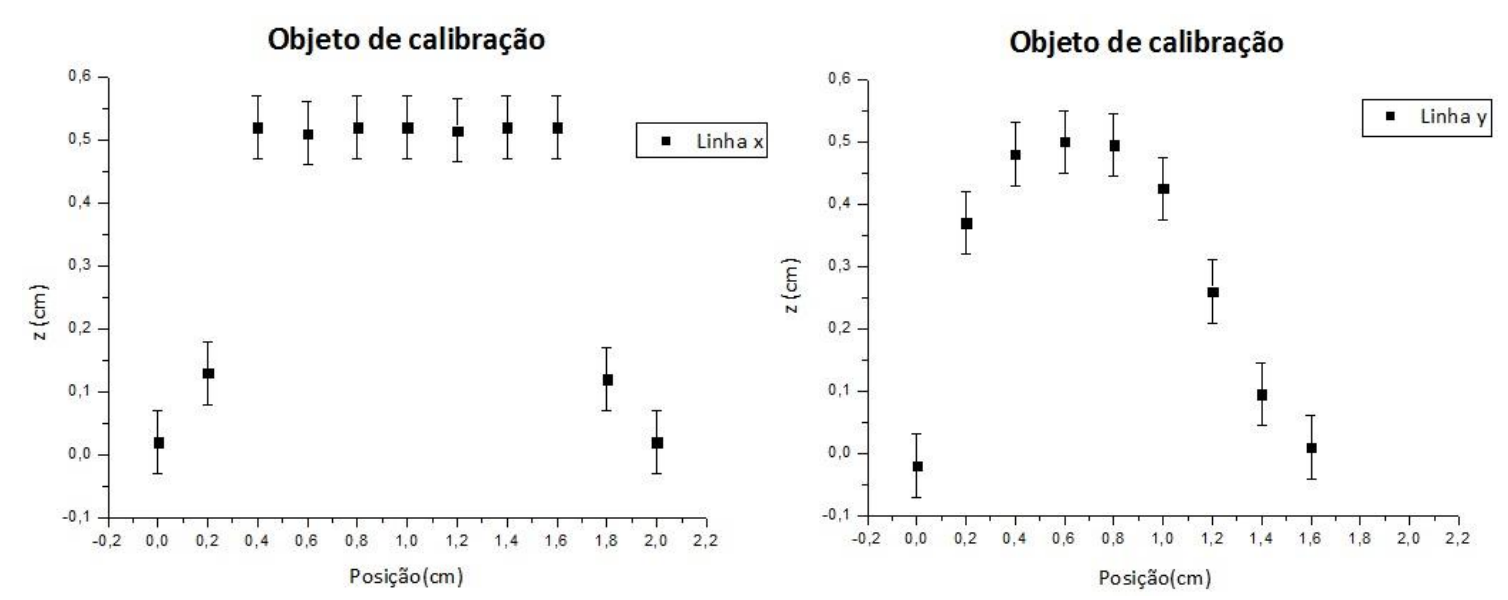

Figura 24: Gráficos da posição no eixo z em função da posição ao longo da linha x (esquerda) e ao longo da linha y (direita) do objeto de calibração.

\subsubsection{Tomada de dados com a Técnica Moiré de Projeção}

Na tomada de dados para a Técnica Moiré de Projeção com Deslocamento de Fase, utilizando-se o arranjo experimental da Figura 11, foram projetadas, uma a uma, quatro grades com a mesma densidade de franjas, cada uma deslocada de $1 / 4$ do período em relação à anterior, no plano de referência sem o objeto. Essas imagens foram fotografadas, obtendo-se as quatro imagens correspondentes. Sem modificar nada no arranjo, projetouse uma das grades no objeto a ser estudado, obtendo-se a quinta imagem, contendo a deformação das grades, conforme exemplificado nas Figuras 25 e 26. 
Já para a Técnica Moiré de Projeção Ortogonal, foram projetadas, uma por vez, duas grades de mesma densidade de franjas, uma ortogonal à outra, no plano de referência sem o objeto. E, após a obtenção das duas imagens, sem modificar nada no arranjo, projetaram-se as mesmas grades no objeto a ser estudado, obtendo mais duas imagens, contendo a deformação das grades, conforme exemplificado nas Figuras 27 e 28.

As grades projetadas foram construídas computacionalmente através de um código programado em MatLab, que permitia regular a densidade das franjas e suas cores.

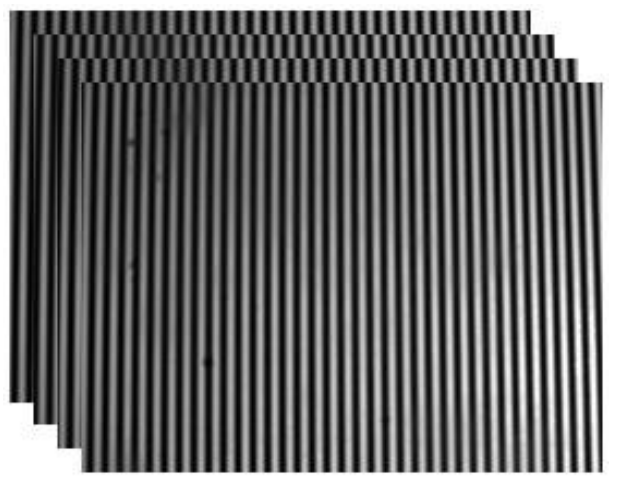

Figura 25: Quatro grades com a mesma

densidade de franjas, cada uma deslocada de 1/4 do período em relação à anterior, projetadas no plano de referência.

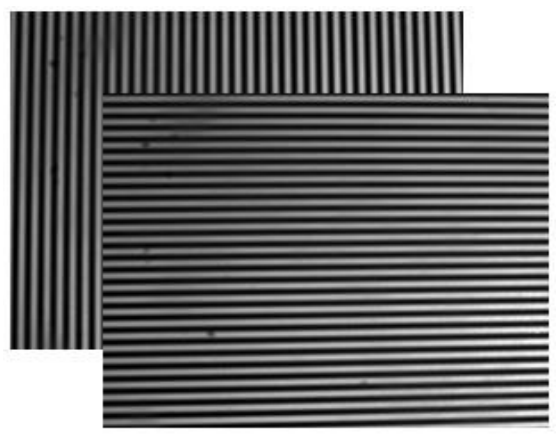

Figura 27: Duas grades com a mesma densidade de franjas, uma ortogonal à outra, projetadas no plano de referência.

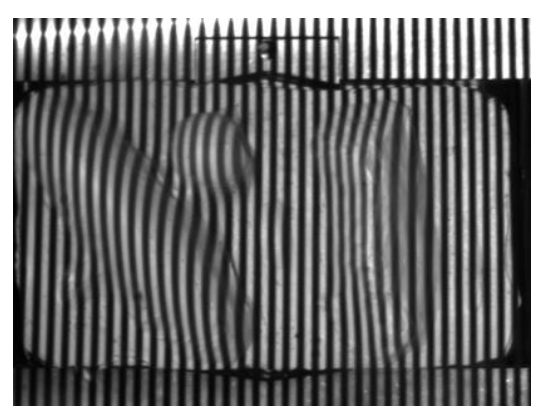

Figura 26: Uma das grades projetada sobre o objeto 1.

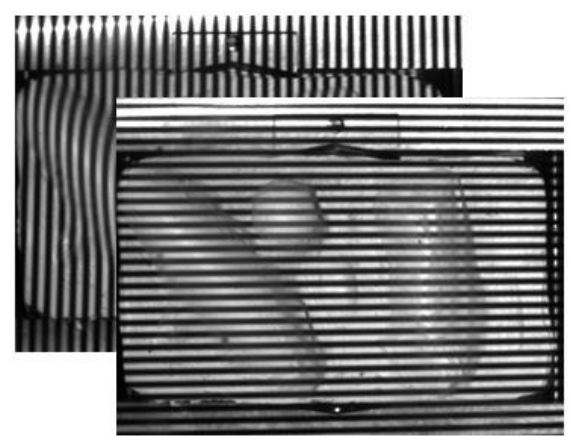

Figura 28: Duas grades com a mesma densidade de franjas, uma ortogonal à outra, projetadas no objeto 1.

\subsubsection{Análise dos dados da Técnica Moiré de Projeção}

A partir das imagens obtidas com a Técnica de Moiré de Projeção com Deslocamento de Fase, com o programa ImageJ, foram subtraídas da imagem com o objeto, com a deformação das franjas (Figura 26), cada uma das imagens das grades projetadas no plano 
de referência (Figura 25), obtendo-se quatro imagens com o padrão moiré, conforme mostrado na Figura 29. Em seguida, foi aplicado um filtro passa-baixa, como o filtro gaussiano, por exemplo, com o intuito de obter somente o padrão moiré, conforme mostrado na Figura 30. E, através de um código programado em MatLab, que resolve o sistema de equações de (6) a (9), foi feita a análise do Método de Deslocamento de Fase, para obter o mapa com as fases moduladas.

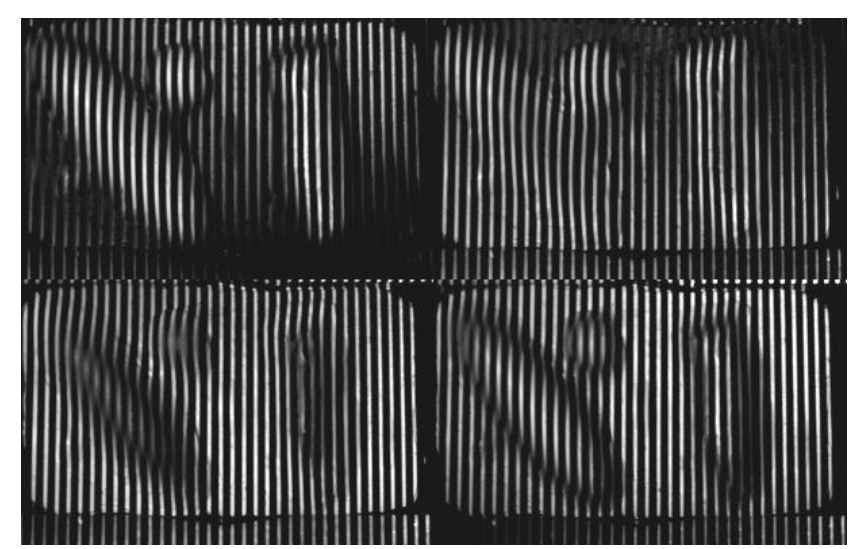

Figura 29: Subtração das imagens com as quatro grades deslocadas de $1 / 4$ do período da com uma das grades projetada no objeto 1, para a análise com a Técnica Moiré de Projeção com Deslocamento de Fase.

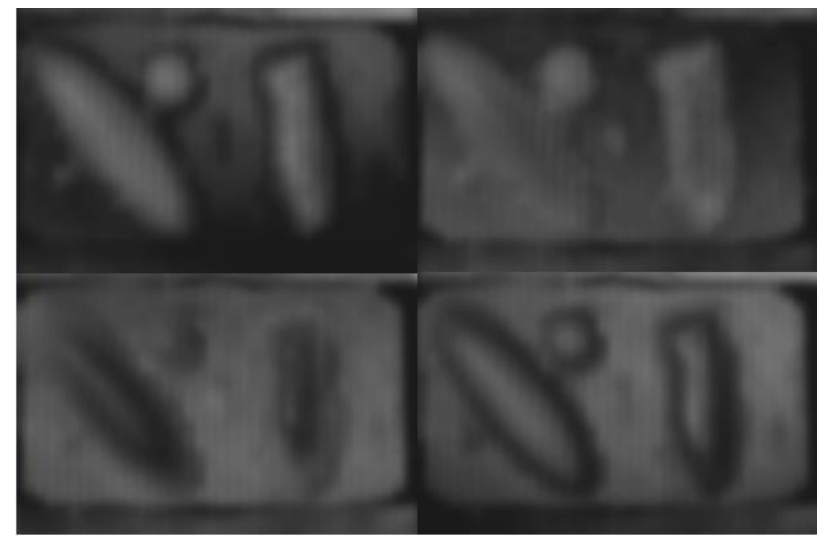

Figura 30: As quatro imagens da Figura 29, após a aplicação do filtro gaussiano, para a obtenção do padrão moiré.

Já para as imagens obtidas com a Técnica de Moiré com Projeção Ortogonal, também com o programa ImageJ, foram subtraídas das imagens das grades ortogonais projetadas no objeto, as respectivas imagens com as grades ortogonais entre si projetadas no plano de referência, obtendo duas imagens com o padrão moiré, conforme mostrado na Figura 31. Em seguida, através de um código programado em MatLab (que faz a Transformada de 
Fourier das imagens, subtrai os espectros, elimina os termos negativos e seleciona o termo de interesse para retirar os portadores de frequência e fazer a Transformada inversa), foi feita a análise do Método de Projeção Ortogonal, para se obter o mapa com as fases moduladas.

Diferentemente do Método de Deslocamento de Fase, nessa análise, não foi necessário fazer a filtragem prévia das imagens, pois o próprio método faz uma filtragem através da seleção, no espectro de Fourier, do termo de primeira ordem, que contém a informação dos padrões moiré modulados.
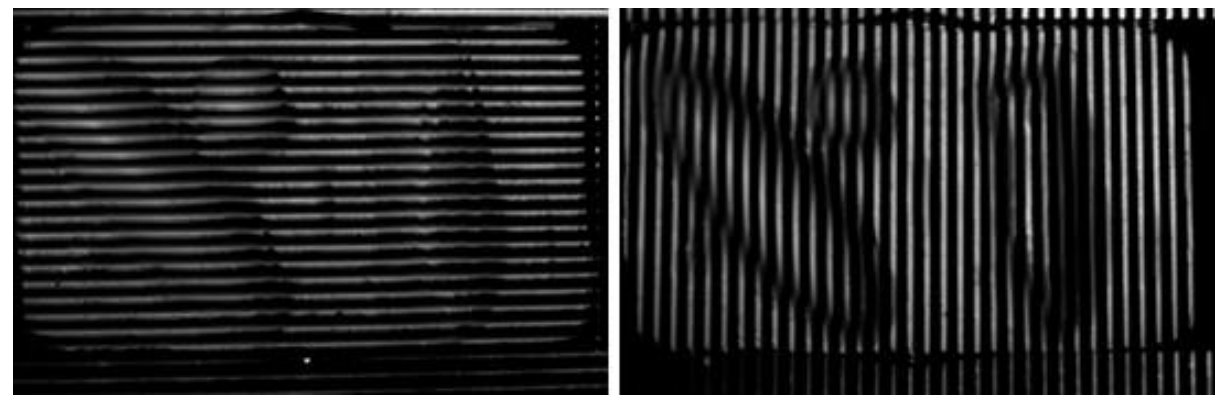

Figura 31: Subtração das imagens das grades ortogonais projetadas no plano de referência das suas respectivas imagens com a grade projetada no objeto 1, para a análise com a Técnica Moiré com Projeção Ortogonal.

Por fim, tanto para os dados obtidos com o Método de Deslocamento de fase, como para com os obtidos com o Método de Projeção Ortogonal, aplicou-se o método de Volkov, para a desmodulação da fase, e a técnica de remoção linear por ajuste de um plano, para remover os portadores de frequência e, assim, pôde-se obter o MDT do objeto.

Os mesmos procedimentos, desde a tomada das imagens até a obtenção do MDT, foram realizados para o objeto de calibração e, através do método de triangulação juntamente com a utilização das dimensões conhecidas deste objeto, obteve-se o fator de calibração C, e determinaram-se as distâncias para os objetos de estudo cujas medidas foram feitas nas mesmas condições experimentais e assim, pôde-se obter o MDT em três dimensões para esses objetos.

As etapas seguidas na análise dos dados obtidos com a Técnica Moiré de Projeção com Deslocamento de Fase e dos obtidos com a Técnica Moiré com Projeção Ortogonal são mostradas resumidamente nas Figuras 32 e 33, respectivamente. 


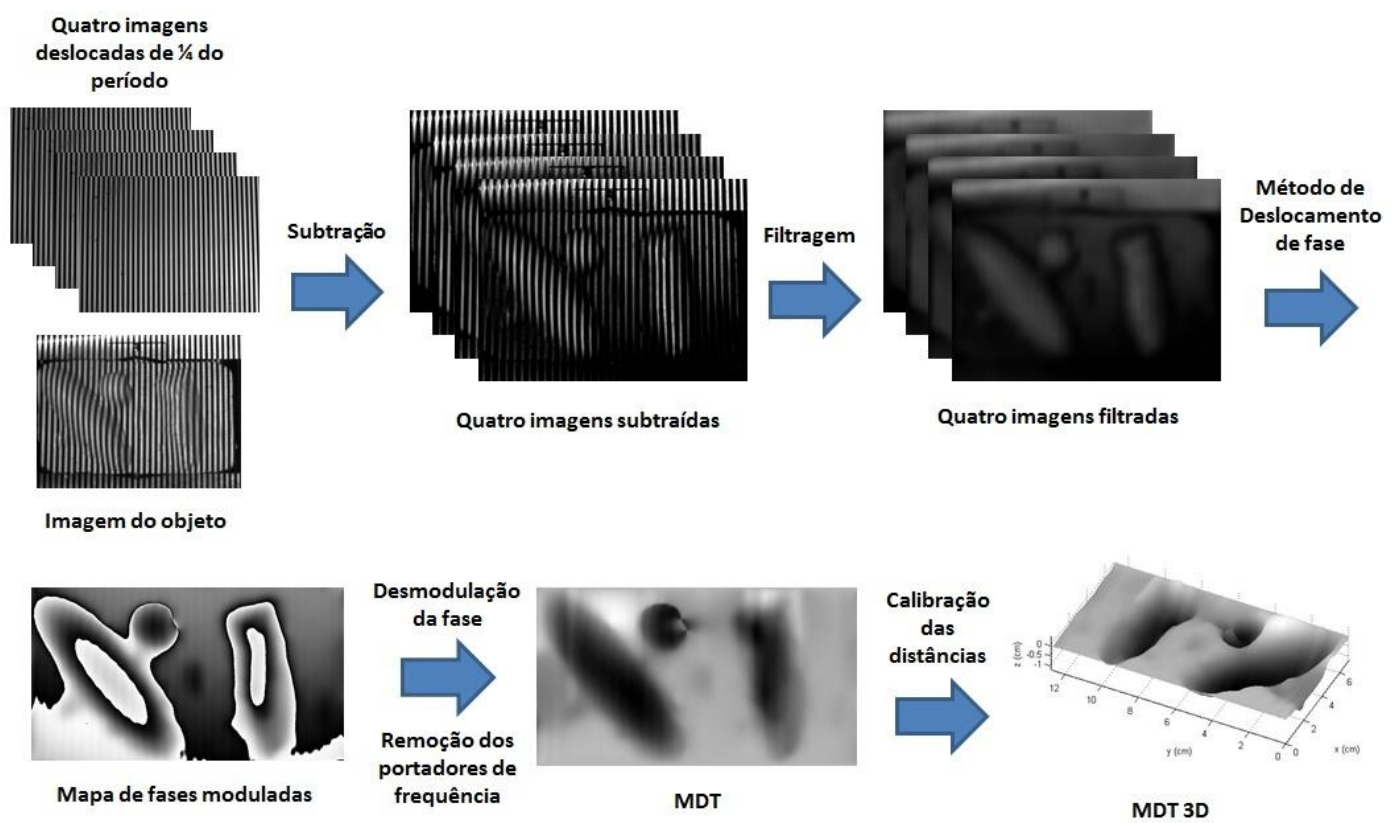

Figura 32: Etapas para a análise dos dados obtidos com a Técnica Moiré de Projeção com Deslocamento de Fase.
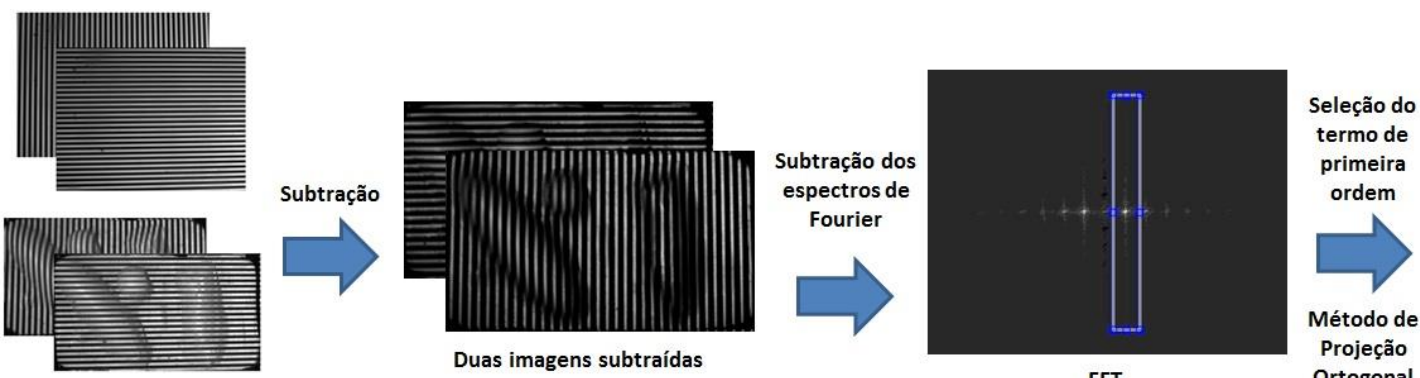

Franjas ortogonais projetadas no plano de referência e no objeto

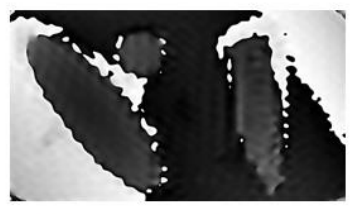

Mapa de fases moduladas

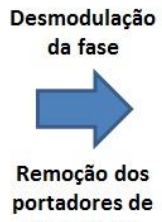

frequência

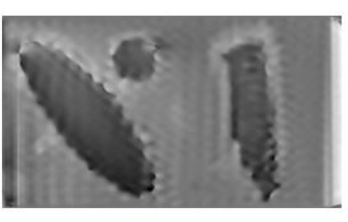

MDT

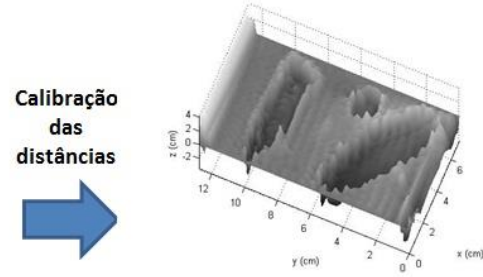

MDT 3D

Figura 33: Etapas para a análise dos dados obtidos com a Técnica Moiré com Projeção Ortogonal.

\subsubsection{Tomada de dados com a Técnica de Projeção de Franjas}

Na tomada de dados da Técnica de Projeção de Franjas com Deslocamento de Fase, utilizando-se o arranjo experimental da Figura 11, foram projetadas quatro grades com a mesma densidade de franjas, cada um deslocada de $1 / 4$ do período em relação à anterior, 
no objeto colocado no plano de referência, conforme mostrado na Figura 34. As quatro imagens obtidas já continham a informação da deformação das grades.

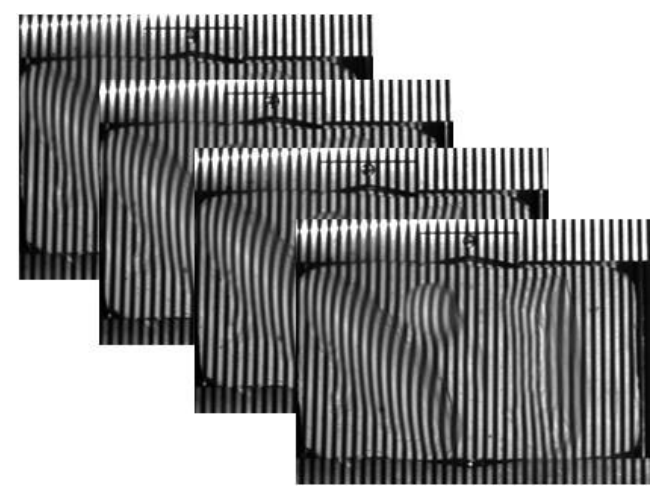

Figura 34: Quatro grades com a mesma densidade de franjas, cada uma deslocada de 1/4 do período em relação à anterior, projetadas no objeto 1 .

Já para a Técnica de Projeção de Franjas com Projeção Ortogonal, bastou projetar duas grades de mesma densidade de franjas, uma ortogonal à outra, no objeto colocado no plano de referência, conforme mostrado na Figura 28. As duas imagens obtidas também já continham a informação da deformação das grades.

\subsubsection{Análise dos dados da Técnica de Projeção de Franjas}

As imagens obtidas com a Técnica de Projeção de Franjas com o Método de Deslocamento de Fase devem ser filtradas antes da aplicação do método em si, pois, muitas vezes, há ruídos nas imagens ou defeitos nas franjas que podem influenciar na reconstrução dos padrões. Para isso, utilizou-se o filtro de transformada de Fourier FFT (Fast Fourier Transform), e selecionou-se apenas o termo de primeira ordem, que contém a informação da modulação das franjas. Os termos de ordem superior são devidos justamente aos ruídos na imagem e a defeitos nas franjas, que podem não ser perfeitamente senoidais. Trata-se de um procedimento semelhante ao da análise de Fourier, para a filtragem, com a diferença de que a fase será calculada pela resolução do sistema de quatro equações (Equações de (6) a (9)) e não pelas transformadas direta e inversa de Fourier.

Já as imagens obtidas com o Método de Projeção Ortogonal não necessitam de nenhum tratamento prévio, pois a aplicação do método em si já inclui a filtragem e seleção dos termos referentes à modulação das franjas. 
Com o código programado em MatLab, foram feitas as respectivas análises do Método de Deslocamento de Fase e do Método de Projeção Ortogonal nas imagens, conforme descrito anteriormente, para se obter o mapa com as fases moduladas.

Em seguida, nos dois métodos, aplicou-se o método de Volkov, para a desmodulação da fase, e a técnica de remoção linear por ajuste de um plano, para remover os portadores de frequência, obtendo o MDT do objeto. Por fim, realizou-se o mesmo processo da Técnica Moiré de Projeção para a calibração das distâncias do objeto de estudo, obtendo um MDT em três dimensões.

As etapas seguidas para a análise dos dados obtidos com a Técnica de Projeção de Franjas com Deslocamento de Fase e com Projeção Ortogonal, são mostradas nas Figuras 35 e 36.

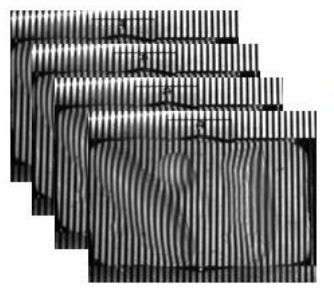

Quatro imagens deslocadas de $1 / 4$ do período
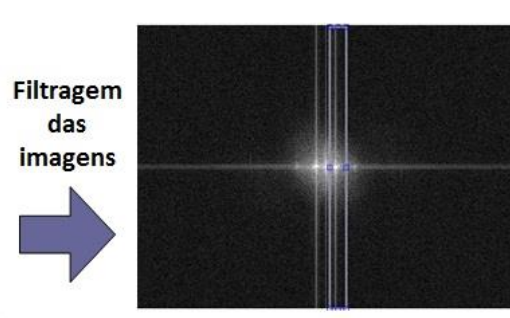

FFT

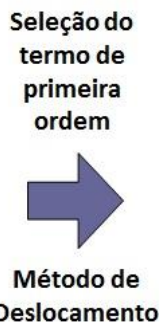

Deslocamento de fase

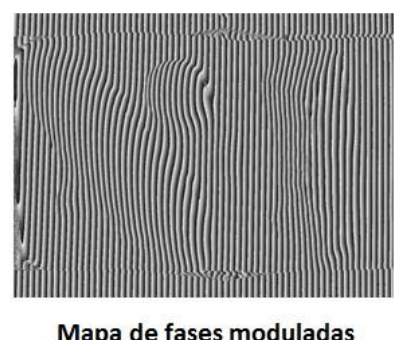

Mapa de fases moduladas

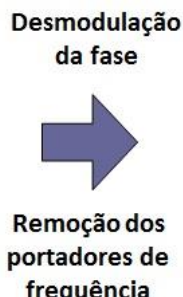

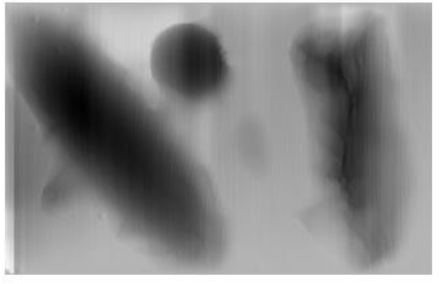

MDT

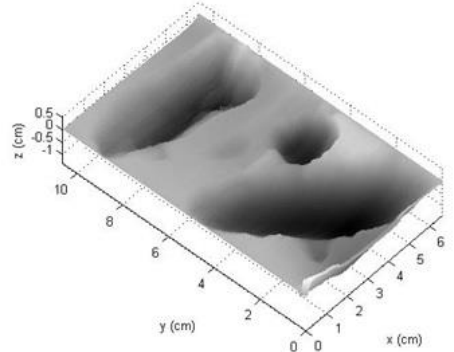

MDT 3D

Figura 35: Etapas para a análise dos dados obtidos com a Técnica de Projeção de Franjas com Deslocamento de Fase. 


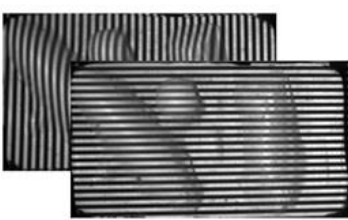

Duas imagens com franjas ortogonais projetadas no objeto

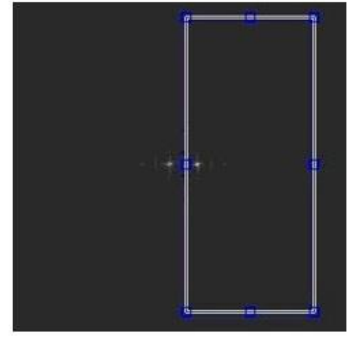

FFT
Seleção do

termo de

primeira

ordem

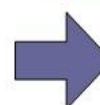

Método de

Projeção Ortogonal

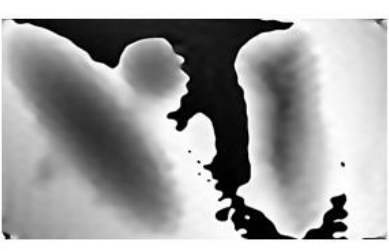

Mapa de fases moduladas

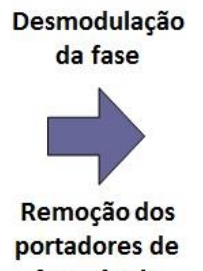

frequência

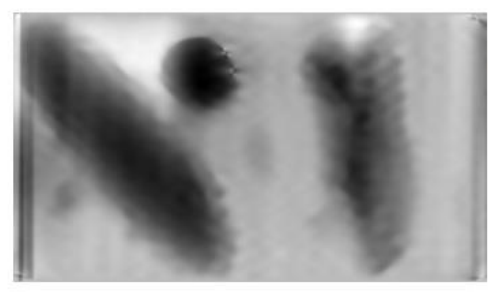

MDT
Calibração das distâncias

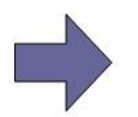

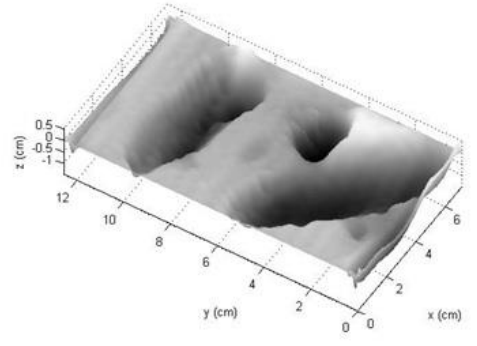

MDT 3D

Figura 36: Etapas para a análise dos dados obtidos com a Técnica de Projeção de Franjas com Projeção Ortogonal.

\subsubsection{Comparação com as medidas obtidas com o paquímetro e estimativa das incertezas}

Após a obtenção dos MDTs, foram traçadas linhas ao longo dos principais eixos nas regiões de interesse na imagem de cada objeto e os perfis ao longo dessas linhas foram comparados aos medidos com o paquímetro, conforme exemplificado na Figura 37, para o perfil da linha 2y traçada no MDT obtido com a Técnica de Projeção de Franjas com Deslocamento de Fase para o objeto 1.

As incertezas nas medidas ao longo dos perfis foram estimadas tomando-se novamente o MDT, traçando outra linha ao longo dos eixos principais das regiões de interesse e subtraindo os valores obtidos ao longo da primeira linha. Essa estimativa deve ser feita, pois não se pode garantir que as medidas realizadas com o paquímetro foram feitas exatamente ao longo da linha traçada no MDT obtido com as técnicas de análise de franjas. 

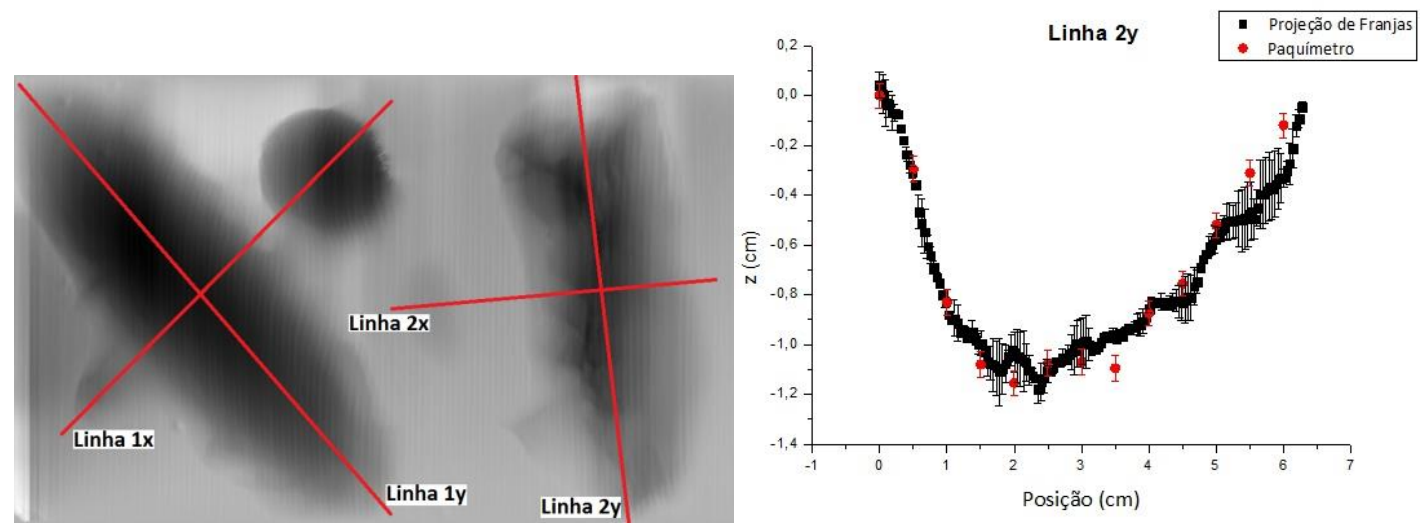

Figura 37: (Esquerda) Linhas traçadas ao longo dos principais eixos das regiões de interesse do objeto 1. (Direita) Comparação dos perfis obtidos com a Técnica de Projeção de Franjas com

Deslocamento de Fase e o medido com o paquímetro, ao longo da linha 2y do objeto 1.

\subsubsection{Obtenção dos mapas de intensidade}

Os mapas de intensidade representam a intensidade de luz em cada ponto $(x, y)$ da imagem do objeto e são obtidos a partir dos termos $A(x, y)$ e $B(x, y)$ da Equação (4).

No Método de Deslocamento de Fase, esses termos foram obtidos a partir da solução do sistema de quatro equações (Equações (6) a (9)); no Método de Projeção Ortogonal, a partir da análise de Fourier. Em ambos os casos, a obtenção desses termos foi programada no código em MatLab utilizado. 


\section{CALIBRAÇÃO E TESTE}

\subsection{Calibração do arranjo experimental}

A primeira etapa importante do trabalho é a calibração do arranjo experimental, ela é importante para encontrar a melhor configuração da disposição espacial e funcionamento dos equipamentos utilizados, além dos fatores que influenciam na aplicação da técnica em si. A seguir são apresentadas as etapas realizadas para a calibração do arranjo experimental.

\subsubsection{Escolha das distâncias}

A escolha das melhores distâncias $L$ e $d$ do arranjo experimental foi baseada na equação (33), levando-se em conta o fato de que essas distâncias devem ser possíveis de se reproduzir em um ambiente hospitalar.

As topografias dos objetos de estudo e a profundidade das feridas possuem uma variação de altura $\Delta h$ em relação ao plano de referência da ordem de dezenas de milímetros. De acordo com a equação (33), há dois parâmetros livres a serem ajustados para que a técnica tenha a resolução adequada: o período espacial das franjas $p$ e o ângulo de iluminação $\theta_{i}$, que depende das distâncias $L$ e $d$ do arranjo experimental.

Optou-se, então, por escolher distâncias de tal forma que o fator no denominador $2 \pi \sin \left(\theta_{i}\right)$ seja aproximadamente um, para que a resolução da técnica dependa basicamente apenas de $p$, e, ao mesmo tempo, satisfaça a condição de poder ser reproduzida em um hospital.

Escolheu-se, portanto, $L$ e $d$ em torno de $(50 \pm 0,5) \mathrm{cm}$ e $(10 \pm 0,5) \mathrm{cm}$, respectivamente.

\subsubsection{Escolha do período espacial das franjas}

Sabendo que as lesões nas quais se quer aplicar o método e os objetos construídos para simulá-las possuem profundidades da ordem de dezenas de milímetros, a sensibilidade requerida para o arranjo experimental deve ser dessa ordem. Essa sensibilidade equivale ao termo $\Delta h / \Delta \phi$ na equação (33), onde o intervalo de dezenas de milímetros deve corresponder a um intervalo de $2 \pi$ na fase. Uma vez conhecida a 
sensibilidade requerida para o método, o período espacial das franjas $p$ pode ser determinado a partir da equação (33).

Dessa forma, estimou-se que, para o arranjo experimental da Figura 11, com $L=(44,5 \pm 0,5) \mathrm{cm}$ e $d=(9,1 \pm 0,5) \mathrm{cm}$, conforme escolhido na seção anterior, o período ideal estaria em torno de $0,20 \mathrm{~cm} /$ franja.

Além disso, sabe-se que o quanto maior a densidade de franjas melhor a sensibilidade do método, porém existe a limitação da câmera e do projetor, que, a partir de certo número de franjas começam a deformar a imagem destas. Por isso, o melhor período a ser utilizado com os parâmetros do arranjo experimental citados anteriormente foi determinado variando-se o número de franjas de 80 a 130, de 10 em 10 franjas, em uma imagem de $1000 \times 600$ pixels e projetando-as sobre o objeto 1 , conforme mostrado na Figura 38 e escolhendo aquele com maior número de franjas, mas que, ao mesmo tempo, apresentava menor deformação destas em relação às franjas senoidais originais e era capaz de fornecer um MDT satisfatório, em que as características da topografia do objeto eram bem representadas.

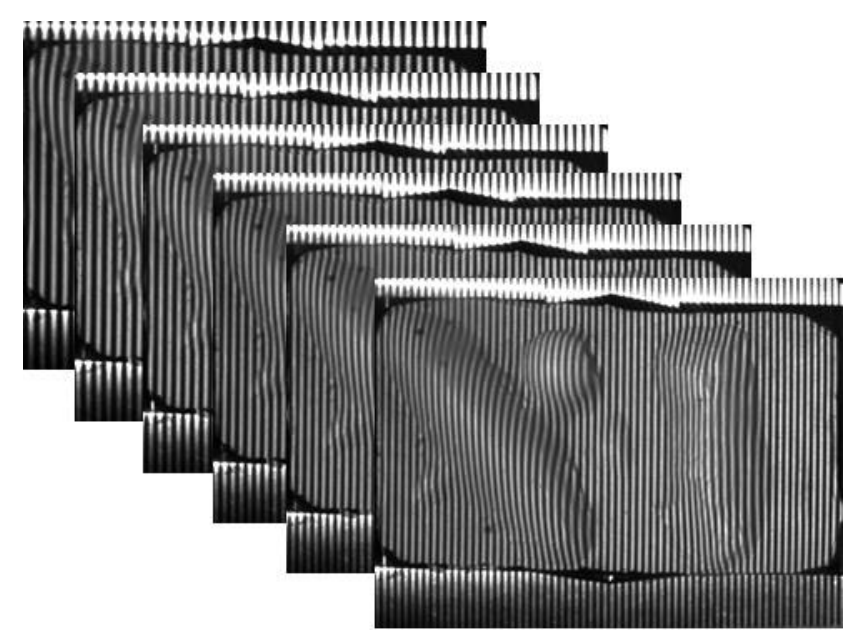

Figura 38: Variação do número de franjas de 80 a 130, de 10 em 10 franjas, em uma imagem de 1000 x 600 pixels e projeção sobre o objeto 1. As imagens adquiridas possuíam $280 \times 960$ pixels.

Para verificar a deformação das franjas no processo de projeção e captura das imagens, em cada uma das imagens obtidas foi traçada uma linha ao longo de uma parte plana do objeto e analisado o perfil de intensidade luminosa, em níveis de cinza, ao longo dessa linha. Na Figura 39, são mostrados os perfis para 90 e 130 franjas, onde se nota que 
o perfil para 130 franjas se mostrou bem mais deformado em relação às franjas de formato senoidal do que o perfil para 90 franjas.

Dessa forma, escolheu-se o maior número de franjas que apresentava menor deformação, que foi justamente 90 franjas, correspondente a um período espacial de $p=(0,33 \pm 0,01) \mathrm{cm} /$ franja. Com esse período espacial também foi possível obter um MDT satisfatório, que representava bem as características da topografia do objeto, conforme se pode observar na Figura 40.

(a)

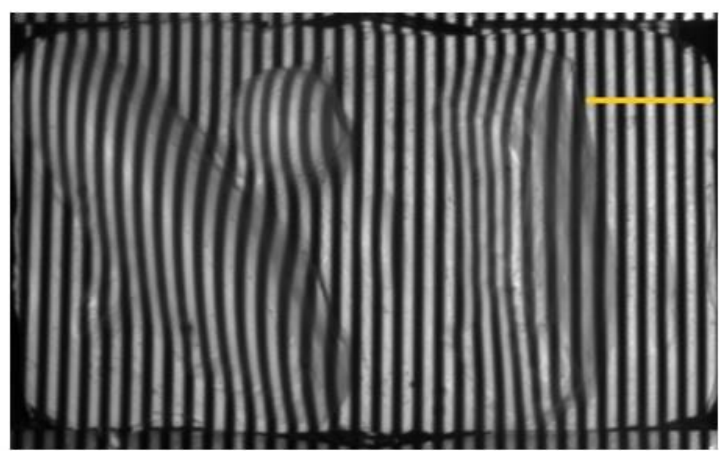

(b)

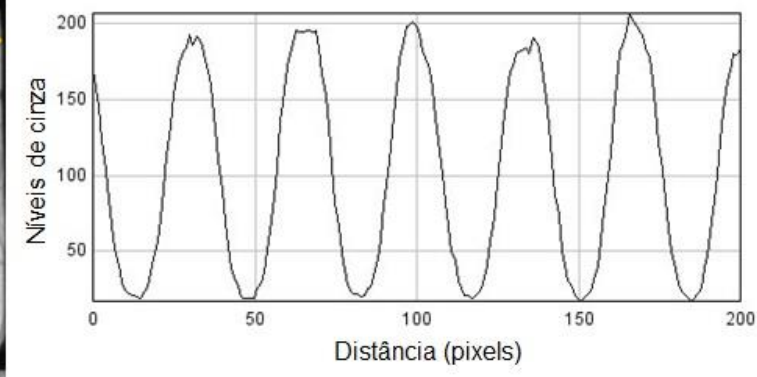

(c)

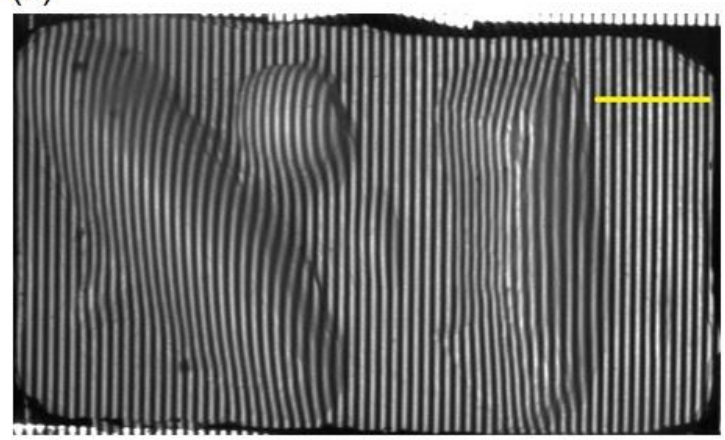

(d)

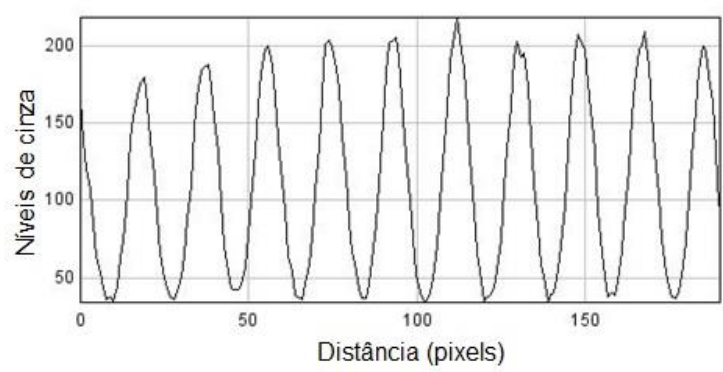

Figura 39: Linhas traçadas em uma parte plana do objeto, com (a) 90 e (c) 130 franjas projetadas. Perfis de intensidade luminosa em níveis de cinza ao longo das linhas traçadas, para (b) 90 e (d) 130 franjas projetadas. 


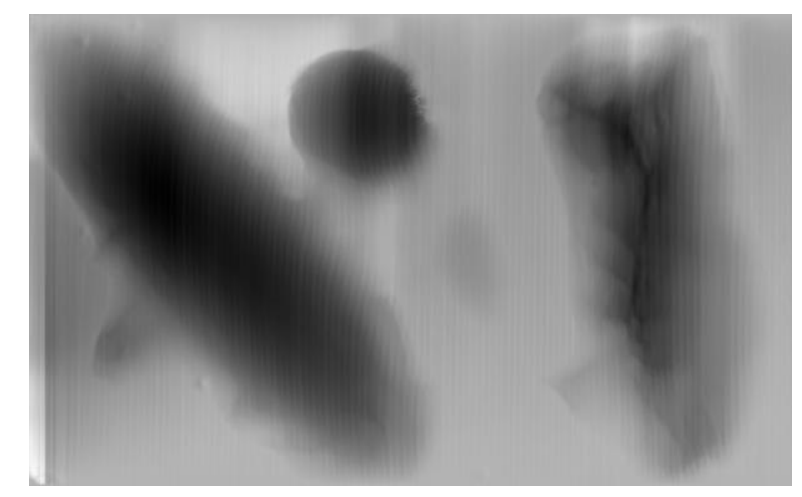

Figura 40: MDT obtido com um período espacial de franjas $p=(0,33 \pm 0,01) \mathrm{cm} /$ franja.

\subsubsection{Escolha da cor das franjas com as amostras coloridas}

No caso das amostras coloridas, foi feito um estudo sobre quais cores seriam as mais adequadas para o fundo e para as franjas com formato senoidal na imagem a ser projetada sobre os objetos que simulavam cores de pele e de lesões. Essas cores de franjas foram escolhidas de forma que haja maior contraste e melhor distinção entre as franjas, ou seja, a cor de fundo deve ser bem absorvida e a das franjas deve ser bem refletida, ao serem projetadas sobre as amostras. Para isso, levou-se em conta qual o comprimento de onda na região do visível, correspondente à determinada cor, seria o mais refletido e o mais absorvido pela pele e pelas lesões.

Também se levou em conta o fato de que, para uma amostra iluminada, os coeficientes de absorção, reflexão e transmissão da luz somam um. Para uma situação em que a transmissão é aproximadamente nula (como é o caso das amostras coloridas estudadas), portanto, em um comprimento de onda em que há mais absorção, haverá menos reflexão.

Assim, em uma amostra em que predominam cores que simulam as cores da melanina, correspondente a coloração da pele, e da hemoglobina, correspondente a uma lesão exposta, de acordo com o espectro de absorção mostrado na Figura 41 [Wang et al., 2010], na região de comprimentos de onda $(\lambda)$ no visível, as cores que mais se contrastariam entre si seriam o ciano $(520 \mathrm{~nm} \leq \lambda \leq 540 \mathrm{~nm})$ e o vermelho $(610 \mathrm{~nm} \leq \lambda \leq 620 \mathrm{~nm})$, pois o comprimento de onda próximo a $430 \mathrm{~nm}$ corresponde praticamente à região ultravioleta e é difícil de ser bem reproduzida com um projetor. 


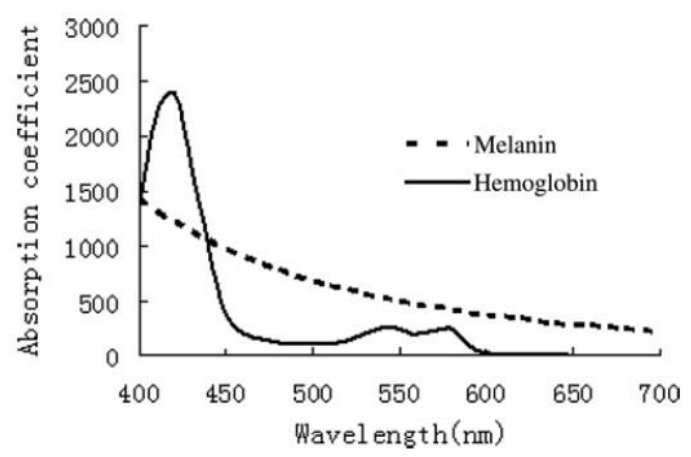

Figura 41: Espectro de absorção da melanina e da hemoglobina (fonte: Wang et al., 2010).

Dessa forma, foram feitos testes projetando franjas em preto e branco, vermelho e branco, ciano e branco, verde e branco, ciano e vermelho e verde e vermelho sobre os objetos coloridos que simulavam pele clara, média, escura e o objeto vermelho. Em seguida, foram analisados os perfis das franjas ao longo de uma linha perpendicular a elas, localizada em uma região com pouco brilho ou sombra. A Figura 42 mostra os resultados para as franjas preto e branco e ciano e vermelho projetadas sobre os objetos pele escura e pele média, respectivamente. Observa-se claramente que a cor das franjas projetadas influencia no formato, na nitidez e distinção entre elas, além de depender da cor da amostra.
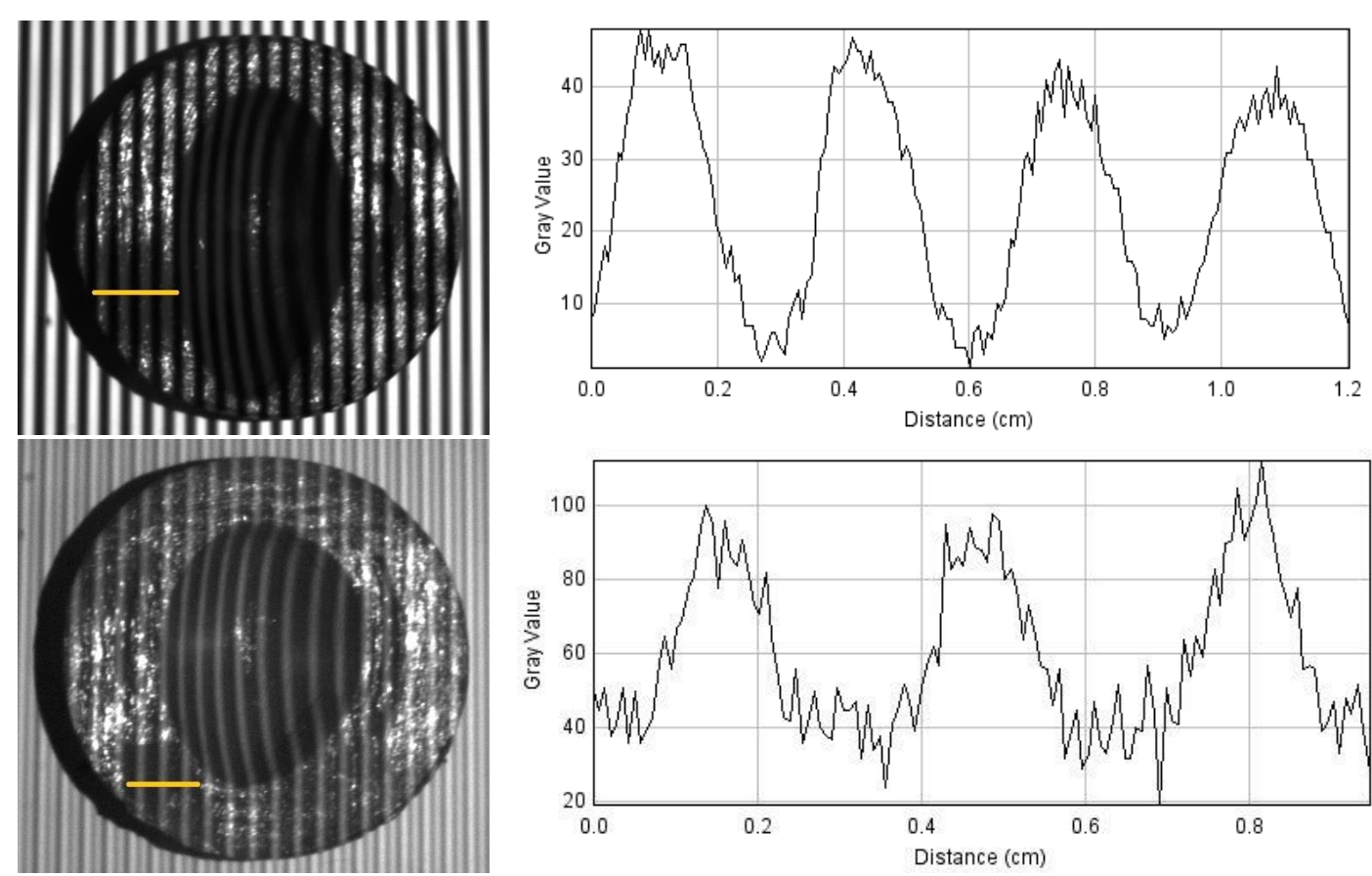

Figura 42: Perfis das franjas preto e branco e ciano e vermelho ao longo da linha amarela, para as amostras de pele escura (acima) e pele média (abaixo), respectivamente. 
Conforme analisado anteriormente, as cores de franjas potencialmente mais contrastantes para essas amostras eram o ciano e o vermelho. No entanto, para todas as amostras, as que apresentaram melhor contraste, nitidez e intensidade com formato mais próximo ao de uma onda senoidal foram as franjas em preto e branco. Isso pode ter ocorrido devido à câmera CCD utilizada ser monocromática e, portanto, captar apenas os níveis de intensidade luminosa, de forma que as diferenças entre cores são interpretadas em termos de níveis de cinza e, assim, a análise de refletividade e absorção não poderia ser feita em termos de comprimento de onda. Caso a câmera CCD captasse cores, provavelmente a hipótese de que, para essas amostras, as cores que mais contrastariam entre si fossem o vermelho e o ciano seria válida.

Portanto, as franjas projetadas em todas as amostras ao longo do trabalho foram as em preto e branco.

\subsubsection{Escolha do brilho e contraste da projeção para as amostras coloridas}

Outro importante fator que influencia na visibilidade e distinção das franjas é o ajuste de brilho e o contraste da projeção. Para escolher os mais adequados, fixou-se uma determinada abertura do diafragma da lente acoplada à câmera CCD, e projetaram-se imagens das franjas preto de branco sobre o objeto de cor pele clara, variando o contraste e o brilho nos ajustes do projetor. Primeiramente deixou-se o contraste fixo igual a 50 e variou-se o brilho de 25 a 95, com passo 10. Em seguida, fixou-se o brilho em 65 e variouse o contraste de 20 a 80, também com passo 10 .

Para a análise, foram traçadas linhas perpendiculares às franjas e analisados os perfis ao longo destas, conforme mostrado nas Figuras 43 e 44, para os brilhos 25 e 95 e para os contrastes 20 e 80 , respectivamente. 

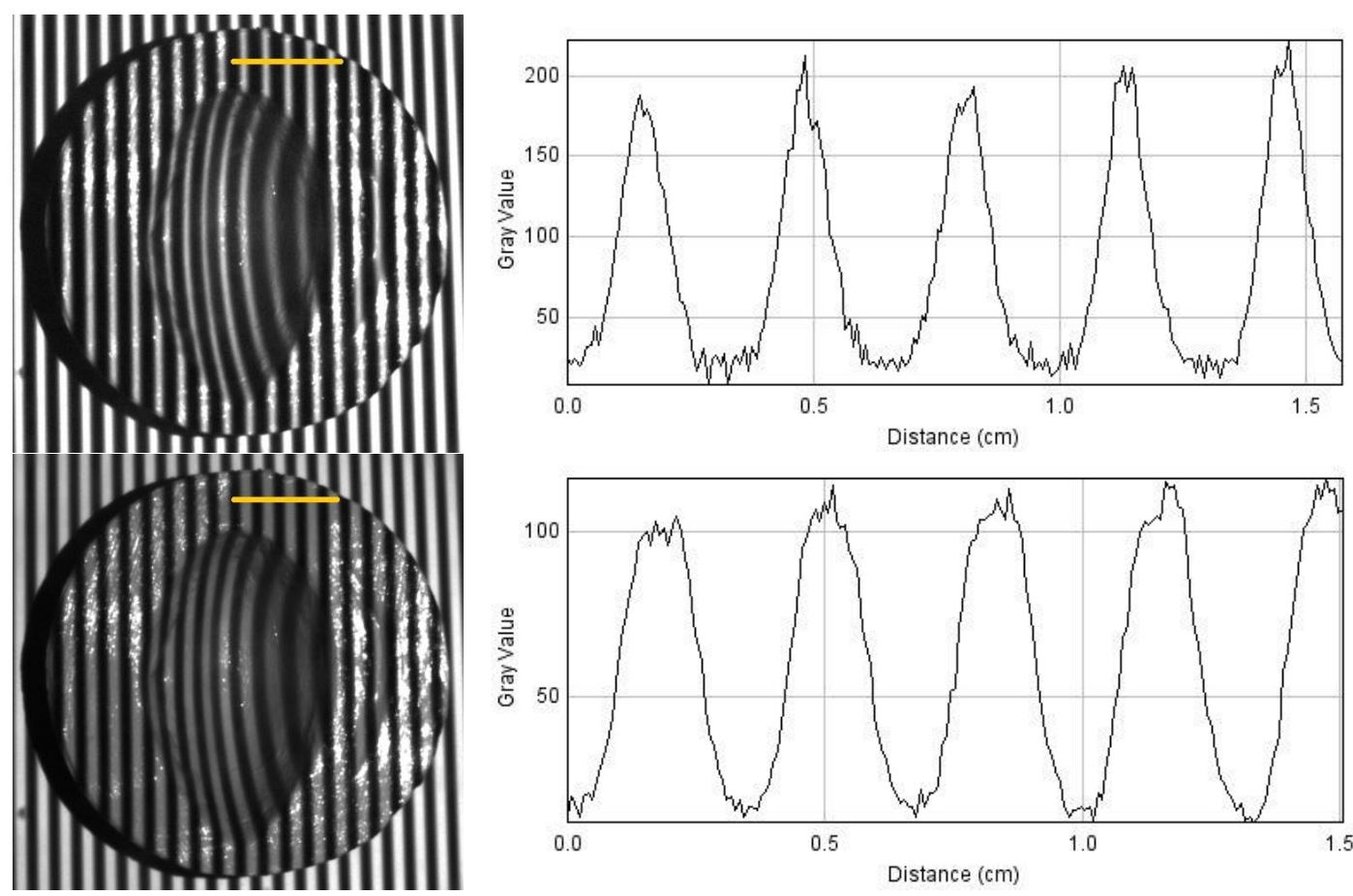

Figura 43: Perfis, ao longo da linha amarela, das franjas preto e branco projetadas sobre o objeto de cor pele clara, com contraste do projetor fixo igual a 50 e brilhos iguais a 25 (acima) e 95 (abaixo).
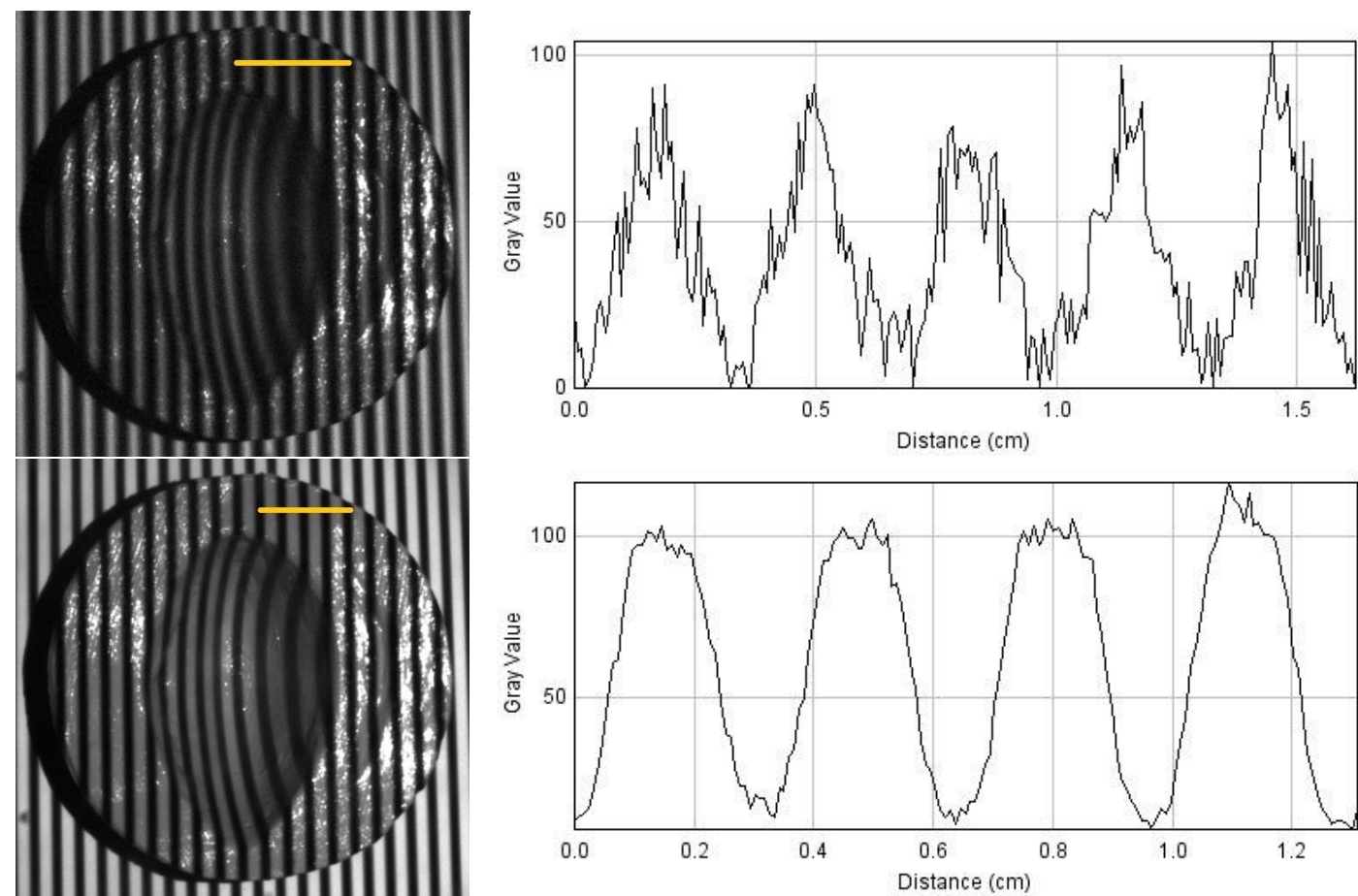

Figura 44: Perfis, ao longo da linha amarela, das franjas preto e branco projetadas sobre o objeto de cor pele clara, com brilho do projetor fixo igual a 65 e contrastes iguais a 20 (acima) e 80 (abaixo). 
Observa-se que o brilho influencia na amplitude dos picos e na sua largura, enquanto que o contraste influencia na nitidez e no formato dos picos. Para o projetor utilizado e para essa abertura do diafragma da câmera CCD, os ajustes de brilho e contraste da projeção cujos perfis eram mais próximos ao de uma onda senoidal foram de 75 e 60, respectivamente. Portanto, esses foram os valores utilizados ao longo do trabalho.

\subsection{Comparação entre a Técnica de Moiré de Projeção e a Projeção de Franjas}

Conhecendo-se que existem duas técnicas de projeção de franjas possíveis de serem utilizadas para a obtenção de topografias de objetos, foi feita uma comparação entre as técnicas de Moiré de Projeção e de Projeção de Franjas, ambas utilizando o Método de Deslocamento de Fase, e escolheu-se a técnica que se apresentou mais adequada ao objetivo de medir dimensões de lesões na pele.

Para isso, aplicaram-se os métodos de análise descritos no capítulo 3 nas imagens obtidas para o objeto 1. O mapa de fases moduladas, o MDT e o MDT 3D obtidos com a Técnica Moiré de Projeção são mostrados nas Figuras 45 e 46, e os obtidos com a Técnica de Projeção de Franjas nas Figuras 47 e 48. Em ambas as técnicas, foi utilizado o método de Deslocamento de Fase.

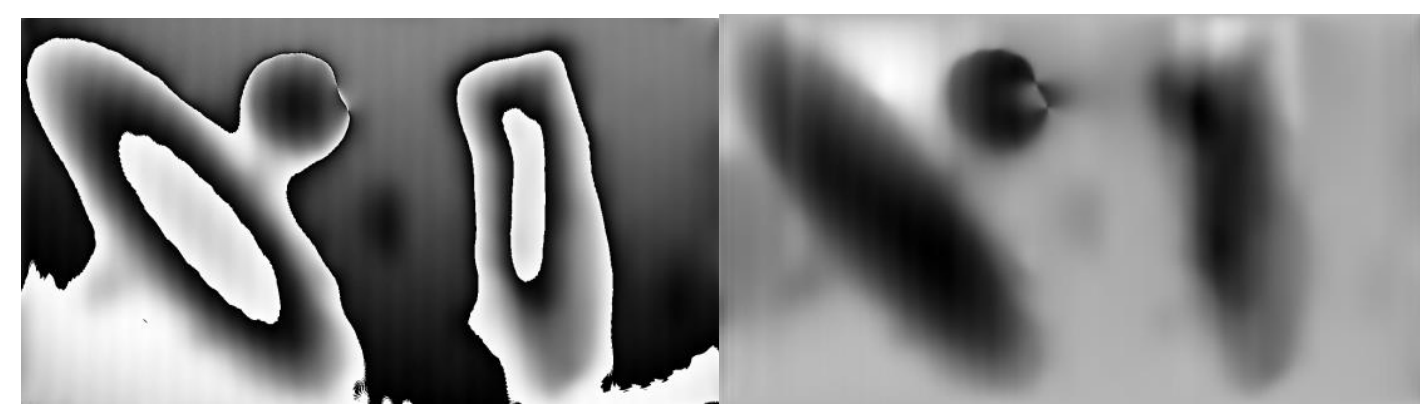

Figura 45: Mapa de fases moduladas (esquerda) e MDT (direita) obtidos com a Técnica Moiré de Projeção com Deslocamento de Fase, para o objeto 1. 


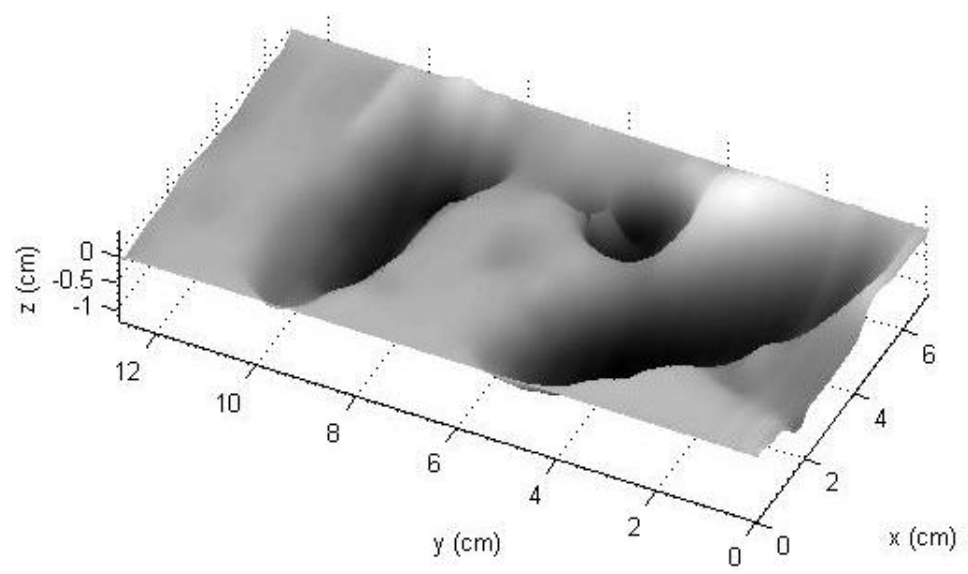

Figura 46: MDT 3D obtido com a Técnica Moiré de Projeção com Deslocamento de Fase, para o objeto 1.

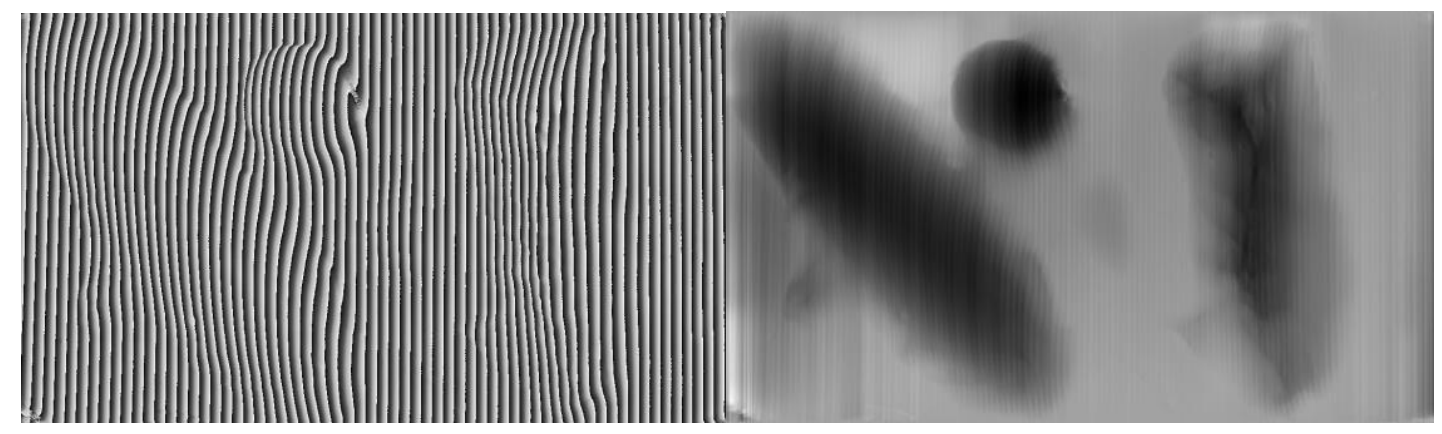

Figura 47: Mapa de fases moduladas (esquerda) e MDT (direita) obtidos com a Técnica de Projeção de Franjas com Deslocamento de Fase, para o objeto 1.

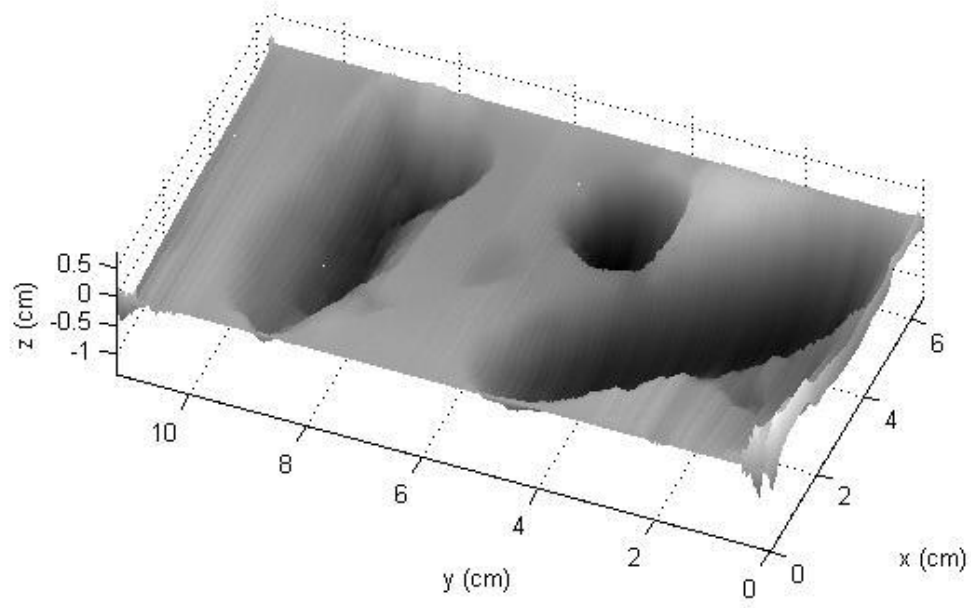

Figura 48: MDT 3D obtido com a Técnica de Projeção de Franjas com Deslocamento de Fase, para o objeto 1. 
Comparando-se os resultados obtidos com as duas técnicas, observa-se que o MDT obtido com a Técnica Moiré de Projeção apresentou artefatos nas regiões (3), (4) e (5) destacadas na Figura 49. As regiões (3) e (5) correspondem a uma região plana do objeto e, nesse MDT, apresentaram uma elevação que não existe no objeto real. Já a região (4) é uma região onde a superfície é mais abrupta, apresentando uma espécie de "degrau", e o artefato deve ter surgido, pois, nesse tipo de superfícies, as franjas não acompanham as variações na topografia e, consequentemente, sofrem deformações abruptas ou descontínuas, que podem ser mais bem resolvidas por uma técnica ou outra. O resultado obtido com a Técnica de Projeção de Franjas também apresentou um artefato nessa região, porém em bem menor intensidade, o que indica que essa técnica é menos sensível a variações abruptas na superfície dos objetos do que a Técnica Moiré de Projeção.

Por outro lado, o MDT obtido com a Técnica de Projeção de Franjas apresentou pequenos artefatos verticais principalmente nas regiões (1) e (2), destacadas na Figura 49. Esses artefatos são devidos principalmente ao processo de desmodulação da fase, pois o algoritmo faz uma transformada de Fourier e um produto escalar com as frequências teóricas encontradas na imagem, o que teoricamente eliminaria os ruídos. Porém, ao encontrar uma descontinuidade ou uma região muito grande com ruídos, fica difícil identificar quais são as frequências teóricas envolvidas, pois, no espectro de Fourier, estas não ficam bem definidas, de modo que a região da imagem em torno da região ruidosa fica mal resolvida e aparecem os artefatos. Esses artefatos estão presentes nos MDTs de ambas as técnicas, mas são mais visíveis na Técnica de Projeção de Franjas, pois o mapa com as fases moduladas apresenta descontinuidades verticais, conforme observado na Figura 47. Esse problema pode ser contornado somente com melhores algoritmos de desmodulação, porém muitos deles, apesar de apresentarem melhores resultados, demandam muito tempo computacional, como o método de confiabilidade guiada [Su e Chen, 2004], por exemplo, ou exigem uma tomada de imagens mais sofisticada, como o método de desmodulação de fase temporal [Huntley e Saldner, 1993], o que seria inconveniente para a aplicação proposta nesse trabalho. 


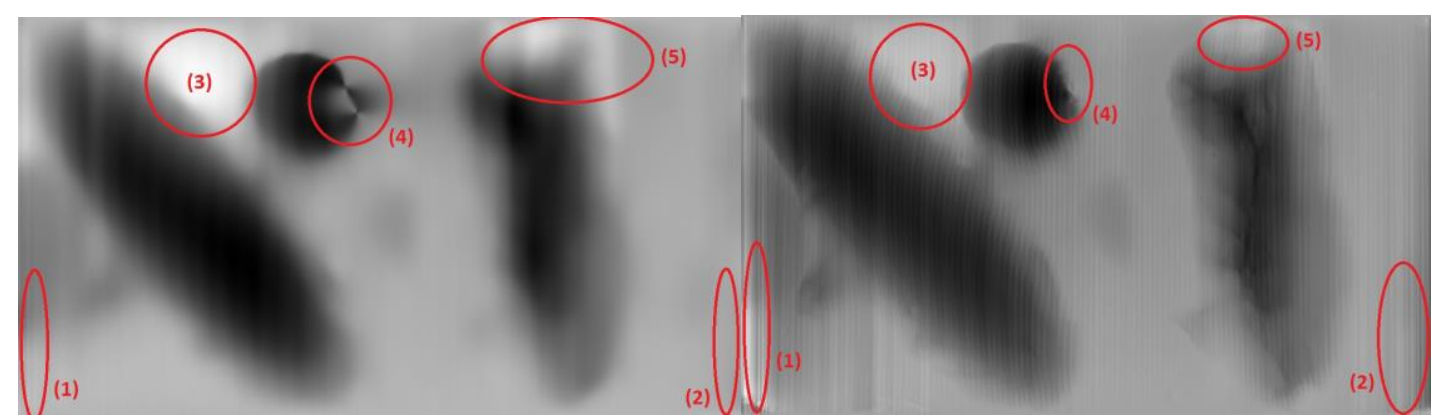

Figura 49: MDTs do objeto 1 obtidos com a Técnica Moiré de Projeção (esquerda) e com a Técnica de Projeção de Franjas (direita), ambas com Deslocamento de Fase.

Apesar dessa última questão, os artefatos presentes no MDT obtido com a Técnica de Projeção de Franjas são menores do que os presentes no MDT da Técnica Moiré de Projeção, e o primeiro visivelmente apresenta mais detalhes da topografia do objeto do que o segundo. Isso provavelmente ocorre porque, na Técnica Moiré de Projeção, as imagens são filtradas antes de serem processadas para a obtenção dos padrões moiré, e esse processo faz com que muitos detalhes das imagens originais possam ser perdidos.

Outra vantagem da Técnica de Projeção de Franjas em relação à de Moiré de Projeção é que, naquela, é necessária a obtenção de somente quatro imagens para o método de Deslocamento de Fase e duas para o de Projeção Ortogonal, enquanto que, na última, são necessárias cinco imagens para o método de Deslocamento de Fase e quatro para o de Projeção Ortogonal. E, uma vez que se pretende fotografar lesões de pacientes em um ambiente hospitalar, é importante que a obtenção das imagens seja feita no menor período de tempo possível, para evitar incômodos e desconfortos ao paciente.

Portanto, a partir dessa comparação entre as duas técnicas, vê-se que a Técnica de Projeção de Franjas se apresentou mais adequada para a medição de dimensões de lesões na pele em pacientes, e essa será técnica desenvolvida ao longo deste trabalho.

\subsection{Comparação entre o Método de Deslocamento de Fase e o Método de Projeção Ortogonal}

Uma vez escolhida a técnica de análise de franjas a ser utilizada, compararam-se dois métodos de reconstrução dos padrões: o Método de Deslocamento de Fase e o Método de Projeção Ortogonal, a diferença básica entre eles é que o primeiro é baseado na análise da diferença de fase do padrão de franjas projetado, já o segundo é baseado na análise de 
Fourier deste padrão. Para fazer essa comparação, utilizou-se a Técnica de Projeção de Franjas e, conforme descrito no capítulo 3, aplicaram-se os dois métodos de reconstrução dos padrões nas imagens obtidas para o objeto 1 .

O mapa de fases moduladas, o MDT e o MDT 3D obtidos com o Método de Deslocamento de Fase são os já mostrados nas Figuras 47 e 48, e os obtidos com o Método de Projeção Ortogonal são mostrados nas Figuras 50 e 51.

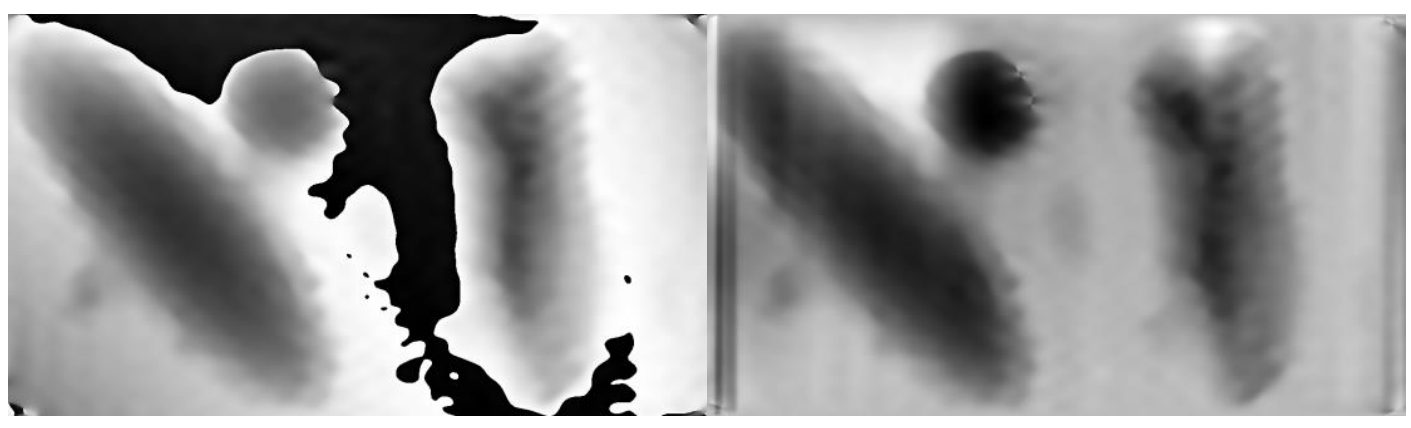

Figura 50: Mapa de fases moduladas (esquerda) e MDT (direita) obtidos com a Técnica de Projeção de Franjas com Projeção Ortogonal, para o objeto 1.

Comparando-se os resultados obtidos com os dois métodos, na Figura 52, observa-se que ambos os MDTs apresentaram os artefatos nas regiões (1) e (2), devido ao processo de desmodulação de fase, conforme discutido na seção anterior.

Por outro lado, o MDT obtido com o Método de Projeção Ortogonal apresentou artefatos nas regiões (3), (4) e (5). Nas regiões (3) e (5) o MDT apresenta uma elevação que não existe na topografia real do objeto, o que possivelmente ocorre, pois a região (4) corresponde a uma região onde a superfície é abrupta, e as franjas não acompanham as variações de topografia, sofrendo descontinuidades, o que causa erros na análise, que influenciam as regiões próximas. O MDT obtido com o Método de Deslocamento de Fase também apresentou artefatos nessas mesmas regiões, porém em bem menor grau, o que indica que este método é menos sensível a esse tipo de variações na topografia do que o Método de Projeção Ortogonal. 


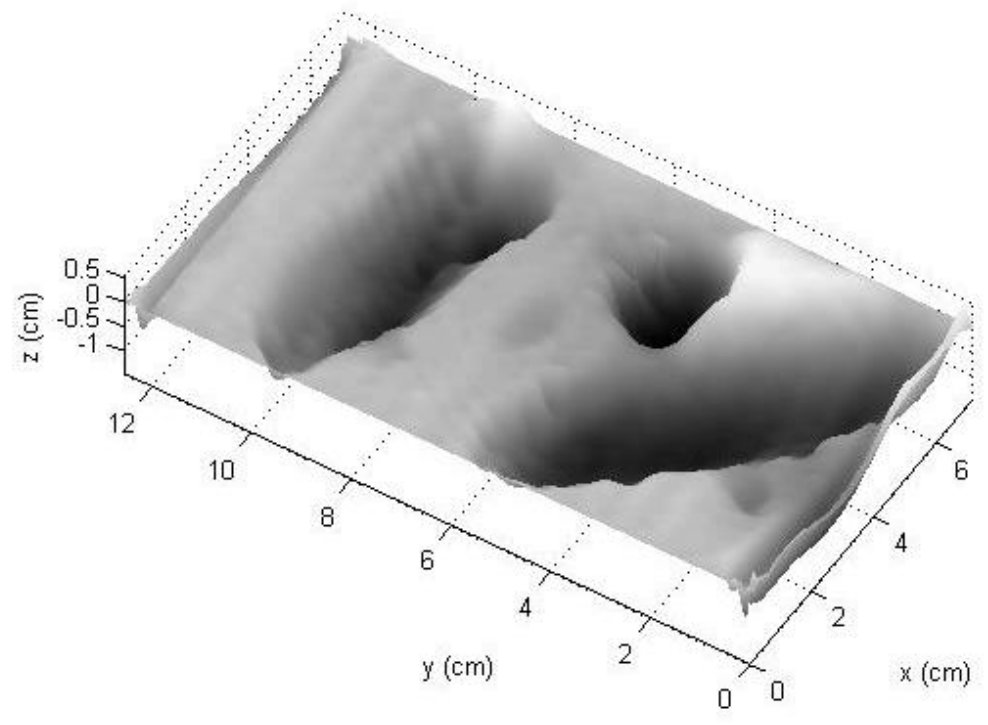

Figura 51: MDT 3D obtido com a Técnica de Projeção de Franjas com Projeção Ortogonal, para o objeto 1.

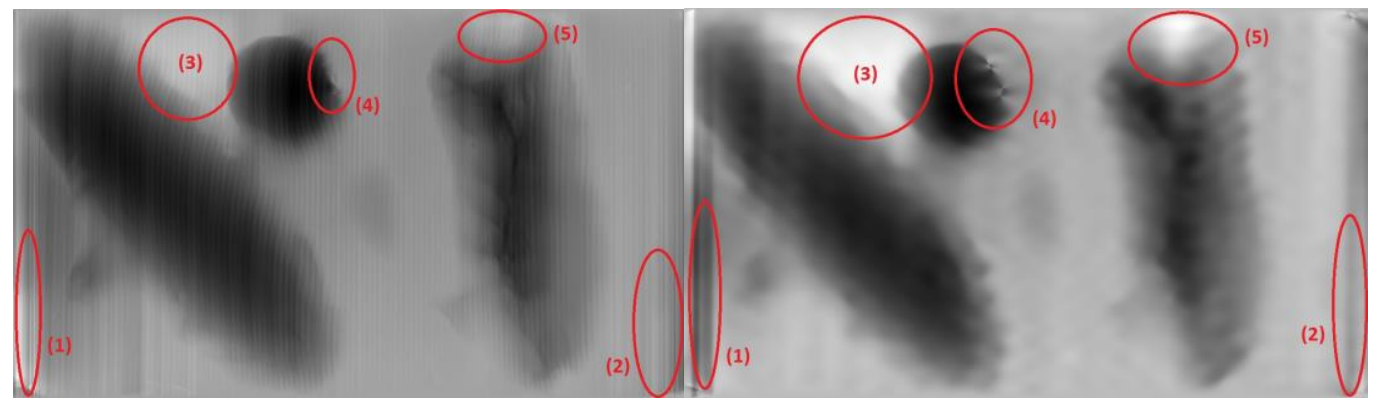

Figura 52: MDTs do objeto 1 obtidos com a Técnica de Projeção de Franjas com Deslocamento de Fase (esquerda) e com Projeção Ortogonal (direita).

Na teoria, o Método de Projeção Ortogonal deveria apresentar melhores resultados, pois se trata de um método bem mais sofisticado, onde toda a informação da topografia do objeto e da modulação das franjas encontra-se no termo de primeira ordem do espectro de Fourier, mostrado na Figura 53. Porém, a dificuldade prática, nesse caso, está no fato de que o termo de primeira ordem aparece muito próximo do termo de ordem zero, que apenas contém informação sobre a iluminação do objeto, não podendo ser isolado de forma efetiva. Essa separação depende da frequência das franjas na imagem projetada no objeto: quanto maior a frequência, maior a separação dos termos. No entanto, devido à resolução do projetor e da câmera utilizados, não era possível aumentar a frequência das franjas, que passariam a sofrer deformações, de forma que, para o arranjo experimental utilizado, o Método de Projeção Ortogonal possui restrições. 

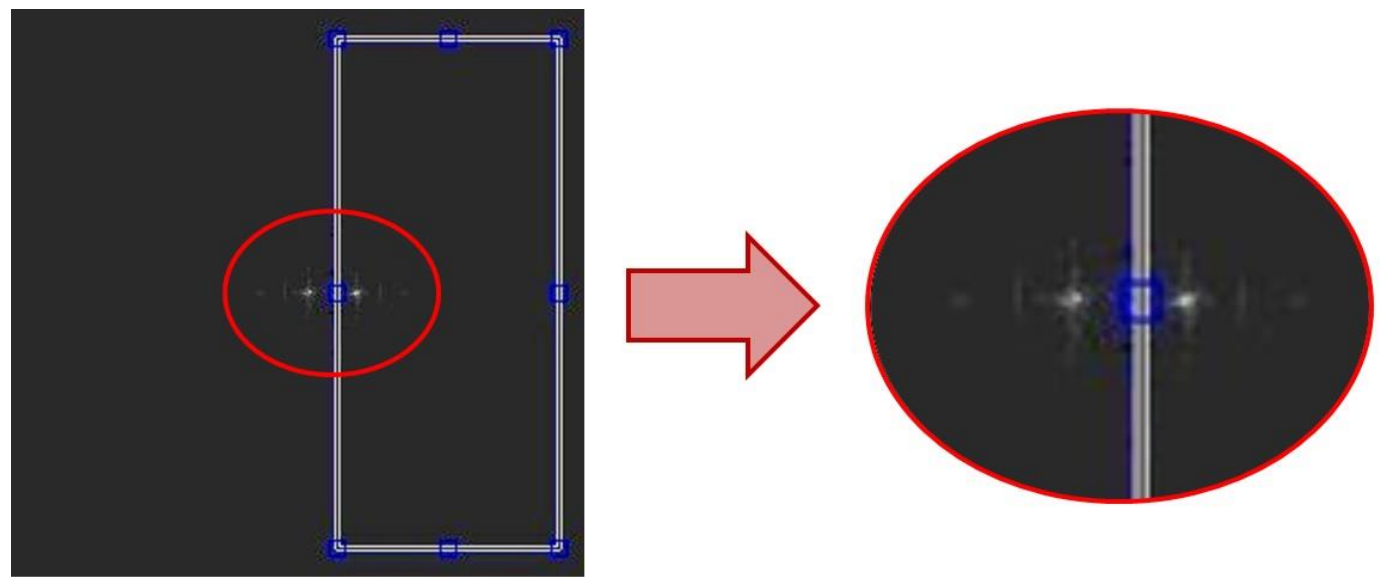

Figura 53: Espectro de Fourier do objeto 1, obtido com a Técnica de Projeção de Franjas com Projeção Ortogonal.

Além disso, no espectro de Fourier, aparecem termos de terceira ordem em diante, que podem ser devidos à topografia do objeto e à modulação das franjas em si, mas também podem ser devidos a defeitos nas franjas, que não são perfeitamente senoidais, ou ruídos na imagem. $E$, por não saber se nesses termos existe informação a respeito da topografia do objeto e da modulação das franjas, optou-se por incluí-los na análise para a reconstrução do padrão. Porém, para ter certeza disso, seria necessário fazer um estudo mais aprofundado e verificar quais termos (ou parte deles) correspondem à topografia do objeto e quais correspondem a ruídos na imagem ou defeitos nas franjas.

Devido a essas restrições e aos artefatos observados nos MDTs obtidos com o Método de Projeção Ortogonal, optou-se por utilizar a Técnica de Projeção de Franjas com Deslocamento de Fase, ao longo deste trabalho. 


\section{RESULTADOS E DISCUSSÃO}

\subsection{Objeto de calibração}

O mapa de fases moduladas do objeto de calibração, o MDT e os perfis obtidos com a Técnica de Projeção de Franjas, comparados com os medidos com o paquímetro, ao longo das linhas traçadas nos principais eixos da região de interesse do objeto, são mostrados na Figura 54 .

(a)

(c)
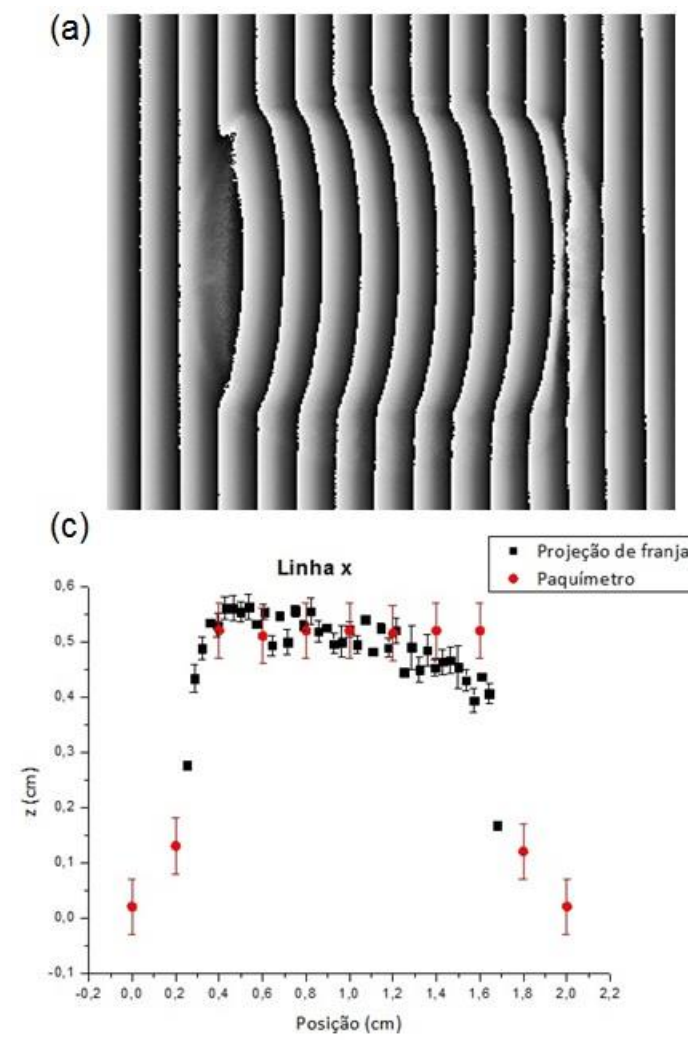

(b)

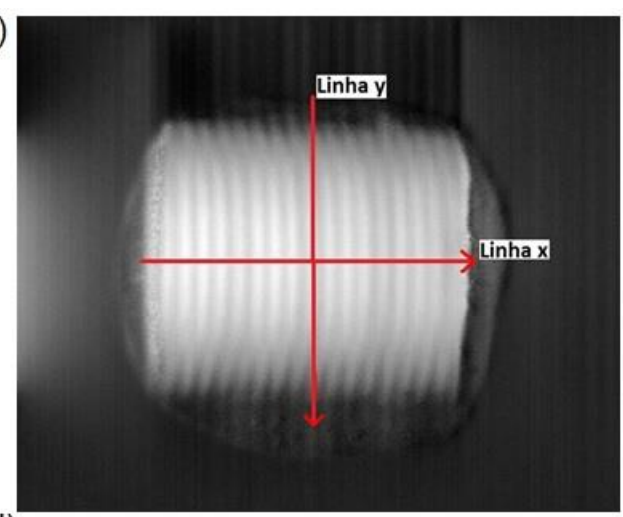

(d)

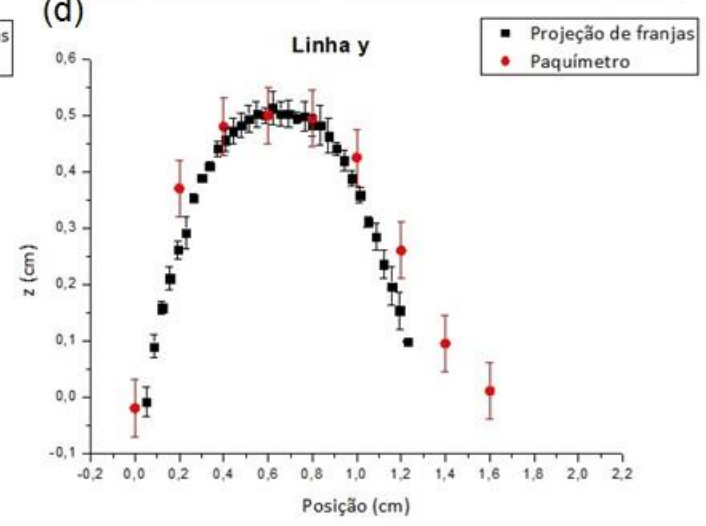

Figura 54: (a) Mapa de fases moduladas do objeto de calibração. (b) MDT. (c) comparação do perfil obtido com a Técnica de Projeção de Franjas e o paquímetro ao longo da linha $x$ e (d) da linha y.

Observa-se que houve artefatos nas laterais do objeto principalmente devido a dois fatores: as bordas abruptas deste ao longo da linha $x$ e a superfície não opaca da cola que mantinha o objeto preso ao plano de referência. Nas bordas abruptas do objeto, as franjas não acompanham as variações de altura na topografia, isso pode ser mais notado no mapa de fases moduladas, onde a modulação das franjas não pôde ser bem resolvida. Já a superfície da cola, não refletia bem as franjas, isso introduziu alguns erros na análise. 
Ainda assim, houve uma boa compatibilidade entre os perfis obtidos e os medidos com o paquímetro ao longo das linhas $x$ e $y$.

O coeficiente de calibração das alturas em cada ponto do objeto foi obtido, como descrito anteriormente, primeiramente através do cálculo utilizando a equação (34) e, em seguida, fazendo-se o ajuste fino para uma maior compatibilidade entre as medidas obtidas com a Técnica de Projeção de Franjas e com o paquímetro. O valor obtido para esse coeficiente foi $\mathrm{C}=0,133 \mathrm{~cm} / \mathrm{rad}$ e esse foi o valor utilizado para calibrar as medidas de todos os objetos tomados nas mesmas condições experimentais do objeto de calibração.

O MDT 3D e o mapa de intensidades obtidos para o objeto de calibração são mostrados na Figura 55. Observa-se que ambos representaram bem a topografia e as características do objeto.
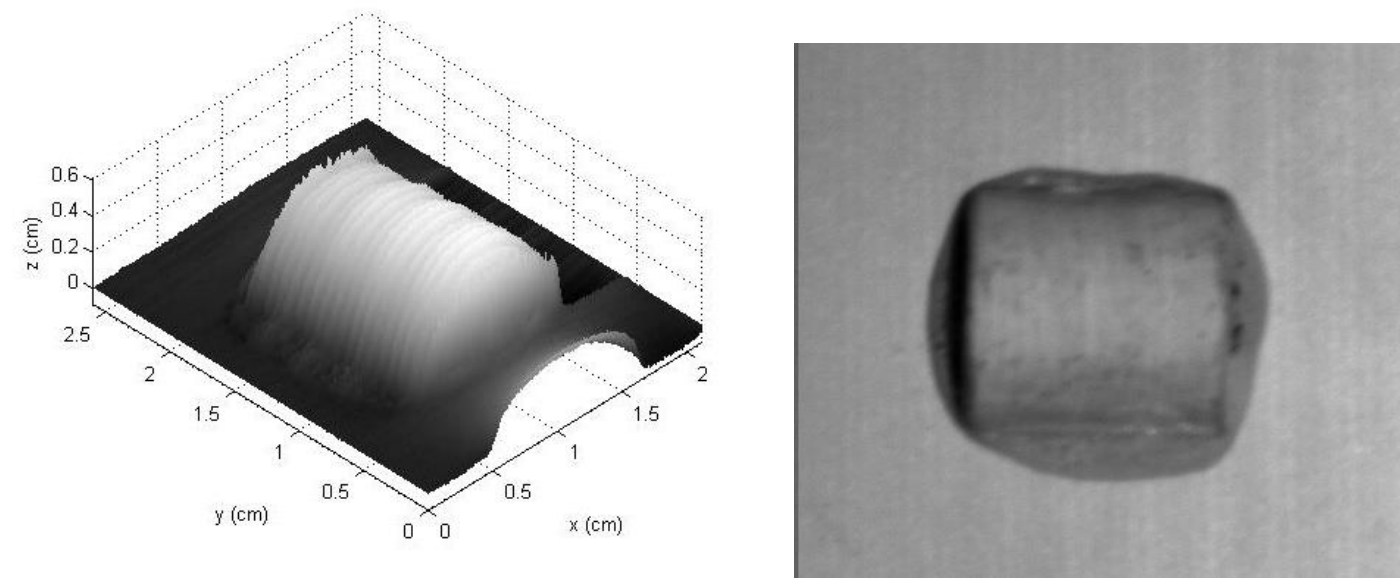

Figura 55: MDT 3D (esquerda) e mapa de intensidades (direita) obtidos para o objeto de calibração.

De um modo geral, as dimensões e a geometria escolhidas para o objeto de calibração foram adequadas, por serem simples e de fácil obtenção pela técnica. Porém alguns fatores deveriam ser mudados, como as bordas abruptas laterais do objeto e a cola escolhida para fixar o objeto no plano de referência. Sugere-se que o objeto de calibração não tenha bordas abruptas ou descontínuas e que seja fixado com uma cola opaca, para refletir as franjas nitidamente, ou com uma fita adesiva dupla face, que não apareça na imagem. 


\subsection{Objetos de topografias de análise mais simples}

Os mapas de fases moduladas, os MDTs e os perfis obtidos com a Técnica de Projeção de Franjas, comparados com os medidos com o paquímetro, para os objetos de topografias de análise simples (objetos 1, 2 e 3) são mostrados nas Figuras 56, 57 e 58.

(a)

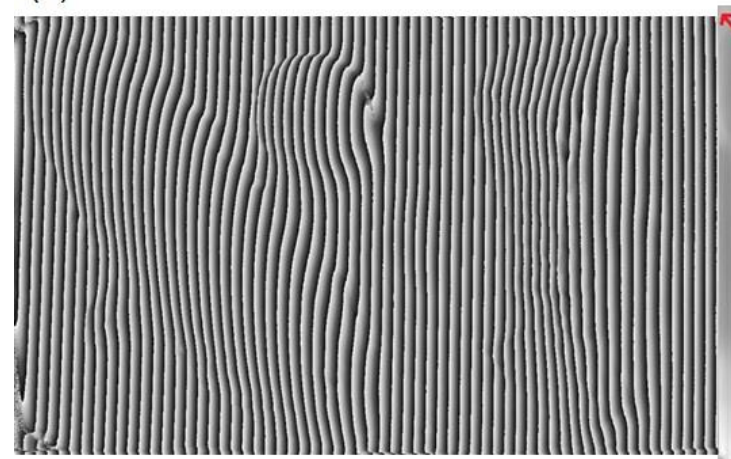

(c)

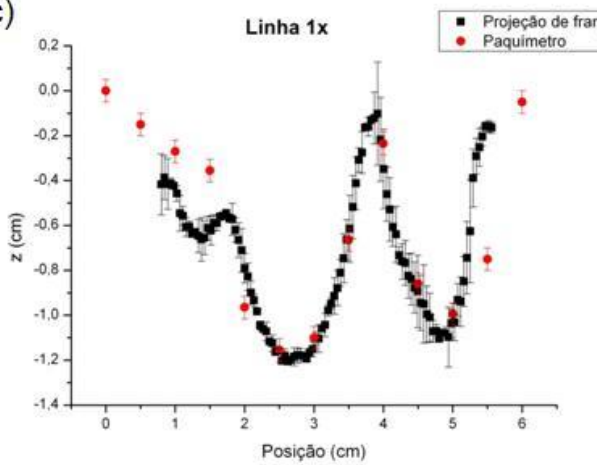

(e)

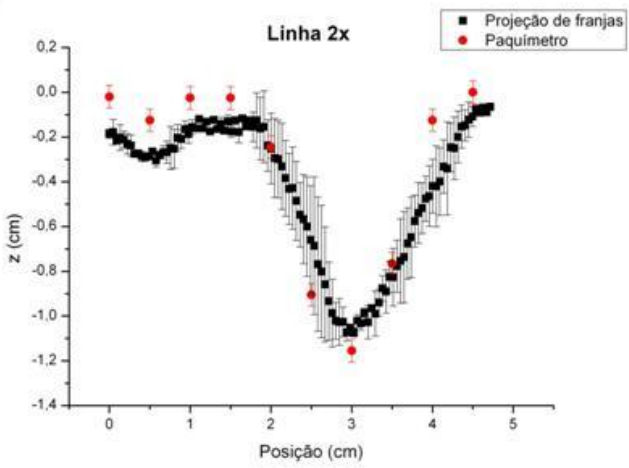

(b)

(d)

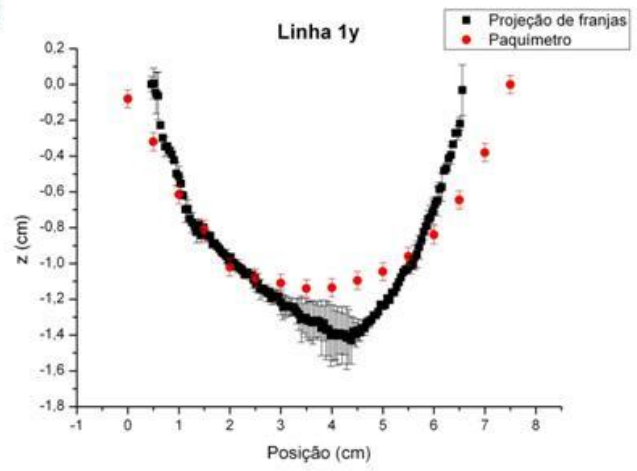

(f)

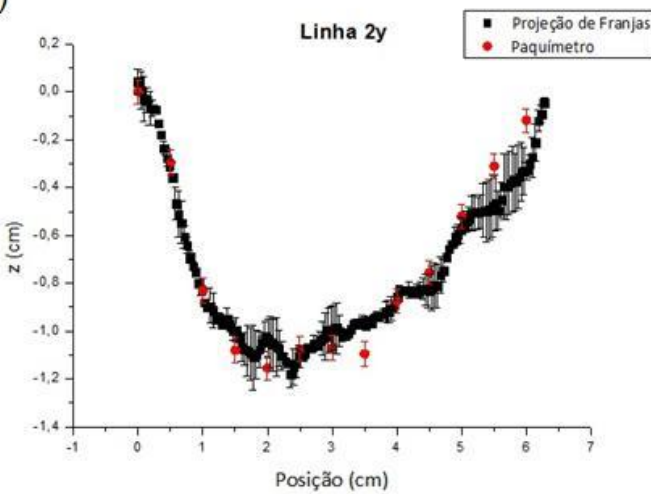

Figura 56: (a) Mapa de fases moduladas do objeto 1. (b) MDT. (c) Comparação do perfil obtido com a Técnica de Projeção de Franjas e o paquímetro ao longo da linha 1x, (d) da linha 1y, (e) da linha $2 x$ e (f) da linha $2 y$. 
(a)

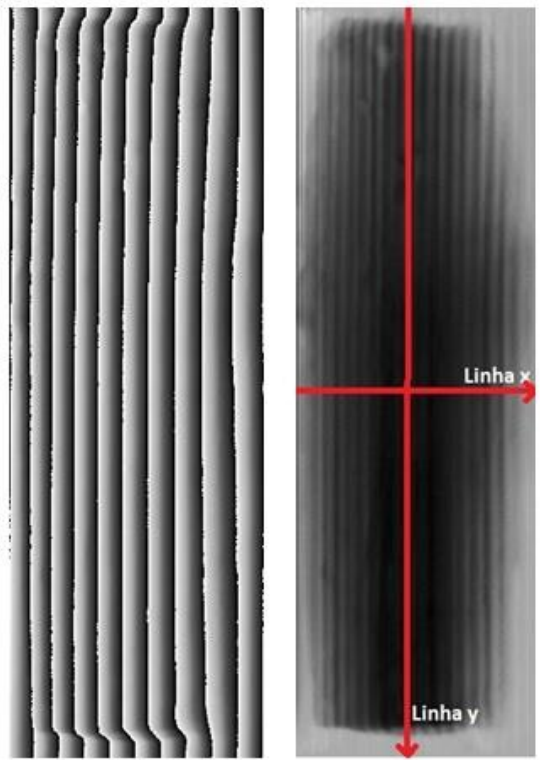

(c)

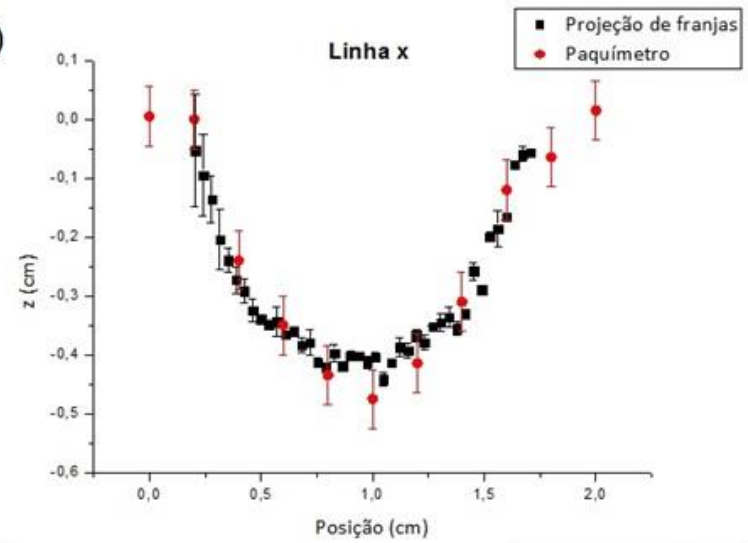

(d)

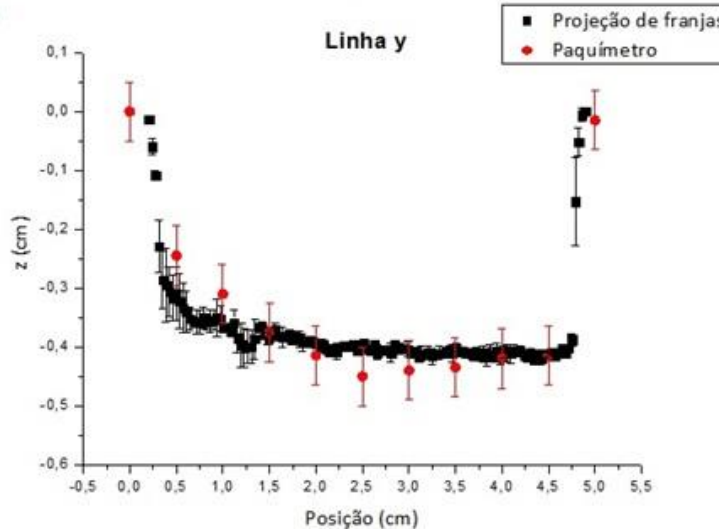

Figura 57: (a) Mapa de fases moduladas do objeto 2. (b) MDT. (c) Comparação do perfil obtido com a Técnica de Projeção de Franjas e o paquímetro ao longo da linha x e (d) da linha y.

(a)

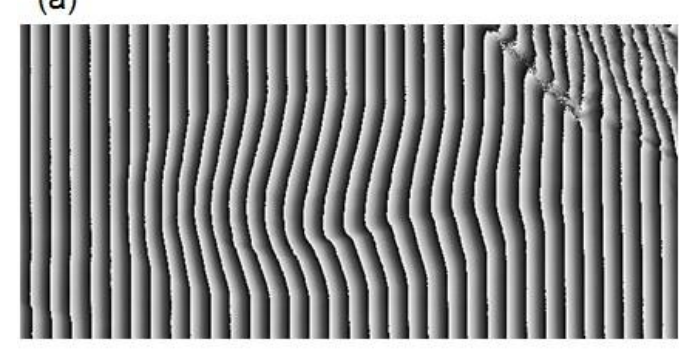

(b)

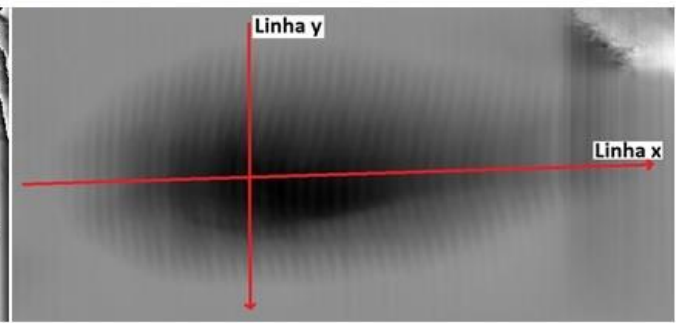

(c)

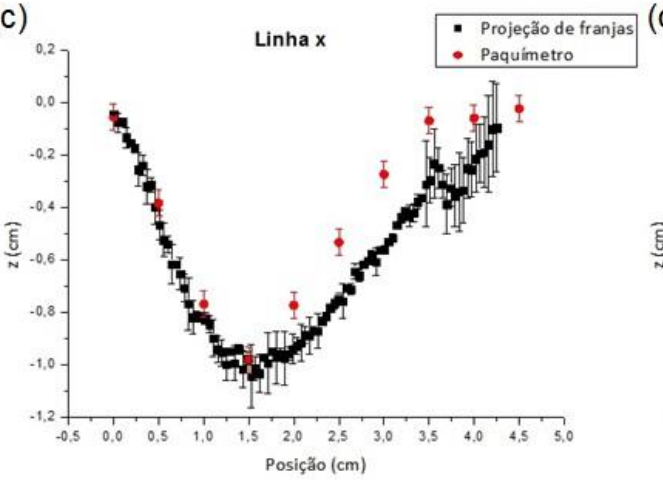

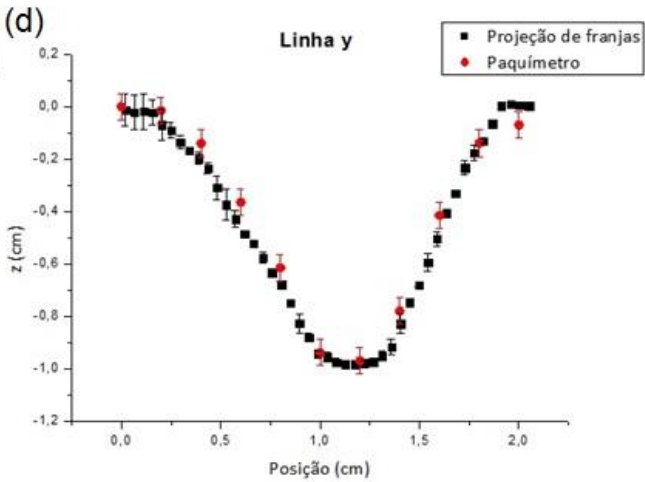

Figura 58: (a) Mapa de fases moduladas do objeto 3. (b) MDT. (c) Comparação do perfil obtido com a Técnica de Projeção de Franjas e o paquímetro ao longo da linha x e (d) da linha y. 
Nos resultados obtidos para o objeto 1, mostrados na Figura 56, como já discutido na seção 4.3, observa-se que o perfil ao longo da linha $2 y$ obtido com a Técnica de Projeção de Franjas, foi compatível com o perfil medido com o paquímetro, já na comparação entre os perfis ao longo da linha 1x, observa-se que a Técnica de Projeção de Franjas foi sensível em medir um pequeno orifício na região no início dessa linha (valores baixos de $\mathrm{x}$ ) que não foi possível medir com o paquímetro e que existe no objeto real, porém o final dessa linha passa por uma região em que a superfície do objeto apresenta uma variação de altura abrupta, difícil de ser acompanhada pela deformação contínua das franjas e que, portanto, ficou subestimada.

Por outro lado, o perfil ao longo da linha $1 y$, apresentou uma abertura menor do que o orifício real e uma profundidade maior em torno da posição y $=4 \mathrm{~cm}$, nota-se também que nas proximidades dessa posição as incertezas foram maiores, o que pode ter ocorrido por ser uma região com mais brilho na imagem, o que introduz erros na forma das franjas, que passam a não ser perfeitamente senoidais, e ruídos na imagem, que prejudicam a análise. Por fim, o perfil ao longo da linha $2 x$ foi compatível com o medido com o paquímetro somente na região do orifício maior, ficando superestimado na região do orifício menor, o que pode ter ocorrido por se tratar de uma região próxima à região do orifício com bordas abruptas ao final da linha $1 x$. Os erros dessa região podem ter sido propagados através do processo de desmodulação da fase, para a região deste pequeno orifício ao início da linha $2 x$, uma vez que nela é mais difícil identificar as frequências das franjas devido aos ruídos.

Já para o objeto 2, na Figura 57, observa-se no mapa de fases moduladas que as franjas foram bem resolvidas pela técnica e que houve compatibilidade entre os dois perfis ao longo das duas linhas. Apenas houve alguns artefatos verticais no MDT devido ao processo de desmodulação da fase, pois a geometria de objeto é retangular com o eixo maior na mesma direção das franjas, prejudicando a resolução da técnica e a identificação das frequências das franjas ao longo dessa direção. Por isso, talvez tivesse sido melhor posicionar o objeto com o eixo maior perpendicular à direção das franjas.

Nos resultados obtidos para o objeto 3, mostrados na Figura 58, nota-se que os perfis ao longo da linha y foram compatíveis entre si, porém, ao final do perfil obtido com a Técnica de Projeção de Franjas ao longo da linha x surgiu um artefato, em forma de uma descontinuidade na topografia, que não existe no objeto real, e que também pode ser observado no MDT. Esse artefato surgiu devido a um defeito do objeto em forma de 
fenda, observado na região superior direita do mapa de fases moduladas e do MDT. Nessa região, as franjas não foram bem refletidas e resolvidas pela técnica, por ser uma região cuja topografia possuía variações abruptas e cuja superfície não refletia bem as franjas. Como o algoritmo de desmodulação da fase depende da identificação da frequência das franjas e ruídos muito grandes prejudicam esse processo, os erros devido à presença desse defeito no objeto se propagaram para as regiões próximas a ele.

Os MDTs 3D e os mapas de intensidades obtidos para esses mesmos objetos são mostrados nas Figuras 59, 60 e 61. Observa-se que, de modo geral, para todos os objetos de análise mais simples, ambos os resultados representaram bem a topografia e as características do objeto, com exceção do MDT 3D do objeto 3, que apresentou o artefato comentado anteriormente. Todos os MDTs 3D apresentam orientação invertida em relação ao mapa de intensidades e aos MDTs 2D, pois a técnica não consegue distinguir entre concavidade positiva ou negativa, de forma que foi necessária a inversão dos valores de altura ou a inversão da ordem de análise das imagens, de acordo com o conhecimento prévio da topografia dos objetos. É importante ressaltar que isso não é um problema para a aplicação pretendida neste trabalho, uma vez que a concavidade das lesões pode ser conhecida previamente com a observação destas.
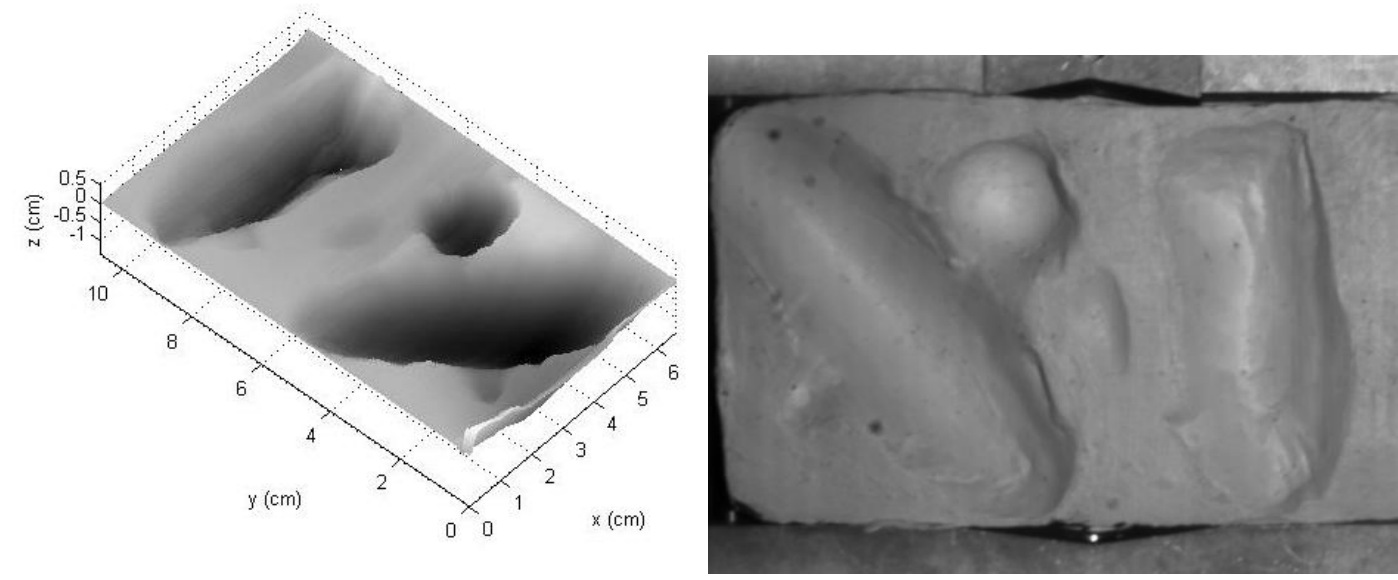

Figura 59: MDT 3D (esquerda) e mapa de intensidades (direita) obtidos para o objeto 1. 

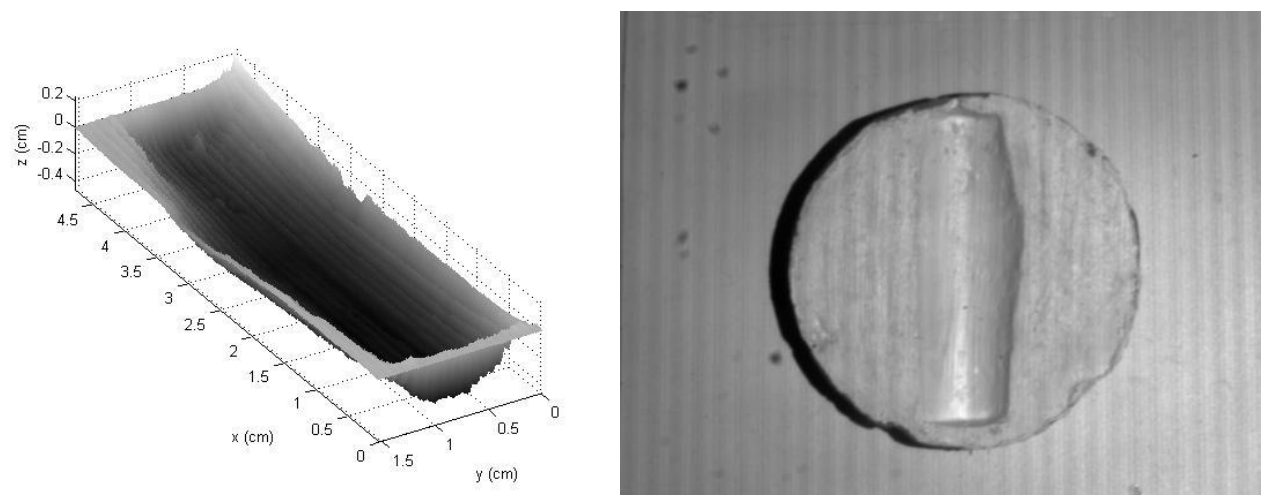

Figura 60: MDT 3D (esquerda) e mapa de intensidades (direita) obtidos para o objeto 2.
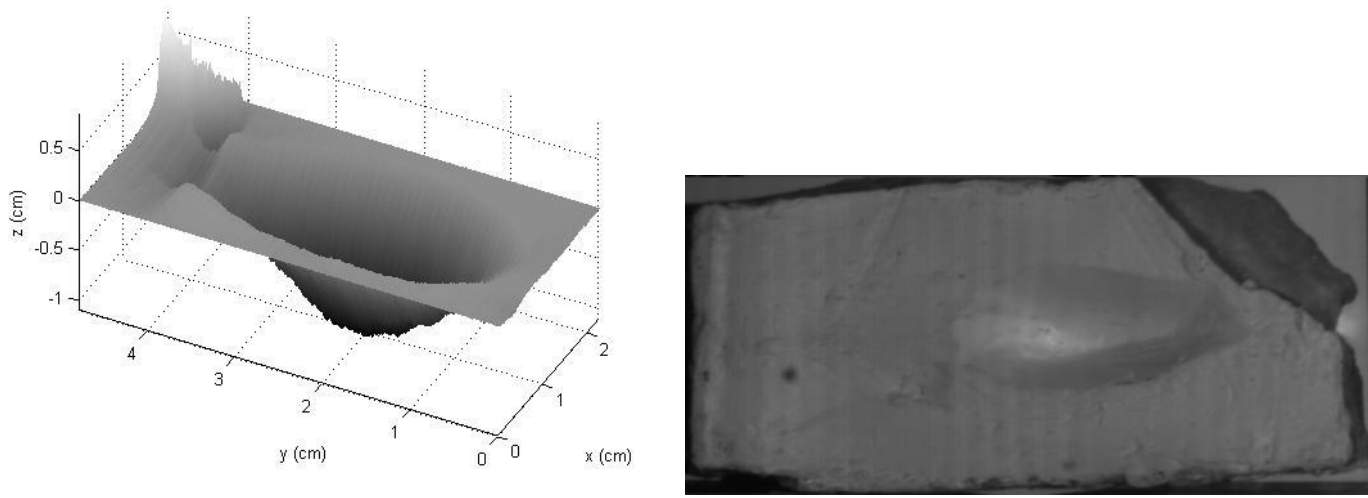

Figura 61: MDT 3D (esquerda) e mapa de intensidades (direita) obtidos para o objeto 3.

De um modo geral, os MDTs e os perfis obtidos para os objetos de topografias de análise simples foram satisfatórios e compatíveis com os reais, representando, inclusive, pequenos orifícios existentes no objeto, que não puderam ser medidos com precisão com o paquímetro.

Porém observou-se que defeitos na topografia dos objetos, superfícies abruptas, onde as franjas não acompanharam continuamente as variações de altura na topografia, e regiões onde há brilho na imagem podem introduzir erros na análise, e que podem, inclusive, gerar artefatos e serem propagados para regiões próximas a essas.

Na Tabela 4, são mostradas as máximas discrepâncias entre as medidas dos perfis obtidas com a Técnica de Projeção de Franjas e com o paquímetro para os objetos de topografia de análise simples. Nota-se que as máximas discrepâncias foram todas inferiores a 0,30 cm. 
Tabela 4: Máximas discrepâncias entre as medidas dos perfis obtidas com a Técnica de Projeção de Franjas e com o paquímetro para os objetos de topografia de análise simples.

\begin{tabular}{|c|cc|}
\multicolumn{1}{c|}{} & \multicolumn{1}{c|}{ Linha } & $\begin{array}{c}\text { Máxima discrepância } \\
\text { (cm) }\end{array}$ \\
\hline \multirow{3}{*}{ Objeto 1 } & $1 \mathrm{x}$ & 0,29 \\
\cline { 2 - 3 } & $1 \mathrm{y}$ & 0,21 \\
\cline { 2 - 3 } & $2 \mathrm{x}$ & 0,28 \\
\cline { 2 - 3 } & $2 \mathrm{y}$ & 0,11 \\
\hline \multirow{4}{*}{ Objeto 2 } & $\mathrm{x}$ & 0,08 \\
\cline { 2 - 3 } & $\mathrm{y}$ & 0,06 \\
\hline Objeto 3 & $\mathrm{x}$ & 0,23 \\
\cline { 2 - 3 } & $\mathrm{y}$ & 0,10 \\
\hline
\end{tabular}

\subsection{Objetos de topografia de análise mais complexa}

Os mapas de fases moduladas, os MDTs e os perfis obtidos com a Técnica de Projeção de Franjas, comparados com os medidos com o paquímetro, ao longo das linhas traçadas nos principais eixos da região de interesse dos objetos de topografia de análise mais complexa (objetos de 4 a 9), são mostrados nas Figuras 62 a 67.

Nos resultados obtidos para o objeto 4, mostrados na Figura 62, observa-se que houve artefatos no MDT, nas laterais do objeto. No lado esquerdo do objeto, isso ocorre, pois se trata de uma região de sombra, que introduz erros na análise e onde as franjas não são bem resolvidas, já no lado direito, existe uma descontinuidade das franjas, que também pode ser observada no mapa de fases moduladas, pelo fato do objeto possuir uma curvatura muito grande em relação ao ângulo de observação, de forma que não se vê bem essa região da superfície do objeto e nem as franjas projetadas nela. Esse possivelmente também é o motivo pelo qual houve uma pequena deformação do objeto ao longo do eixo y, observada pela incompatibilidade entre os perfis ao longo desse eixo. Já, ao longo da linha $x$, os perfis foram compatíveis entre si, apesar dos artefatos mencionados, que influenciaram mais o plano de referência do que o objeto em si.

Já nos resultados obtidos para o objeto 5 , mostrados na Figura 63, nota-se pelo mapa de fases moduladas e pelo MDT que, na região do lado direito do objeto, as franjas não puderam ser bem resolvidas, produzindo uma elevação no plano de referência desse lado. Além disso, a inclinação das paredes do orifício desse objeto é muito íngreme e, mesmo que não se trate de uma descontinuidade na topografia, as franjas não acompanharam as 
mudanças na topografia de forma contínua. Isso pode ter contribuído para o surgimento do artefato no plano de referência no lado esquerdo do objeto, que ficou abaixo do real, e para o fato de que os perfis obtidos com a Técnica de Projeção de Franjas apresentaram uma profundidade para o objeto maior do que a medida com o paquímetro, mesmo apresentando um formato compatível com o real.

Como os objetos 5 e 6 são similares, diferenciando-se apenas pelo tipo de concavidade, no lado esquerdo do objeto 6 , as franjas também não puderam ser bem resolvidas. Isso produziu uma elevação no plano de referência desse lado e no próprio lado esquerdo desse objeto, conforme observado no início do perfil ao longo da linha x (valores baixos de x) nos resultados para esse objeto, mostrados na Figura 64. Isso ocorreu porque essa é uma região de sombra no objeto, onde as franjas não podem ser vistas na imagem, o que, consequentemente, introduz erros na análise. O MDT desse objeto também apresentou pequenos artefatos devido a sua superfície íngreme nas laterais, conforme pode ser visto também no início do perfil ao longo da linha y. Porém foram artefatos menores comparados com os apresentados pela reconstrução do objeto 5, pois, diferentemente dos perfis obtidos para o objeto 5 , os desse objeto não ficaram super ou subestimados em relação aos perfis medidos com o paquímetro, apresentando apenas os artefatos citados e incertezas maiores nas bordas.

Já na Figura 65, nos resultados obtidos para o objeto 7 , observa-se que, o MDT apresentou artefatos nas regiões onde há sombra no objeto, na parte externa do lado esquerdo do objeto e na parte interna do lado direito, nas extremidades da linha $x$. Nessas regiões, as franjas não puderam ser bem resolvidas, conforme pode ser visto no mapa de fases moduladas, e, como o algoritmo de desmodulação da fase depende disso para identificar a frequência das franjas, esses erros foram propagados para as regiões próximas a essa, gerando artefatos principalmente no plano de referência, como elevações e ondulações, e a subestimação da altura das bordas, conforme observado no MDT e no início do perfil ao longo da linha x. Além disso, o orifício do objeto era muito profundo e tinha bordas abruptas, onde as franjas não acompanham as variações da topografia, sofrendo descontinuidades, conforme se nota no mapa de fases moduladas. Isso causou artefatos e incertezas maiores nas bordas do objeto, conforme visto nos perfis ao longo das linhas $x$ e $y$. 
Nos resultados obtidos para o objeto 8, mostrados na Figura 66, observa-se que houve um artefato muito grande ao longo do eixo horizontal, conforme observado pela elevação seguida de um vale no plano de referência no lado esquerdo do objeto. Esse artefato foi causado pela região de sombra nesse mesmo lado do objeto, combinado com o fato das bordas deste serem abruptas. Isso causou uma descontinuidade nas franjas, juntamente com ruídos, conforme se nota no mapa de fases moduladas. O fato das bordas serem abruptas e as franjas não acompanharem as variações de altura na topografia do objeto, implicou na subestimação das alturas obtidas com a Técnica de Projeção de Franjas, conforme observado nos perfis ao longo das linhas $x$ e $y$. Isso ocorre, pois, por se tratar de uma descontinuidade nas franjas, o processo de desmodulação da fase não consegue distinguir em que intervalo exato de $2 \pi$ as fases se encontram, de forma que a fase resultante pode estar em um intervalo distante de um múltiplo inteiro de $2 \pi$, do intervalo real. Todos esses fatores contribuíram também para que as incertezas nas bordas do objeto sejam grandes, conforme se nota ao longo dos perfis das linhas $\mathrm{x}$ e $\mathrm{y}$.

Observa-se que nos resultados obtidos para o objeto 9, mostrados na Figura 67, assim como nos obtidos para o objeto 8 , houve um artefato muito grande, que fica evidente no MDT, pela presença de um vale no plano de referência seguida de uma região de ruído e uma elevação no lado esquerdo do objeto. Esses artefatos também foram resultado da sombra nesse mesmo lado do objeto e das bordas abruptas deste, que causaram ruídos na reconstrução e descontinuidades nas franjas, conforme se nota no mapa de fases moduladas. Isso prejudicou o processo de desmodulação da fase, fazendo com que novamente não se pudesse distinguir o intervalo exato de $2 \pi$ em que as fases se encontram, conforme explicado anteriormente, e influenciou na subestimação dos valores de altura nos perfis ao longo das linhas $x$ e y e no aumento das incertezas nas regiões próximas às bordas do objeto. 
(a)

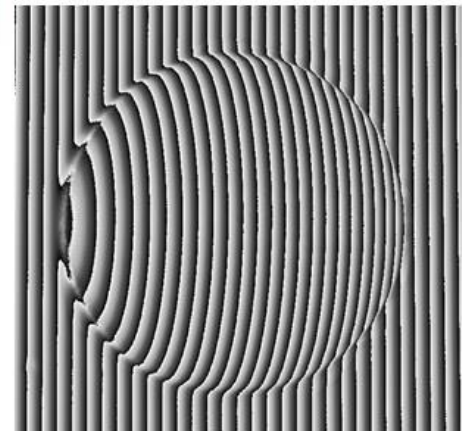

(c)

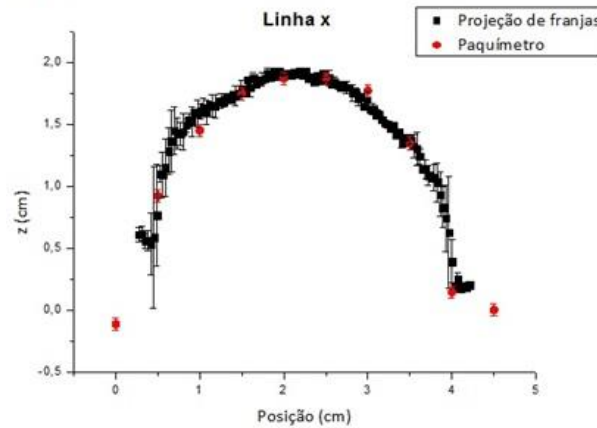

(b)

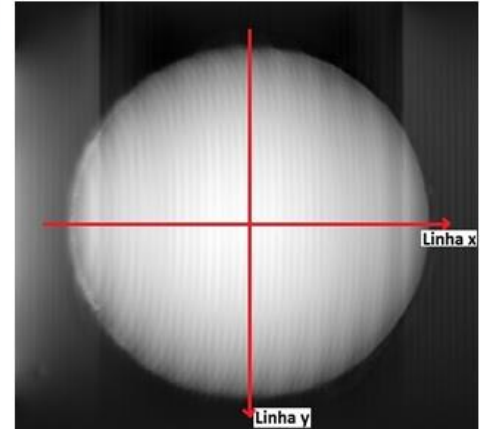

(d)

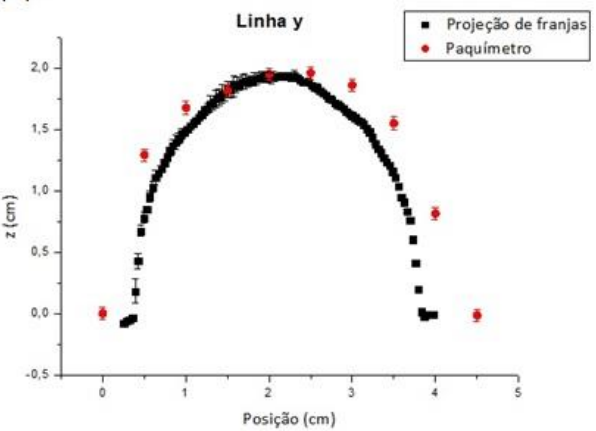

Figura 62: (a) Mapa de fases moduladas do objeto 4. (b) MDT. (c) comparação do perfil obtido com a Técnica de Projeção de Franjas e o paquímetro ao longo da linha x e (d) da linha y.

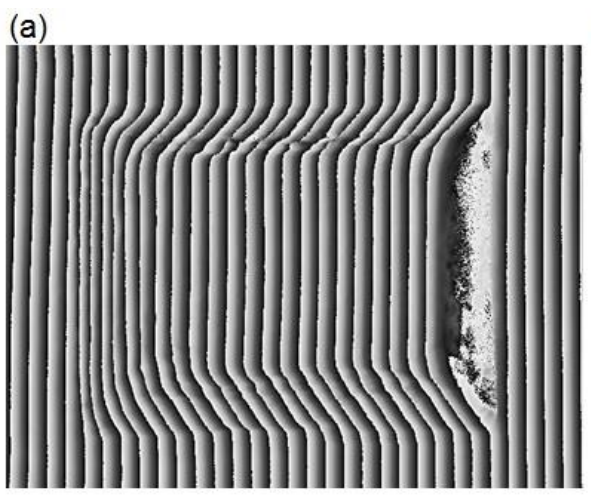

(c)

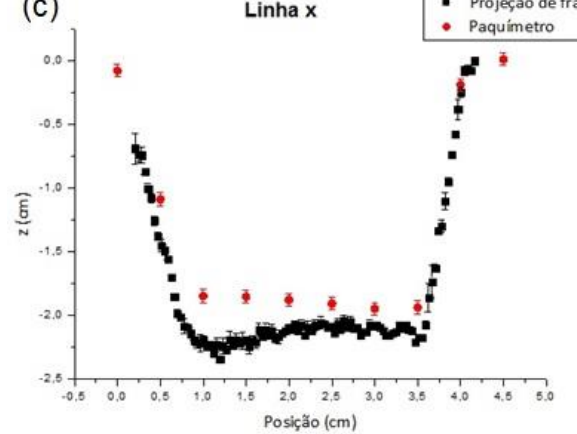

(b)

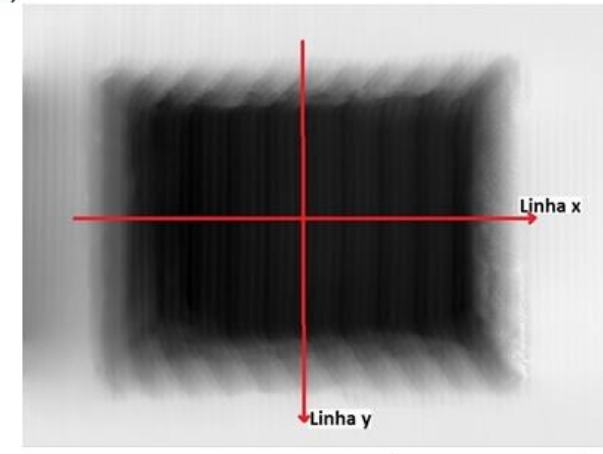

(d)

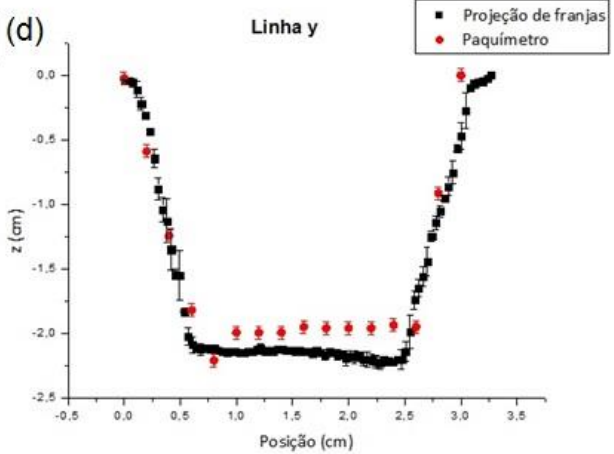

Figura 63: (a) Mapa de fases moduladas do objeto 5. (b) MDT. (c) comparação do perfil obtido com a Técnica de Projeção de Franjas e o paquímetro ao longo da linha x e (d) da linha y. 
(a)

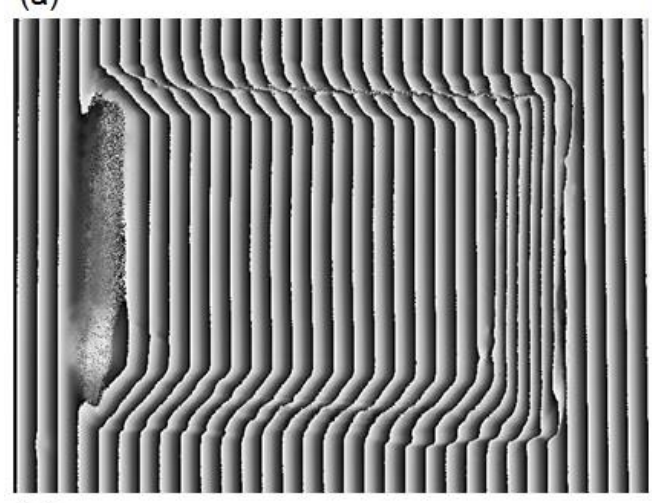

(c)

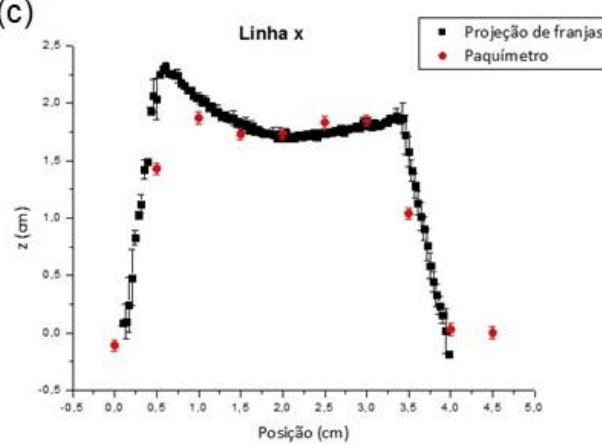

(b)
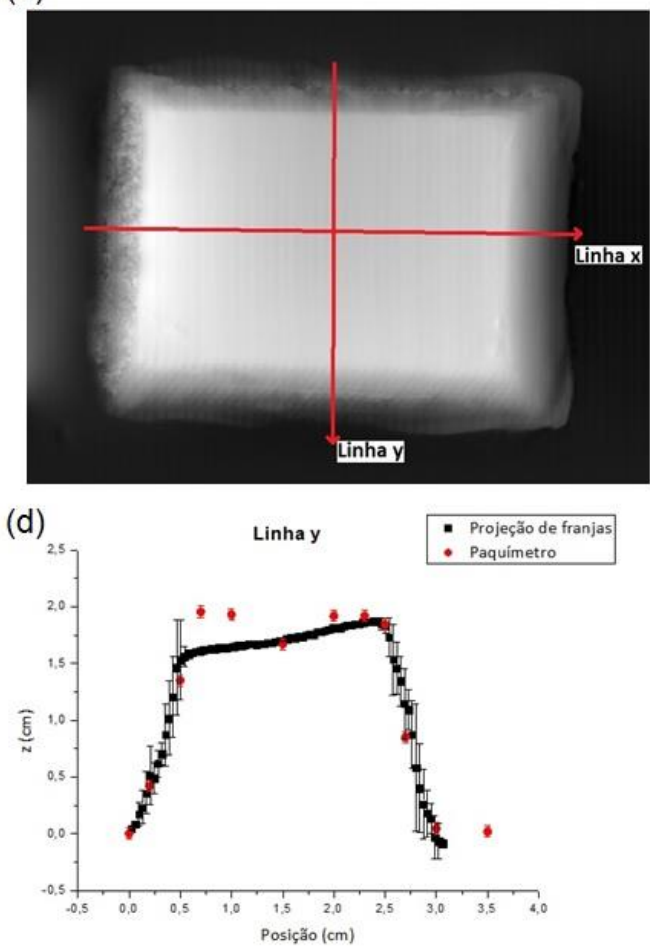

Figura 64: (a) Mapa de fases moduladas do objeto 6. (b) MDT. (c) comparação do perfil obtido com a Técnica de Projeção de Franjas e o paquímetro ao longo da linha x e (d) da linha y.

(a)

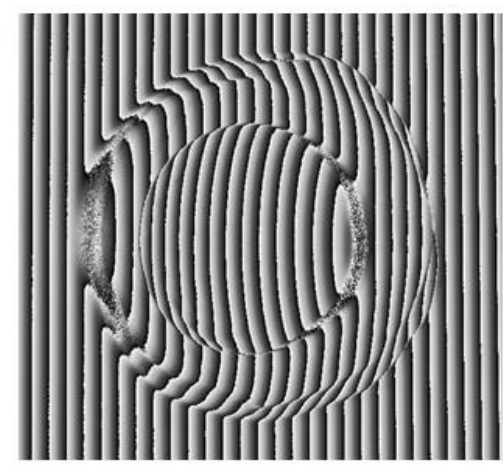

(c)

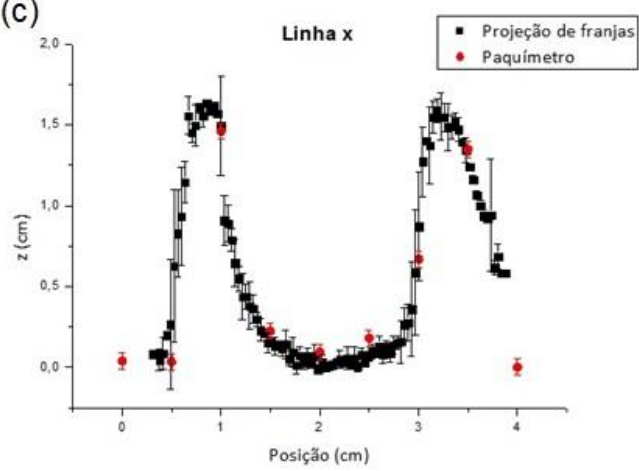

(b)

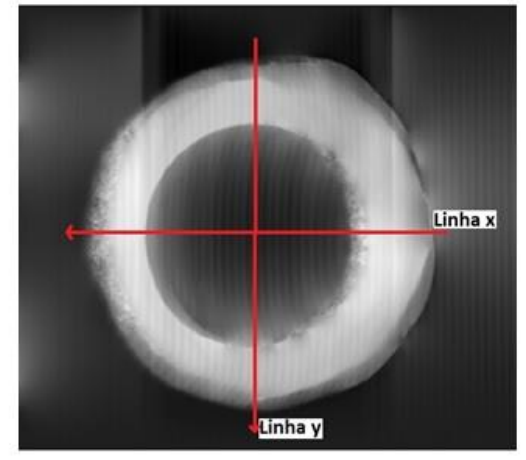

(d)

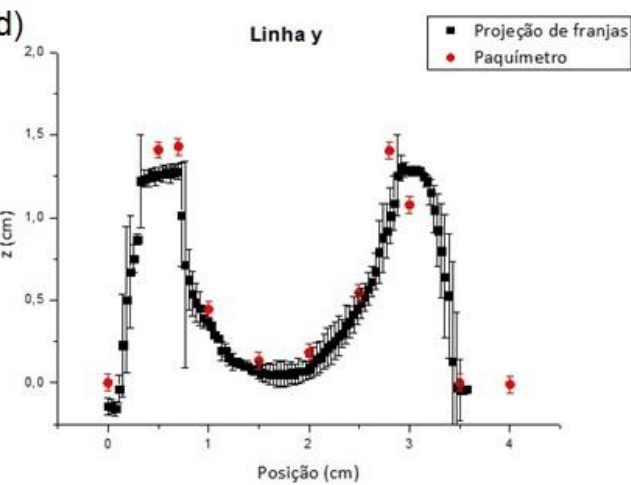

Figura 65: (a) Mapa de fases moduladas do objeto 7. (b) MDT. (c) comparação do perfil obtido com a Técnica de Projeção de Franjas e o paquímetro ao longo da linha x e (d) da linha y. 
(a)

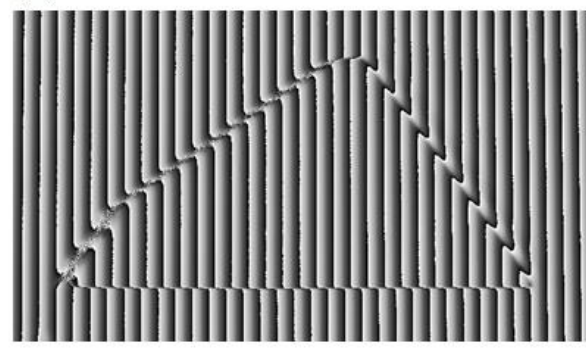

(c)

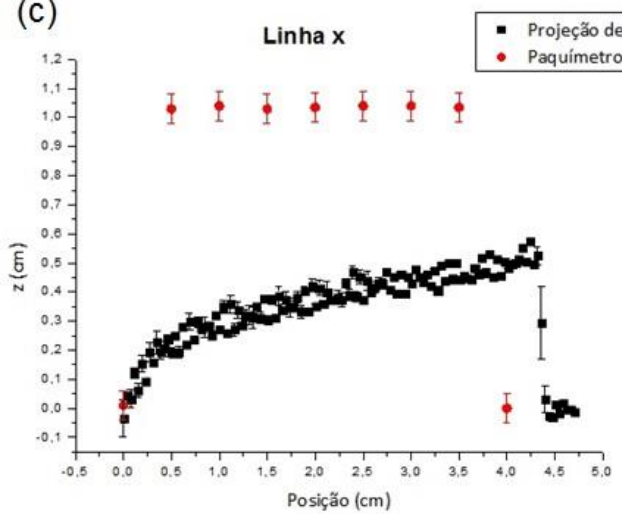

(b)
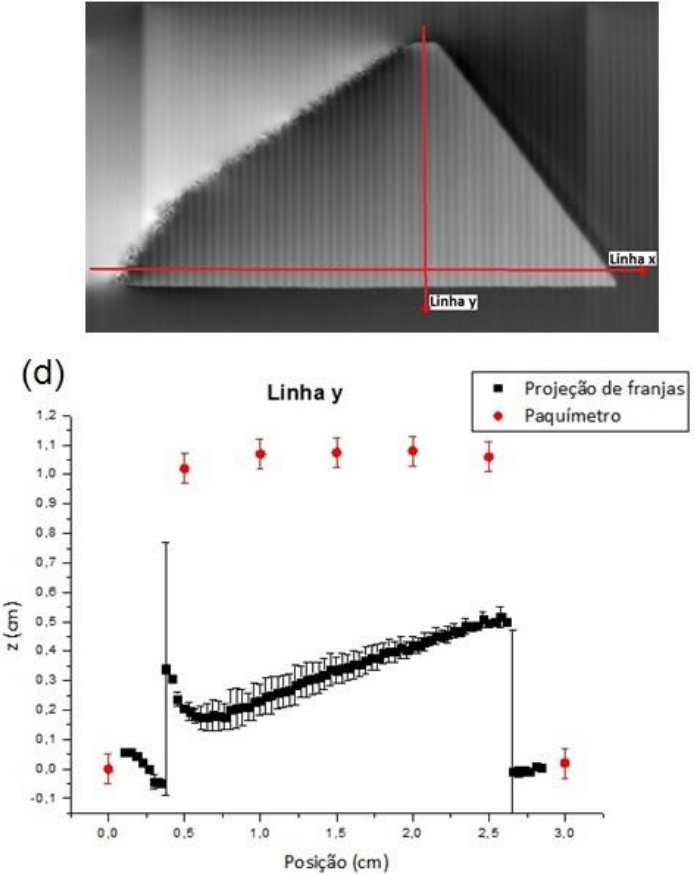

Figura 66: (a) Mapa de fases moduladas do objeto 8. (b) MDT. (c) comparação do perfil obtido com a Técnica de Projeção de Franjas e o paquímetro ao longo da linha x e (d) da linha y.

(a)

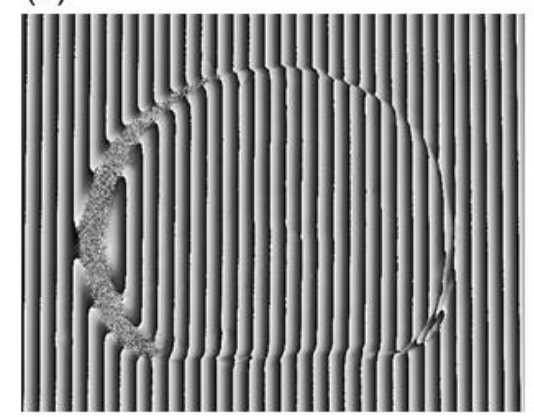

(c)

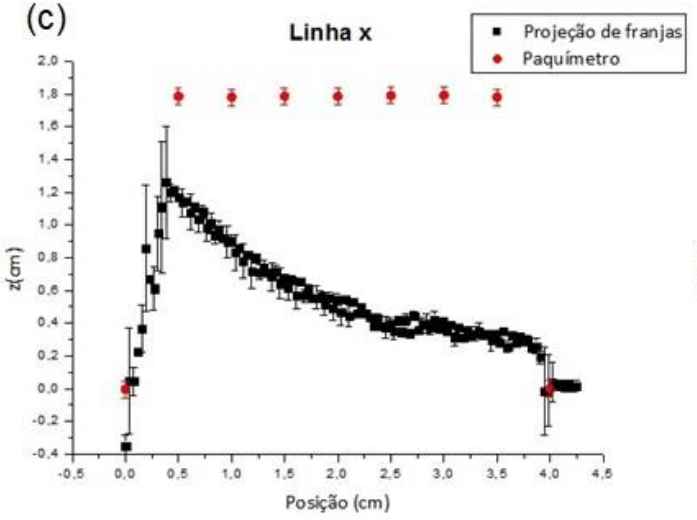

(b)

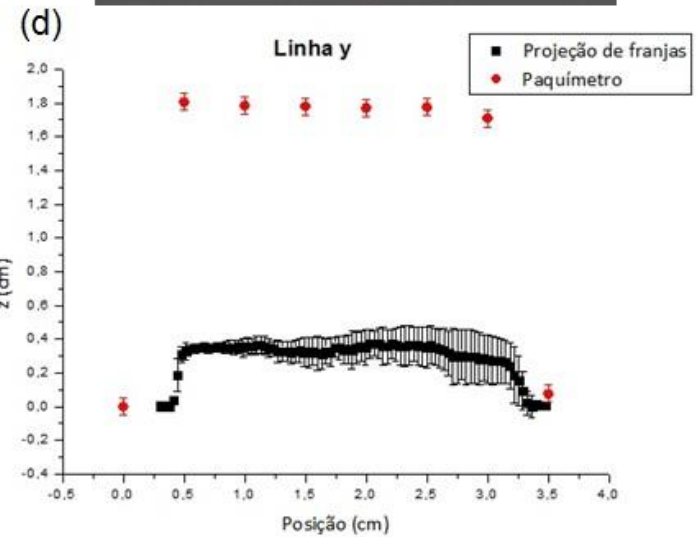

Figura 67: (a) Mapa de fases moduladas do objeto 9. (b) MDT. (c) comparação do perfil obtido com a Técnica de Projeção de Franjas e o paquímetro ao longo da linha x e (d) da linha y. 
Os MDTs 3D e os mapas de intensidades obtidos para os objetos de topografia de análise mais complexa são mostrados nas Figuras 68 a 73, novamente os MDTs 3D apresentam orientação invertida em relação ao mapa de intensidades e aos MDTs 2D, pelo fato da técnica não conseguir distinguir entre concavidade positiva ou negativa, de forma que é necessária a inversão dos valores de altura de acordo com o conhecimento prévio da topografia dos objetos.

Nos MDTs 3D de cada objeto, ficam evidentes os artefatos e deformações citados anteriormente, sendo que o MDT 3D do objeto 4, de um modo geral, representou bem a topografia do objeto, apesar dos artefatos, o que não ocorreu para os outros objetos. Todos os mapas de intensidades dessa categoria representaram bem as características dos objetos, e neles se pode observar com mais detalhes as regiões de sombra, as bordas e as variações abruptas nas topografias de cada objeto, além das inclinações e topografias íngremes dos que possuem essas características.
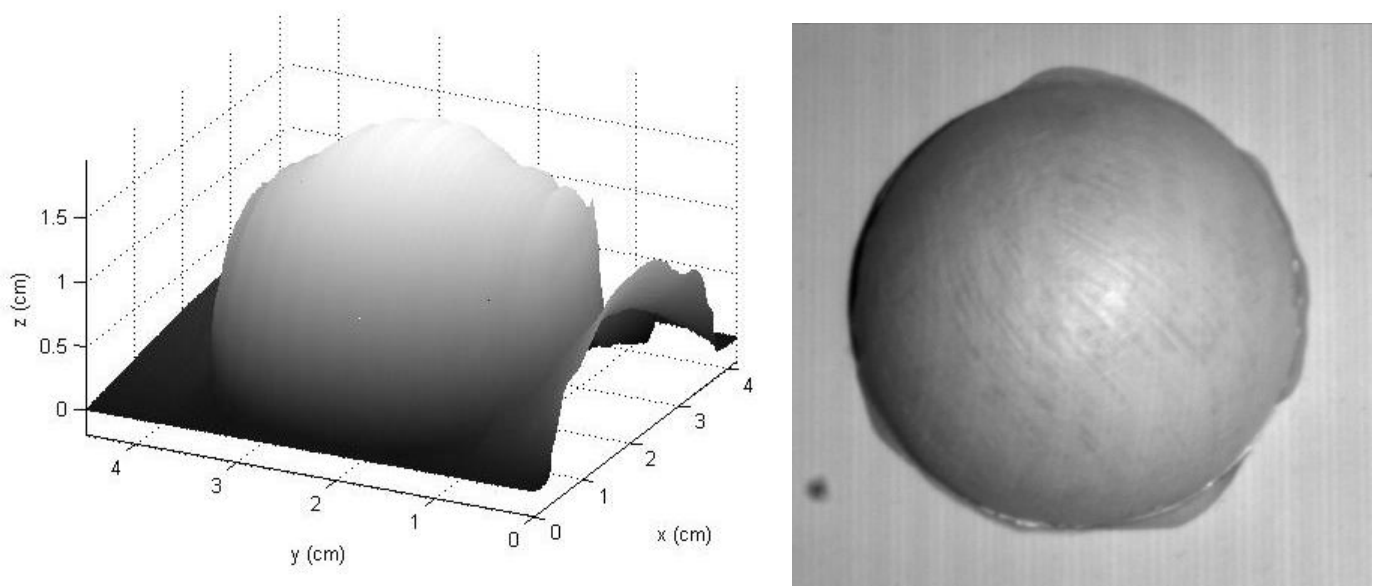

Figura 68: MDT 3D (esquerda) e mapa de intensidades (direita) obtidos para o objeto 4. 

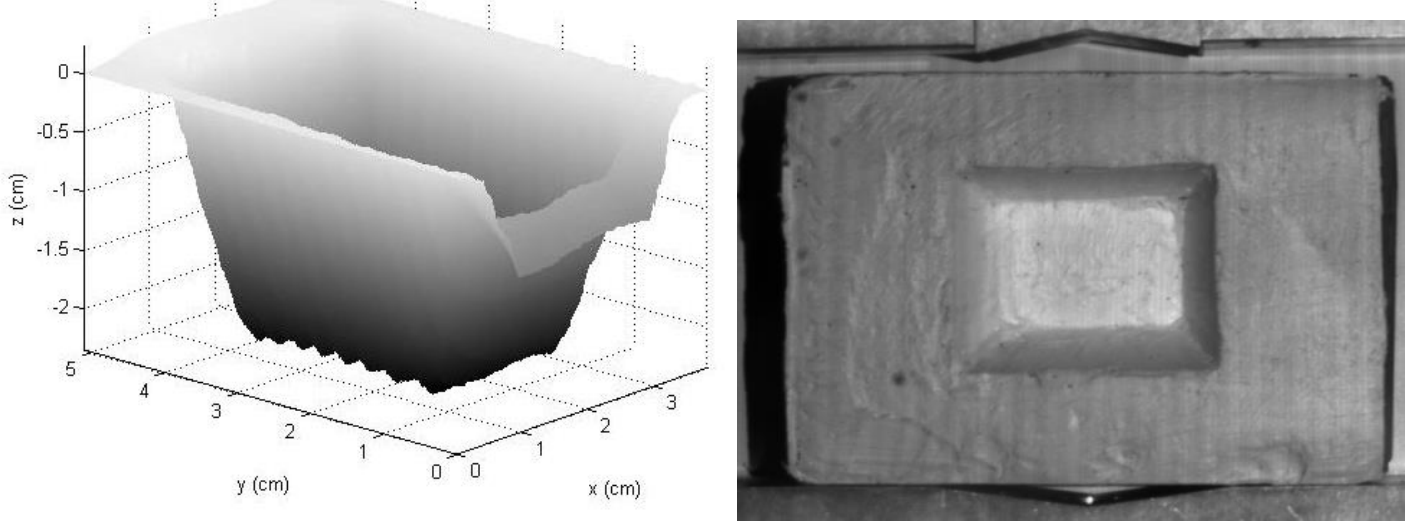

Figura 69: MDT 3D (esquerda) e mapa de intensidades (direita) obtidos para o objeto 5.
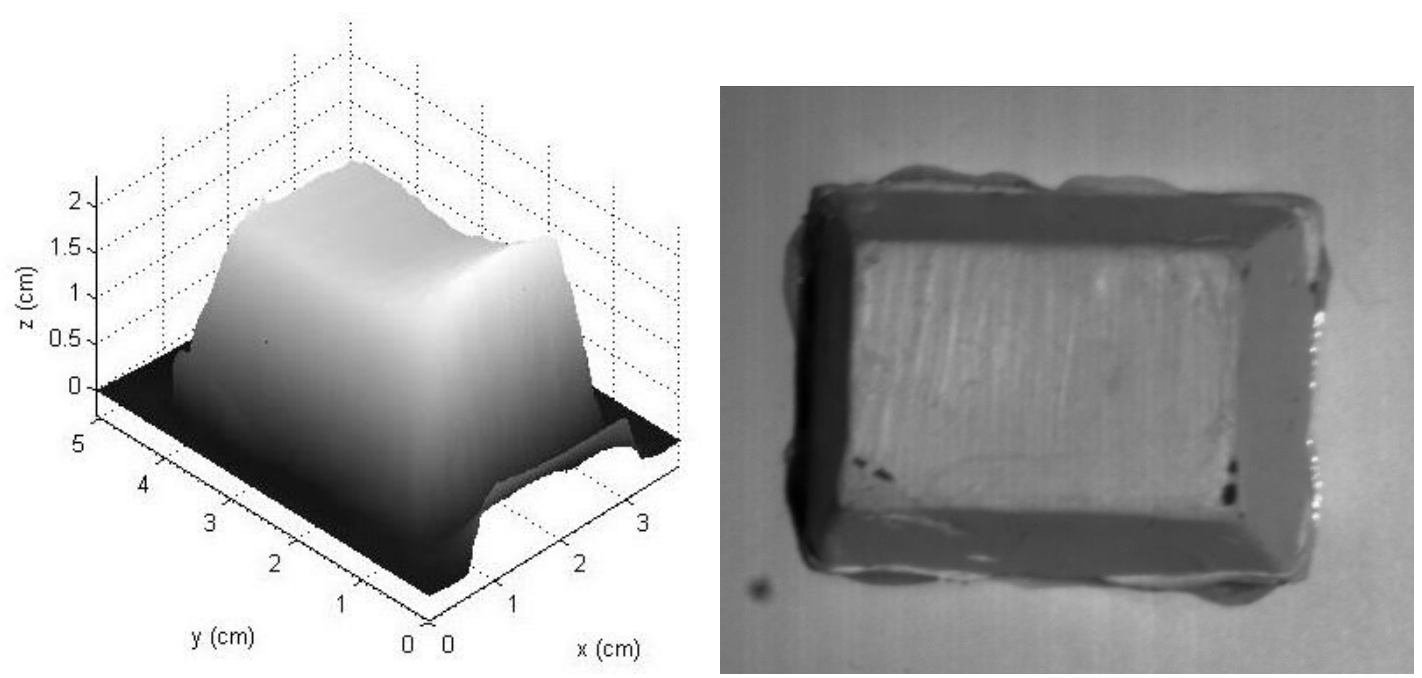

Figura 70: MDT 3D (esquerda) e mapa de intensidades (direita) obtidos para o objeto 6.
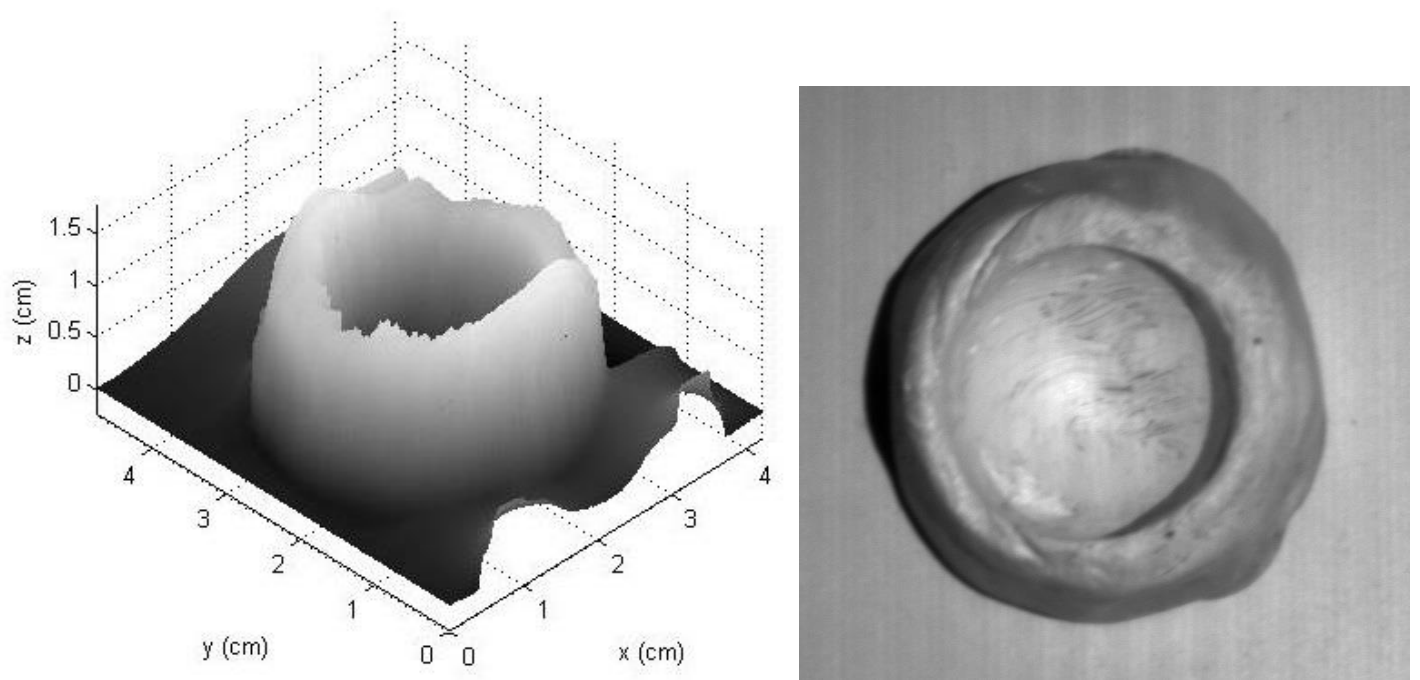

Figura 71: MDT 3D (esquerda) e mapa de intensidades (direita) obtidos para o objeto 7. 

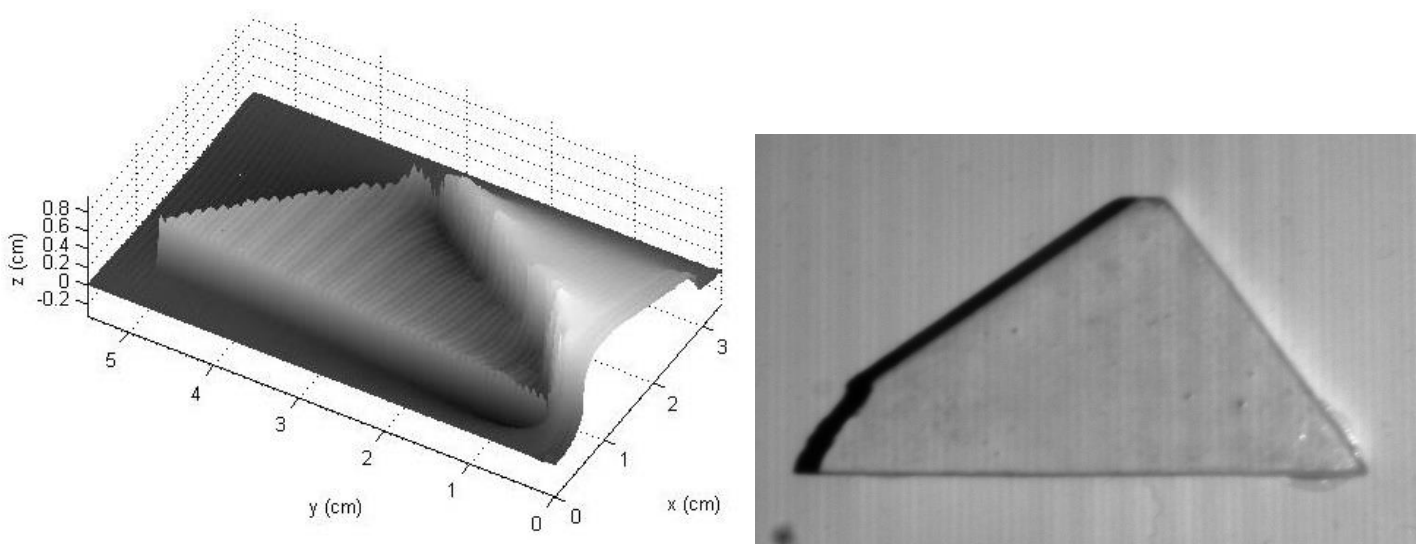

Figura 72: MDT 3D (esquerda) e mapa de intensidades (direita) obtidos para o objeto 8.

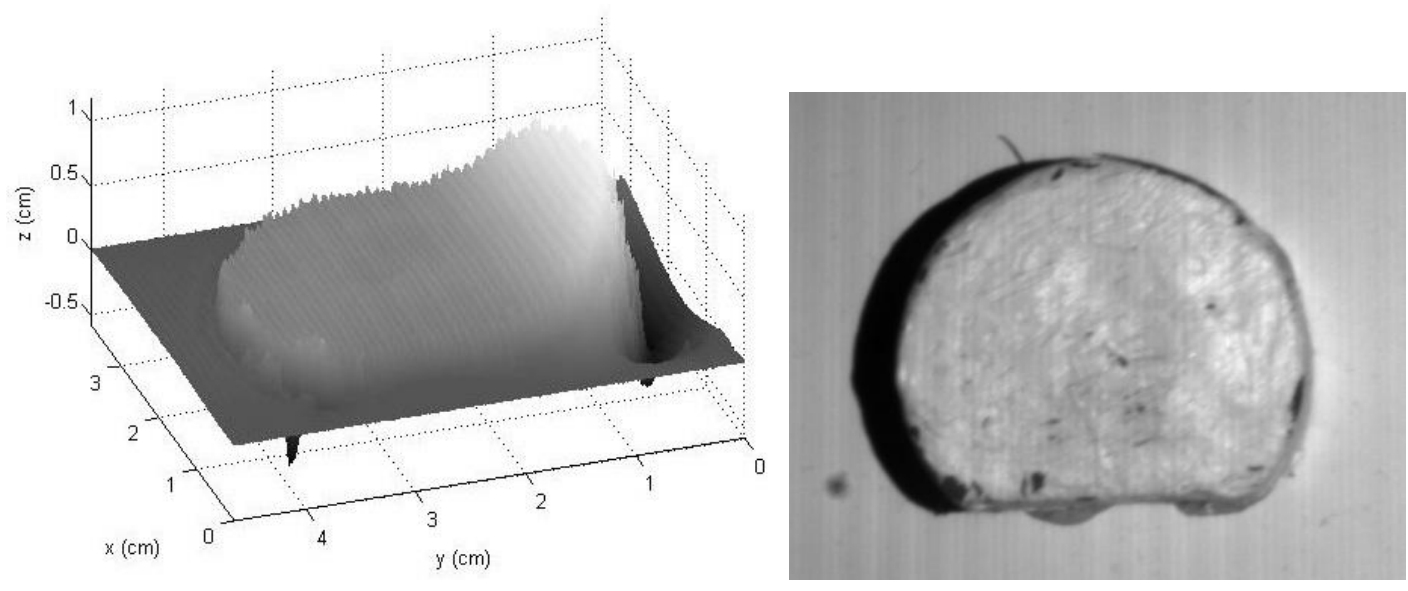

Figura 73: MDT 3D (esquerda) e mapa de intensidades (direita) obtidos para o objeto 9.

Dos resultados obtidos para os objetos de topografia de análise mais complexa, conclui-se que a Técnica de Projeção de Franjas é sensível a regiões de sombra, bordas abruptas, regiões muito grandes com ruídos na imagem e regiões de brilho na imagem. Em todas essas situações, as franjas não puderam ser bem resolvidas, de forma que objetos que possuem essas características não podem ser reconstruídos pela técnica ou estarão sujeitos ao surgimento de artefatos e à super ou subestimação dos valores de altura na sua topografia. Já nas regiões que não possuíam essas características ou elas apareciam de forma que não afetasse a visibilidade e a distinção entre as franjas, o formato do objeto foi bem resolvido e compatível com o real.

Na Tabela 5, são mostradas as máximas discrepâncias entre as medidas dos perfis obtidas com a Técnica de Projeção de Franjas e com o paquímetro, considerando pontos nas regiões em que há artefatos e desconsiderando-os, para os objetos de topografia de análise mais complexa. Nota-se, então que, quando se incluem os pontos das regiões em 
que há artefatos, as discrepâncias são sempre maiores ou iguais às que se observa quando não se incluem os pontos dessas regiões. Quando não se incluem esses pontos, para os objetos de topografia de análise mais complexa, as máximas discrepâncias foram também todas inferiores a $0,30 \mathrm{~cm}$, exceto para os objetos 8 e 9, que não foram bem reproduzidos pela técnica e para os quais praticamente não havia regiões sem artefatos.

Tabela 5: Máximas discrepâncias entre as medidas dos perfis obtidas com a Técnica de Projeção de Franjas e com o paquímetro para os objetos de topografia de análise mais complexa.

\begin{tabular}{|c|c|c|c|}
\cline { 2 - 4 } \multicolumn{1}{c|}{} & Linha & $\begin{array}{c}\text { Máxima discrepância } \\
\text { com pontos nas regiões } \\
\text { em que há artefatos (cm) }\end{array}$ & $\begin{array}{c}\text { Máxima discrepância sem } \\
\text { pontos nas regiões em que } \\
\text { há artefatos (cm) }\end{array}$ \\
\hline \multirow{2}{*}{ Objeto 4 } & $\mathrm{x}$ & 0,13 & 0,13 \\
\cline { 2 - 4 } & $\mathrm{y}$ & 0,42 & 0,09 \\
\hline \multirow{2}{*}{ Objeto 5 } & $\mathrm{x}$ & 0,34 & 0,23 \\
\cline { 2 - 4 } & $\mathrm{y}$ & 0,29 & 0,29 \\
\hline Objeto 6 & $\mathrm{x}$ & 0,61 & 0,11 \\
\cline { 2 - 4 } & $\mathrm{y}$ & 0,34 & 0,10 \\
\hline Objeto 7 & $\mathrm{x}$ & 0,52 & 0,08 \\
\cline { 2 - 4 } & $\mathrm{y}$ & 0,21 & 0,09 \\
\hline Objeto 8 & $\mathrm{x}$ & 0,60 & - \\
\cline { 2 - 4 } & $\mathrm{y}$ & 0,82 & - \\
\hline Objeto 9 & $\mathrm{x}$ & 0,55 & - \\
\cline { 2 - 4 } & $\mathrm{y}$ & 1,45 & \\
\hline
\end{tabular}

\subsection{Objetos coloridos}

Os mapas de fases moduladas, os MDTs e os perfis obtidos com a Técnica de Projeção de Franjas, comparados com os medidos com o paquímetro, ao longo das linhas traçadas nos principais eixos da região de interesse dos objetos coloridos, são mostrados nas Figuras 74 a 77.

Já que todos os objetos coloridos possuíam formatos semelhantes, nos resultados obtidos, observa-se que os MDTs apresentaram um bom comportamento e representaram bem o formato e a topografia dos objetos. Exceto pela presença de artefatos nas laterais dos MDTs dos objetos, que surgiram por causa do plano de referência destes, que apresentava descontinuidades por não ser suficientemente grande e abranger toda a imagem. Isso causou descontinuidades nas franjas, conforme pode ser visto nos mapas de fases moduladas. Esses artefatos influenciaram nos resultados obtidos para os perfis ao 
longo das linhas horizontais (linha $\mathrm{x}$ ), onde se observa que os pontos próximos à borda direita apresentaram incertezas maiores ou não foram compatíveis com as medidas obtidas com o paquímetro. As linhas horizontais também passavam por regiões de sombra, brilho na imagem e pelas bordas muito íngremes dos objetos, o que também causou incompatibilidade com os dados medidos com o paquímetro e incertezas muito grandes, conforme pode ser visto principalmente nas extremidades dos perfis obtidos ao longo dessas linhas.

Já a linha na mesma direção das franjas (linha y) apresentou bom comportamento e foi compatível para todos os objetos, exceto para a região central dessa linha ao longo do objeto cor de pele escura, que passa por uma região de brilho que contrasta muito com a cor escura do objeto.

Os MDTs 3D e os mapas de intensidades obtidos para os objetos coloridos são mostrados nas Figuras 78 a 81. Nos MDTs 3D de todos os objetos coloridos, ficam claros os artefatos citados, porém tanto estes como os mapas de intensidades representaram bem as características dos objetos.
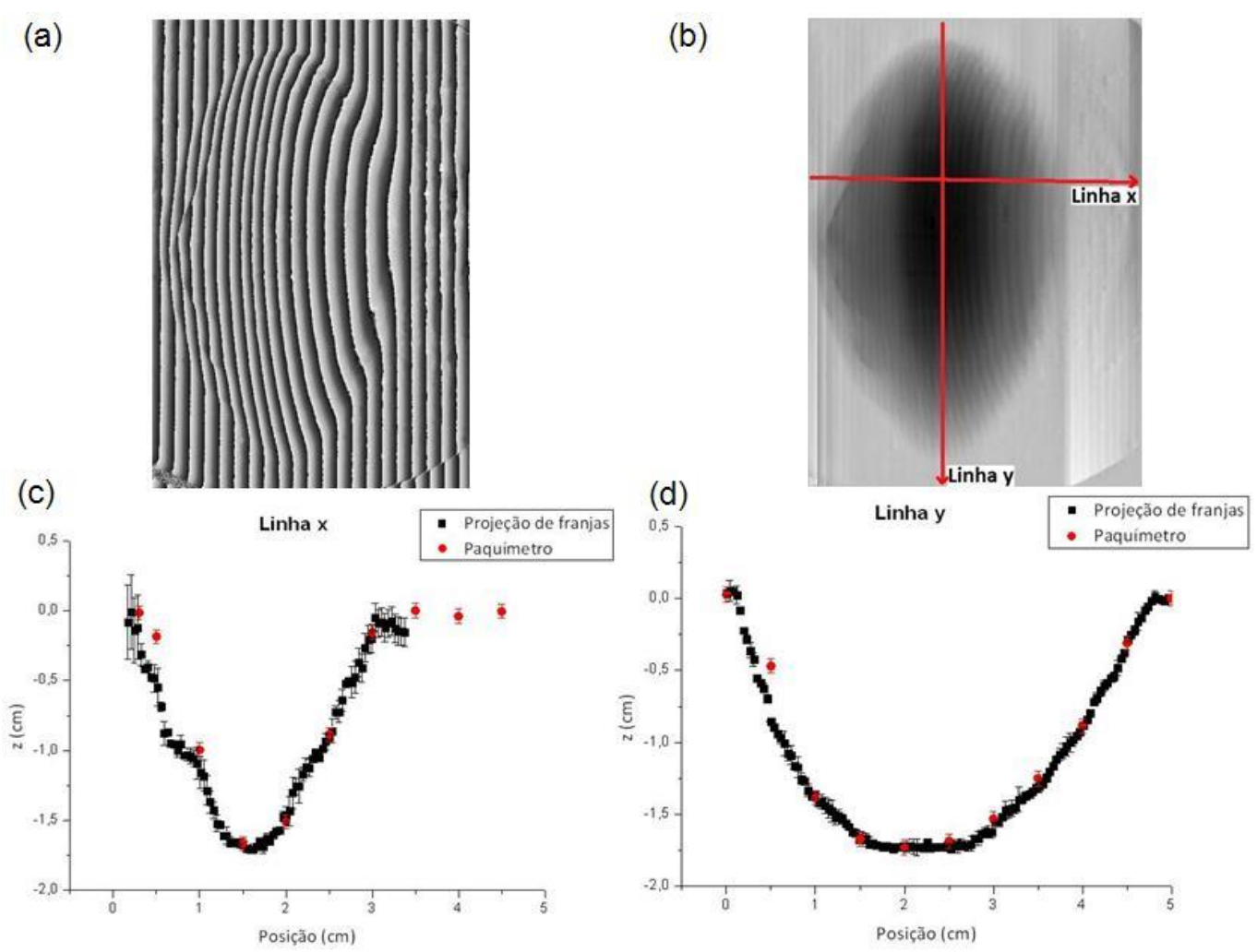

Figura 74: (a) Mapa de fases moduladas do objeto pele clara. (b) MDT. (c) comparação do perfil obtido com a Técnica de Projeção de Franjas e o paquímetro ao longo da linha x e (d) da linha y. 
(a)

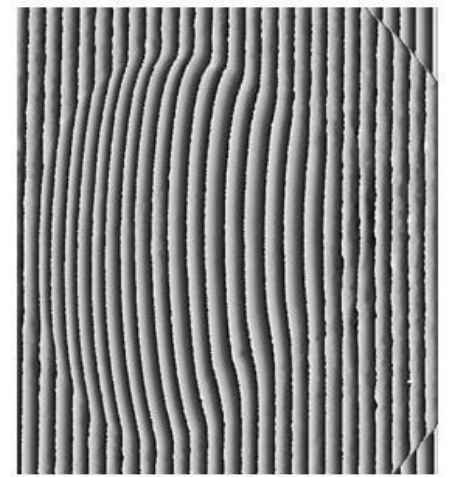

(c)

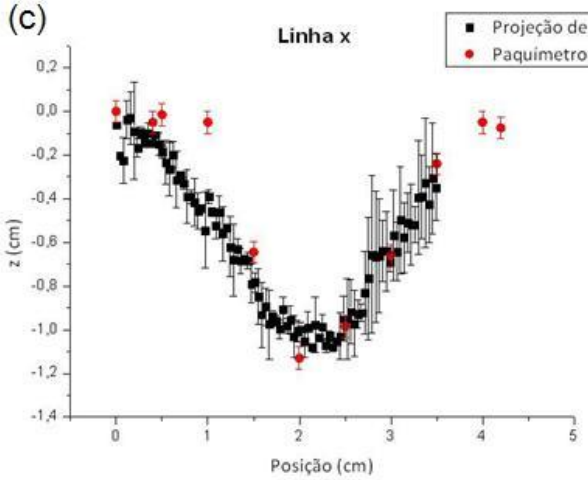

(b)

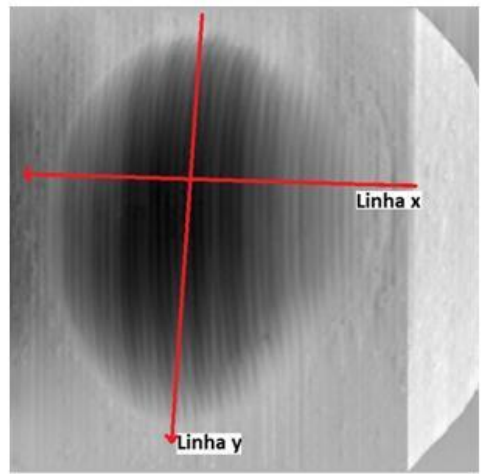

(d)

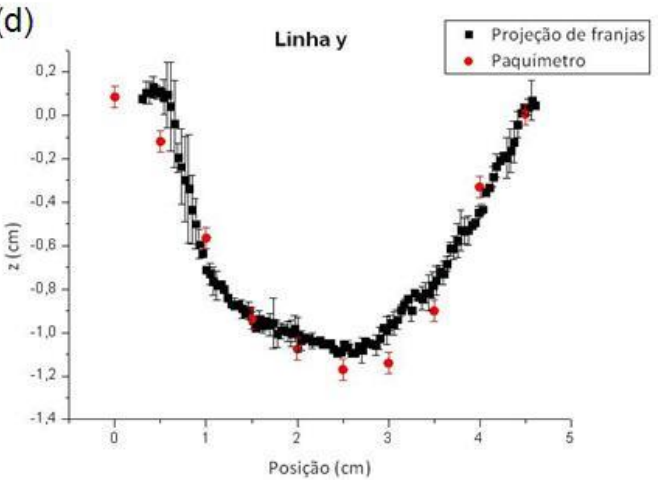

Figura 75: (a) Mapa de fases moduladas do objeto pele média. (b) MDT. (c) comparação do perfil obtido com a Técnica de Projeção de Franjas e o paquímetro ao longo da linha x e (d) da linha y.

(a)

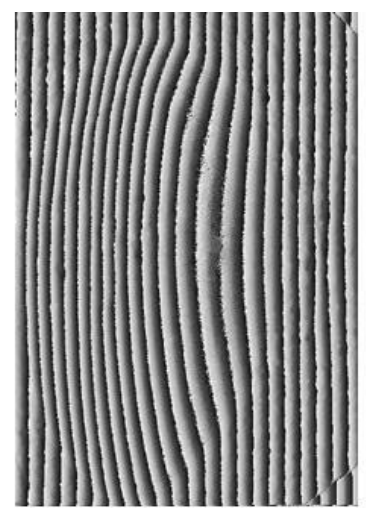

(c)

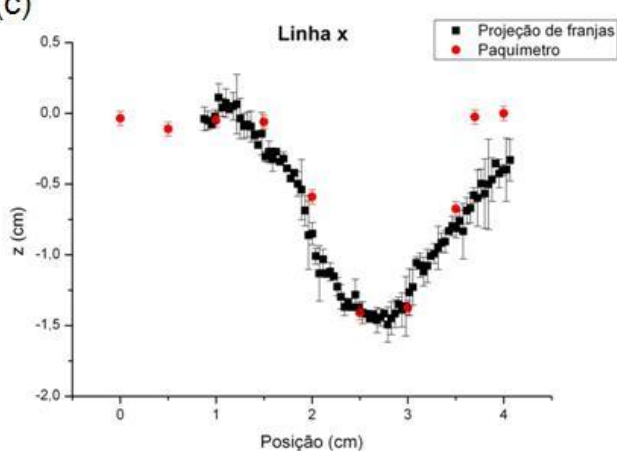

(b)

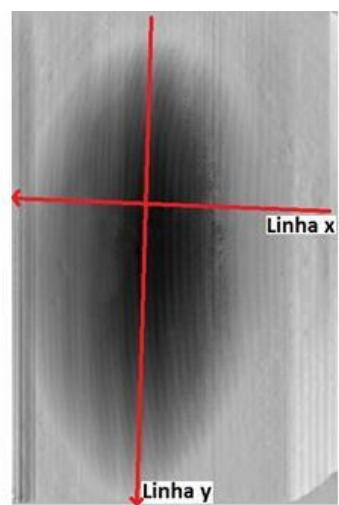

(d)

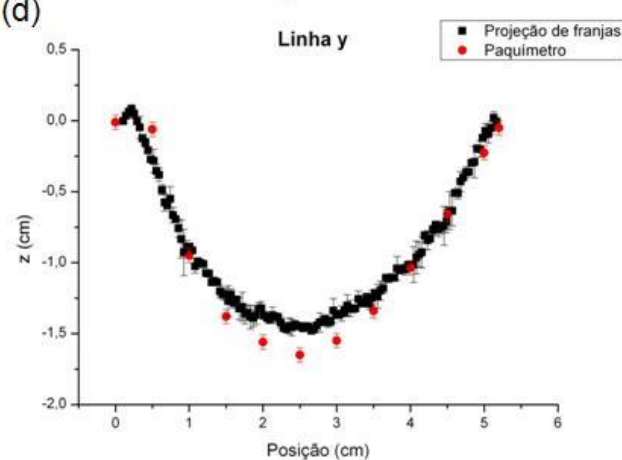

Figura 76: (a) Mapa de fases moduladas do objeto pele escura. (b) MDT. (c) comparação do perfil obtido com a Técnica de Projeção de Franjas e o paquímetro ao longo da linha x e (d) da linha y. 
(a)

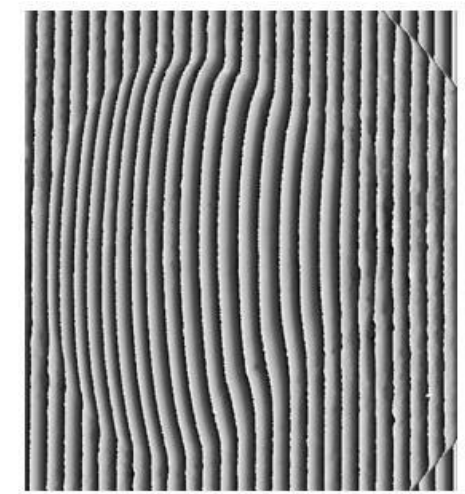

(c)

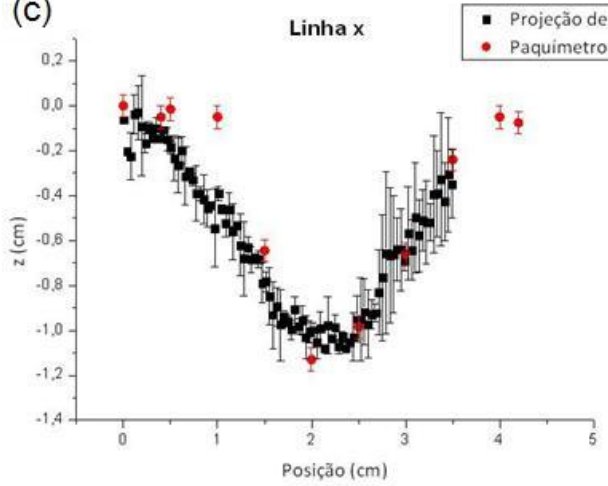

(b)

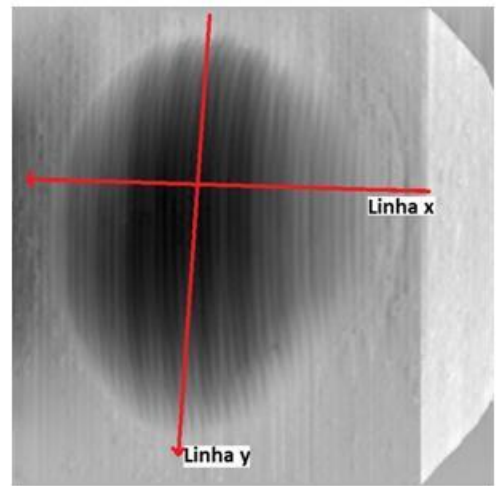

(d)

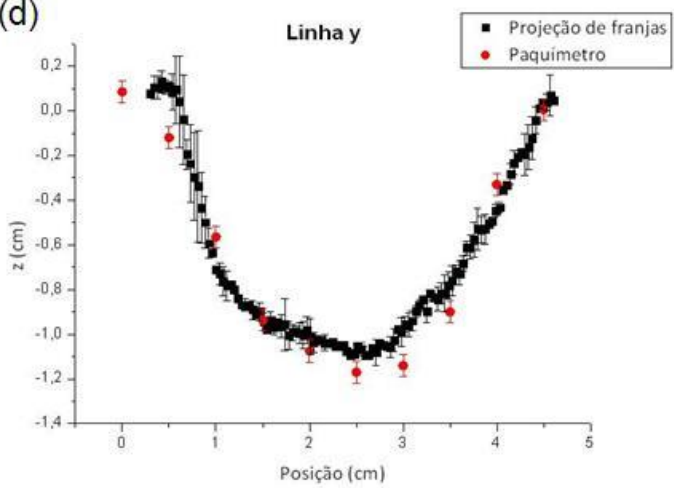

Figura 77: (a) Mapa de fases moduladas do objeto vermelho. (b) MDT. (c) comparação do perfil obtido com a Técnica de Projeção de Franjas e o paquímetro ao longo da linha x e (d) da linha y.
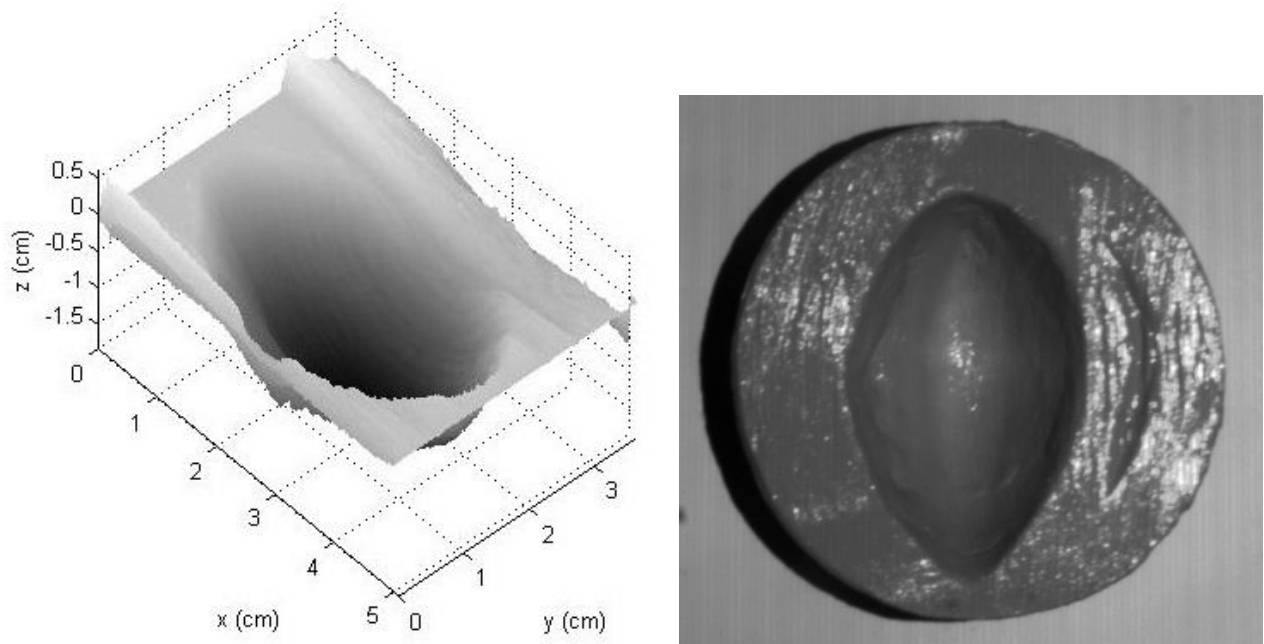

Figura 78: MDT 3D (esquerda) e mapa de intensidades (direita) obtidos para o objeto pele clara. 

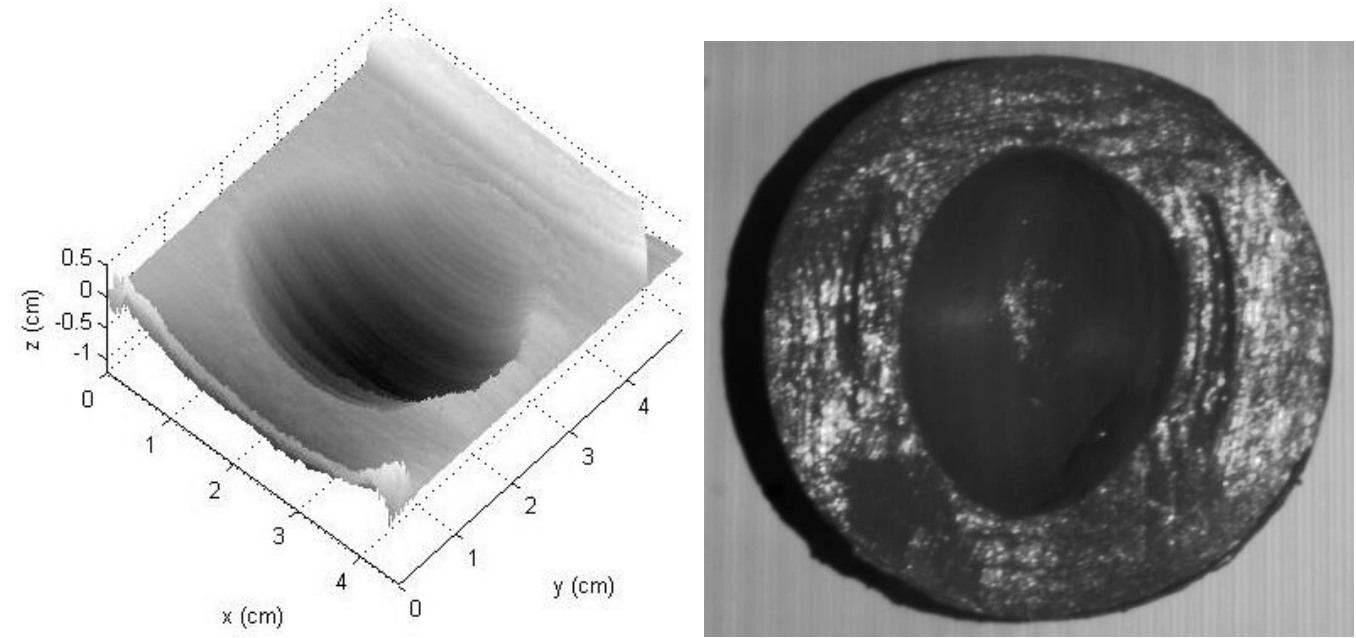

Figura 79: MDT 3D (esquerda) e mapa de intensidades (direita) obtidos para o objeto pele média.
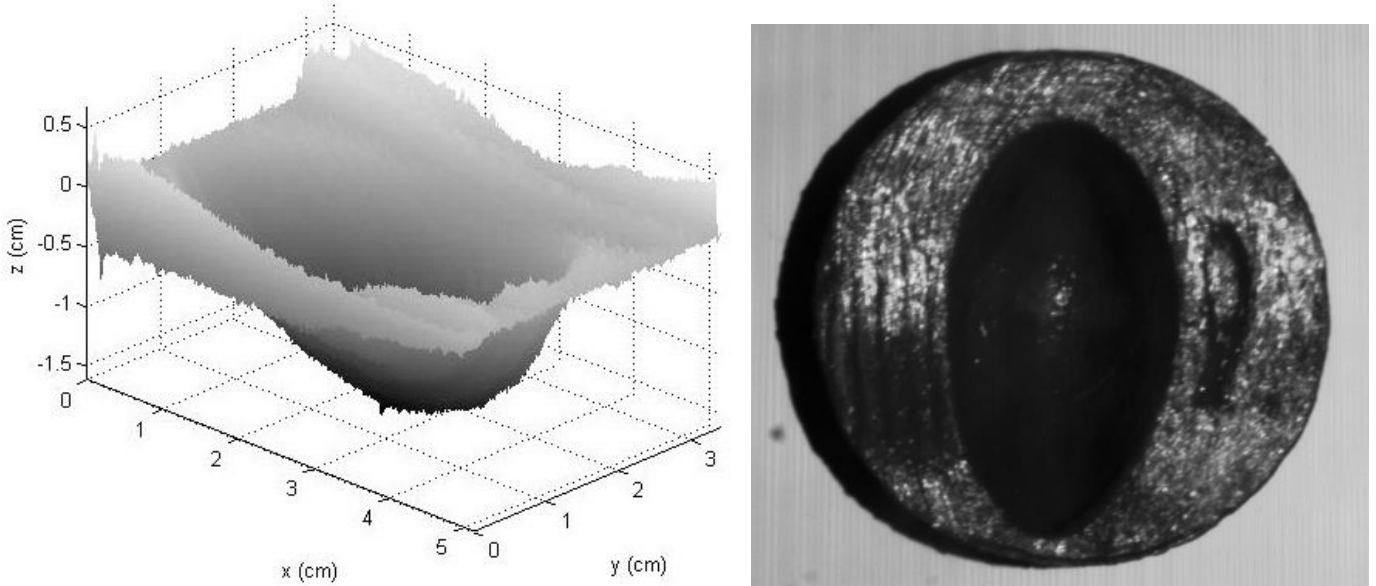

Figura 80: MDT 3D (esquerda) e mapa de intensidades (direita) obtidos para o objeto pele escura.
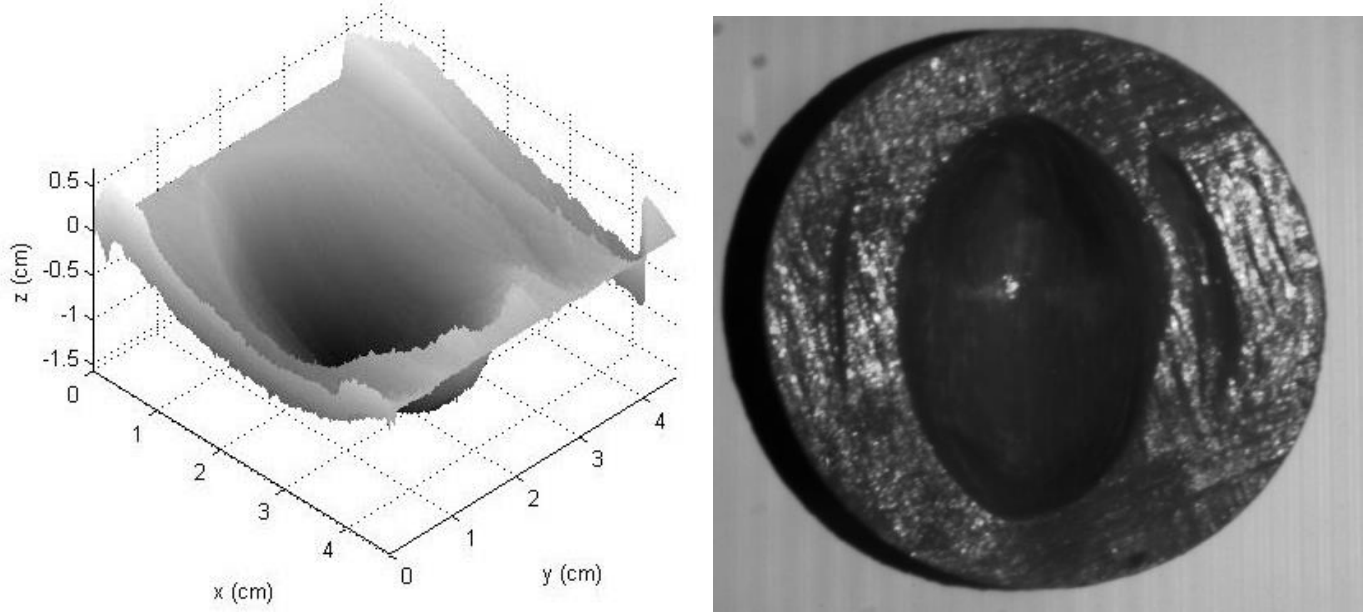

Figura 81: MDT 3D (esquerda) e mapa de intensidades (direita) obtidos para o objeto vermelho. 


\subsection{Objetos que simulam lesões}

\section{Objeto lesões}

O mapa de fases moduladas e o mapa de intensidades obtidos para o objeto lesões são mostrados na Figura 82. Os MDTs, os MDTs 3D e os perfis ao longo dos principais eixos de cada lesão deste objeto são mostrados nas Figuras 83, 84 e 85.

Nos resultados de todas as lesões, se observa que houve artefatos no lado direito das lesões, devido à presença de sombra nos orifícios desse lado, provenientes da direção de iluminação do objeto e da profundidade e formato das lesões. Essa sombra tornou difícil a distinção entre as franjas, o que dificultou a análise dessas regiões, conforme pode ser observado também na Figura 82, nos mapas de fase moduladas e nos mapas de intensidades. Contudo, de um modo geral, os MDTs 3D de todas as lesões representaram bem as características das topografias e os perfis obtidos ao longo das linhas $\mathrm{x}$ e y também foram compatíveis com os medidos com o paquímetro.

Especificamente no mapa de intensidades e no mapa de fases moduladas da lesão 1, se nota que na região do artefato também há brilho contrastando com a cor da lesão e bordas abruptas onde as franjas sofrem descontinuidades. A dificuldade de obter a topografia dessa região da lesão 1 também é refletida no fato de que as incertezas na região central da linha $1 y$ e na extremidades da linha $1 x$ foram grandes, conforme pode ser visto na Figura 83.

Já nos resultados obtidos para a lesão 2, observa-se que houve pequenos artefatos verticais devido ao processo de desmodulação da fase, o que é notado por uma dificuldade maior de obter o perfil ao longo do eixo perpendicular à direção das franjas na região de interesse (linha 2x), onde as incertezas ficaram bem elevadas. Isso ocorre devido à pequena região de sombra no lado direito do orifício citada anteriormente e também porque a topografia deste é muito irregular.

Nos resultados obtidos para a lesão 3, além da região de sombra no lado direito, havia uma região de brilho no fundo da lesão, que contrastava com a cor desta. Isso causou o pequeno artefato citado e incertezas maiores na região central dos perfis 3x e 3y. 


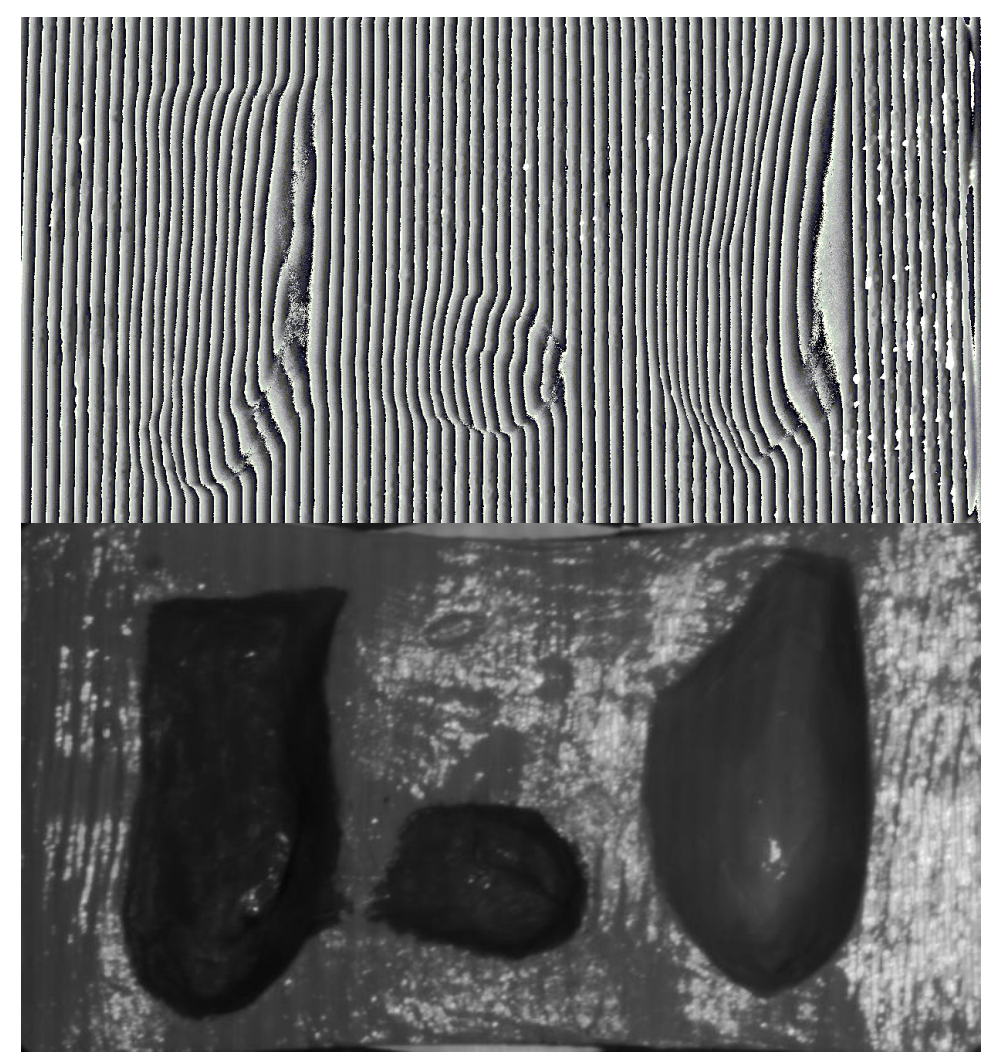

Figura 82: Mapa de fases moduladas (acima) e mapa de intensidades (abaixo) para o objeto lesões.

(a)

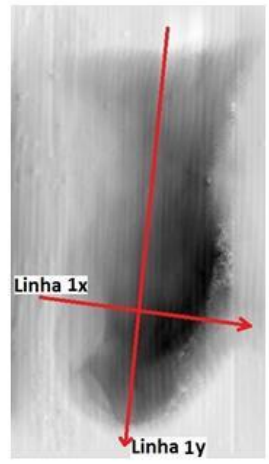

(c)

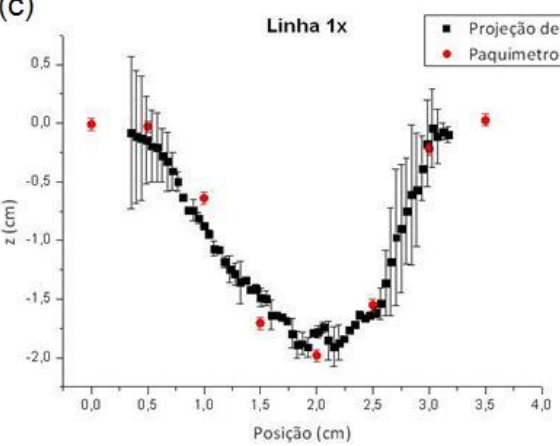

(b)

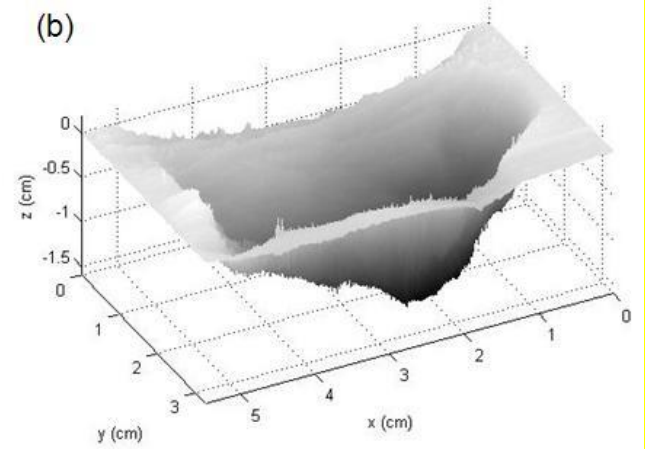

(d)
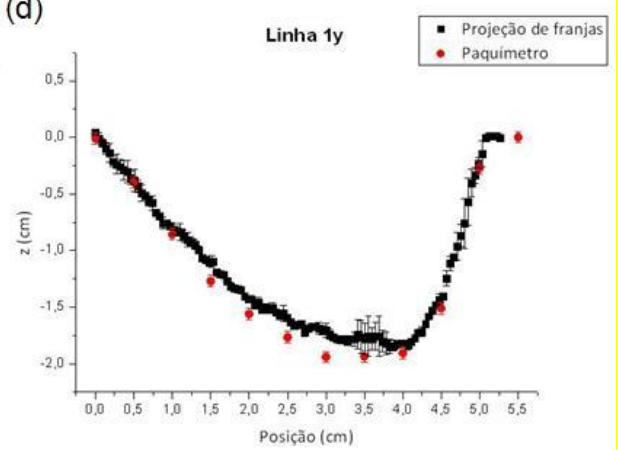

Figura 83: (a) MDT da lesão 1 do objeto lesões. (b) MDT 3D. (c) comparação do perfil obtido com a Técnica de Projeção de Franjas e o paquímetro ao longo da linha x e (d) da linha y. 
(a)

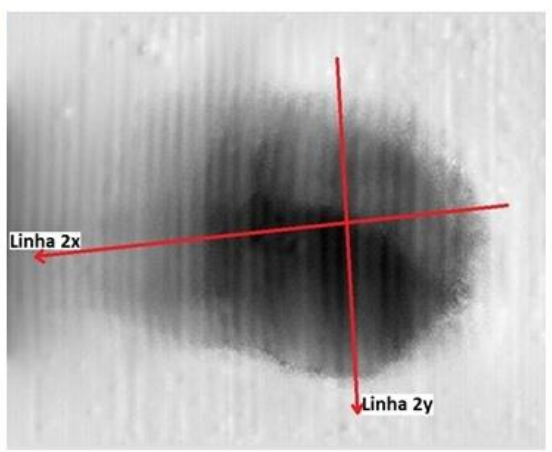

(c)

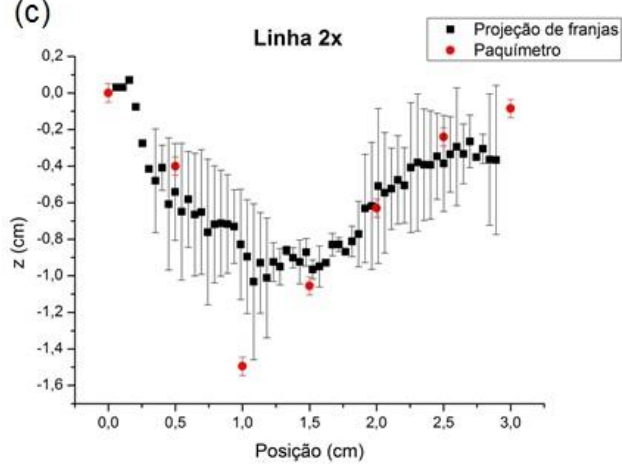

(b)

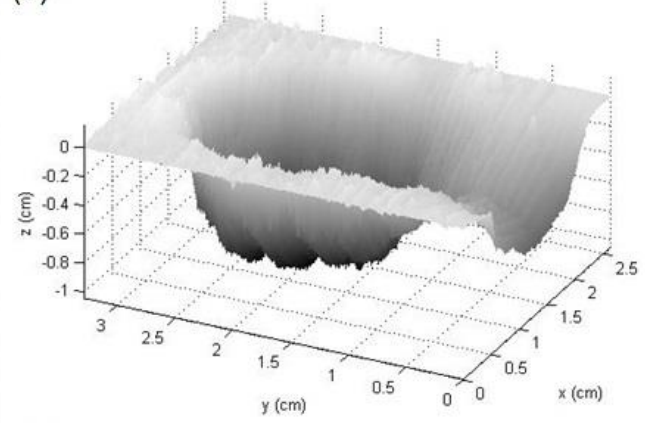

(d)

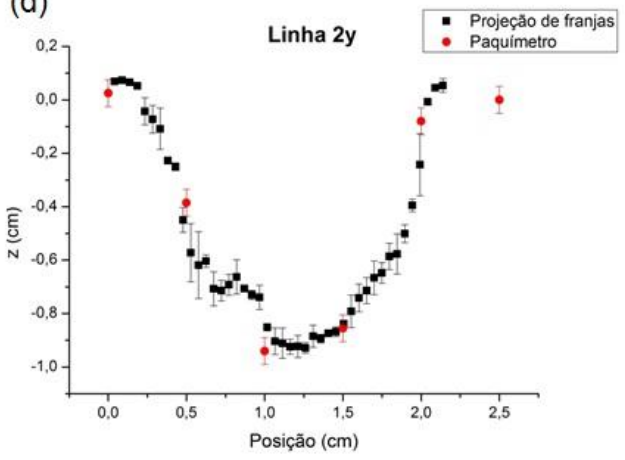

Figura 84: (a) MDT da lesão 2 do objeto lesões. (b) MDT 3D. (c) comparação do perfil obtido com a Técnica de Projeção de Franjas e o paquímetro ao longo da linha x e (d) da linha y.

(a)

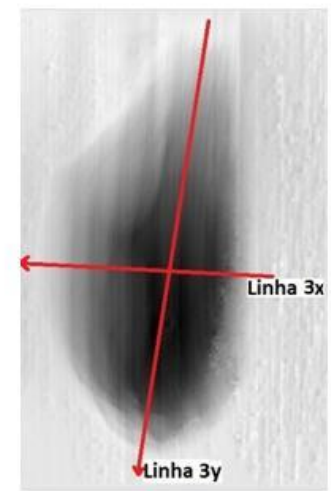

(c)

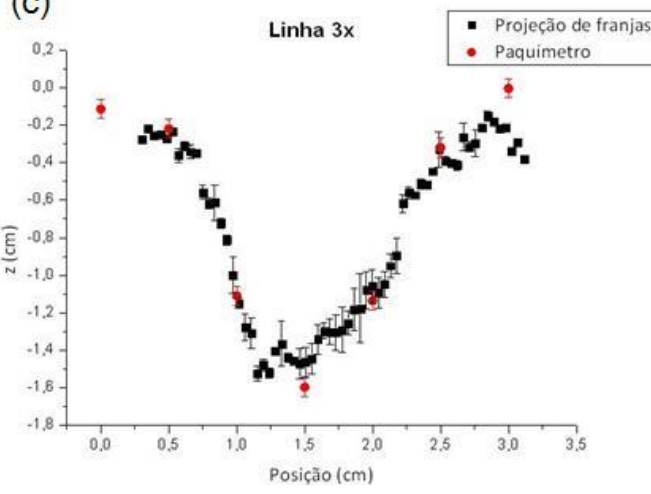

(b)

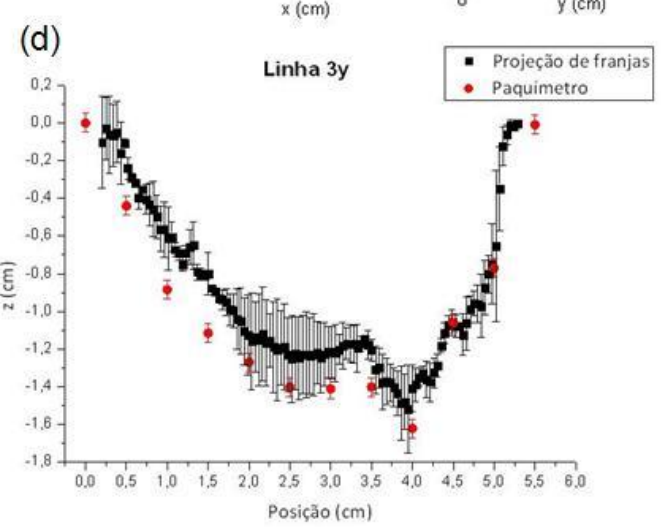

Figura 85: (a) MDT da lesão 3 do objeto lesões. (b) MDT 3D. (c) comparação do perfil obtido com a Técnica de Projeção de Franjas e o paquímetro ao longo da linha x e (d) da linha y. 


\section{Lesão em mão de borracha}

O mapa de fases moduladas da lesão confeccionada em uma mão de borracha, o MDT e os perfis obtidos com a Técnica de Projeção de Franjas, comparados com os medidos com o paquímetro, ao longo das linhas traçadas nos principais eixos da região de interesse do objeto, são mostrados na Figura 86. Observa-se, no MDT, que houve muitos artefatos verticais, principalmente devido ao brilho na superfície da mão, que dificultava o reconhecimento da frequência das franjas no processo de desmodulação da fase, isso também pode ser visto pela irregularidade e defeito nas franjas obtidas no mapa de fases moduladas. Além disso, não houve compatibilidade entre os valores obtidos com a Técnica de Projeção de Franjas e os medidos com o paquímetro ao longo dos perfis $\mathrm{x}$ e y e, nas bordas da lesão, os valores obtidos com a técnica ficaram sistematicamente superestimados. Isso provavelmente se deve ao brilho e à dificuldade de distinguir as franjas, mas também devido ao fato da lesão ser muito rasa, sendo difícil de medir suas dimensões, inclusive com o paquímetro.

(a)

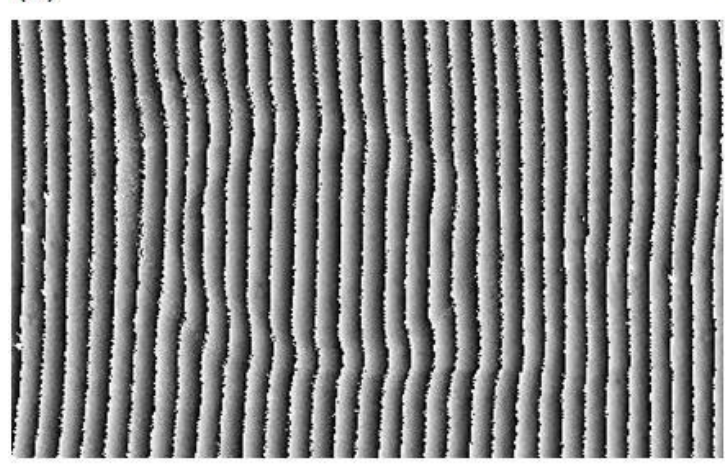

(c)

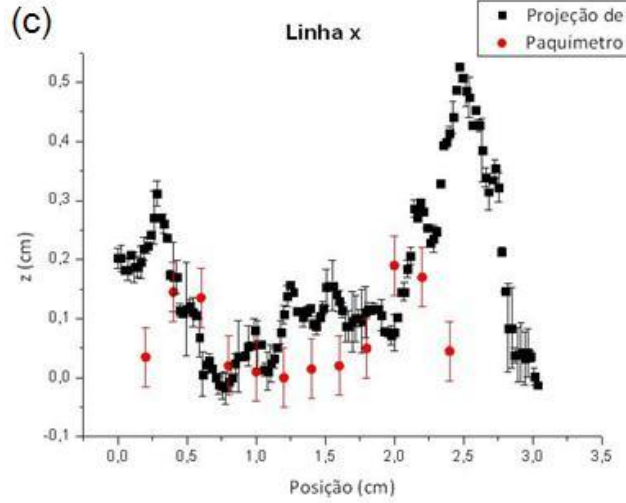

(b)

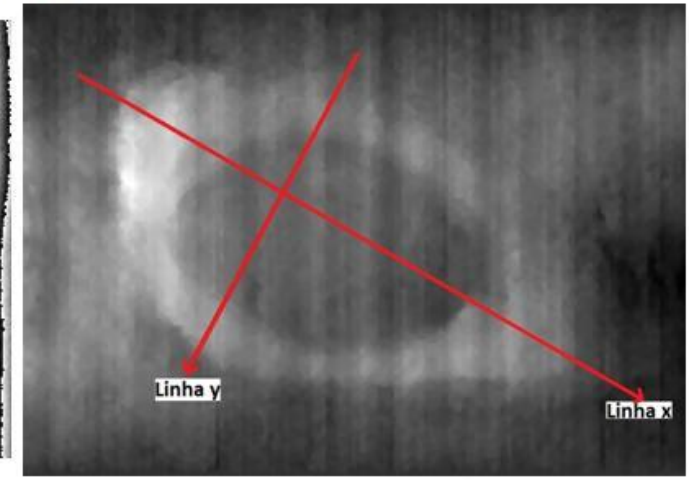

(d)
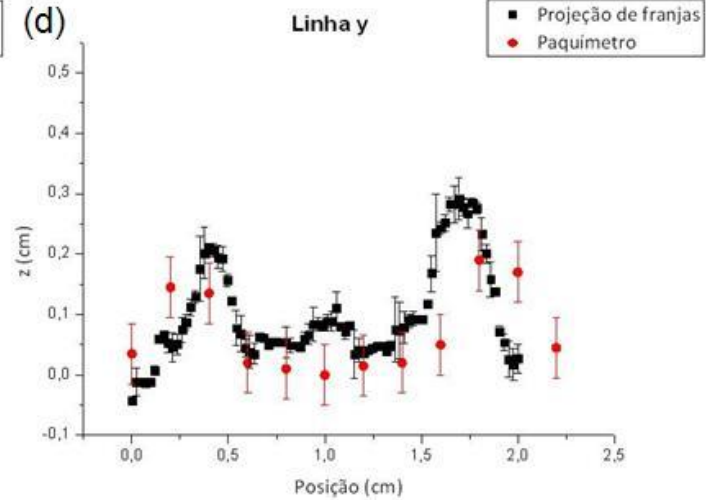

Figura 86: (a) Mapa de fases moduladas da lesão confeccionada em mão de borracha. (b) MDT. (c) comparação do perfil obtido com a Técnica de Projeção de Franjas e o paquímetro ao longo da linha $x e(d)$ da linha y. 
Na Figura 87, são mostrados o MDT 3D e o mapa de intensidades obtidos para a lesão confeccionada na mão de borracha, no MDT 3D, se nota os artefatos citados anteriormente, que dificultaram a identificação do formato da lesão, e no mapa de intensidades ficam claras as regiões de brilho na imagem, que prejudicaram a análise.
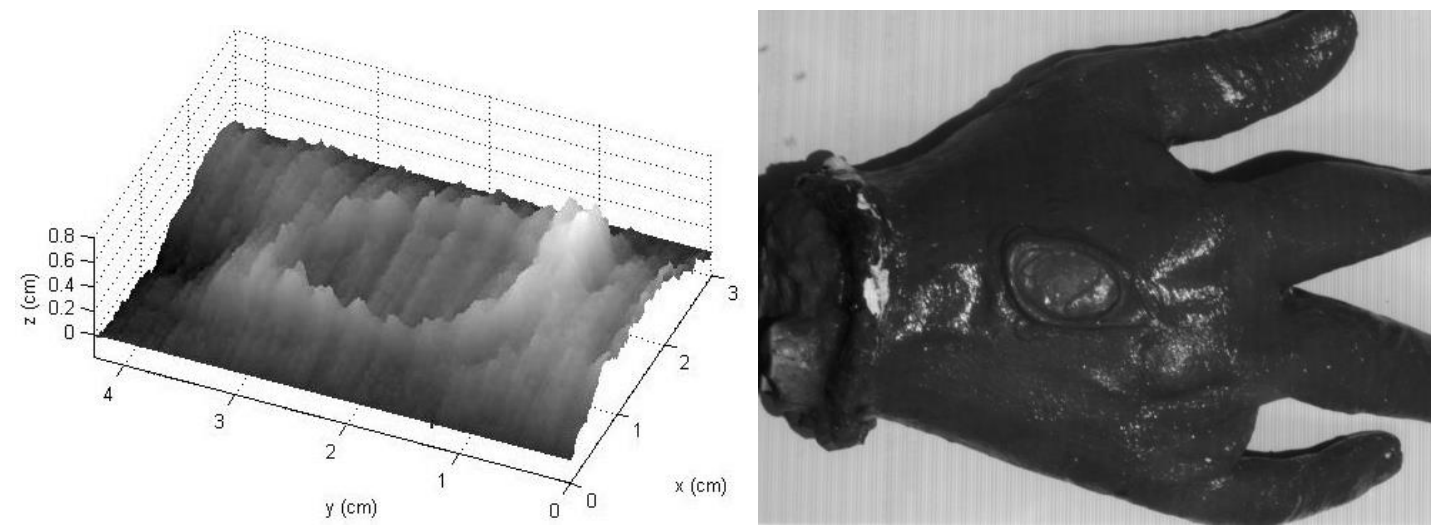

Figura 87: MDT 3D (esquerda) e mapa de intensidades (direita) obtidos para a lesão confeccionada em mão de borracha.

Do estudo dos objetos coloridos e dos objetos que simulam lesões, conclui-se que, de um modo geral, a técnica reproduziu bem o formato de todos eles, mas que novamente houve dificuldade em reproduzir regiões onde há brilho na imagem, sombra ou bordas abruptas, onde as franjas e sua frequência não são bem identificadas, causando artefatos, incertezas elevadas e super ou subestimação dos valores em relação aos medidos com o paquímetro.

Além disso, observou-se que, quanto mais escura é a coloração do objeto, é mais difícil se obter contraste entre as franjas, porém foi possível contornar esse problema ajustando a abertura da lente acoplada na câmera CCD e a luminosidade de fundo.

Na Tabela 6, são mostradas as máximas discrepâncias entre as medidas dos perfis obtidas com a Técnica de Projeção de Franjas e com o paquímetro, incluindo os pontos das regiões em que há artefatos e não os incluindo, para os objetos coloridos e para os que simulam lesões. Nota-se, então que, quando se inclui os pontos das regiões em que há artefatos, as discrepâncias são sempre maiores ou iguais de quando não se os inclui. Quando não se inclui esses pontos, tanto para os objetos coloridos quanto para os que simulam lesões, as máximas discrepâncias foram inferiores a $0,30 \mathrm{~cm}$, que é o mesmo resultado obtido anteriormente para os outros objetos. 
Tabela 6: Máximas discrepâncias entre as medidas dos perfis obtidas com a Técnica de Projeção de Franjas e com o paquímetro para os objetos coloridos e para os que simulam lesões.

\begin{tabular}{|c|c|c|c|}
\hline & Linha & $\begin{array}{c}\text { Máxima discrepância com } \\
\text { pontos nas regiōes em que } \\
\text { há artefatos }(\mathrm{cm})\end{array}$ & $\begin{array}{l}\text { Máxima discrepância sem } \\
\text { pontos nas regiōes em } \\
\text { que há artefatos }(\mathrm{cm})\end{array}$ \\
\hline \multirow{2}{*}{$\begin{array}{l}\text { Objeto pele } \\
\text { clara }\end{array}$} & $x$ & 0,76 & 0,23 \\
\hline & $y$ & 0,39 & 0,05 \\
\hline \multirow{2}{*}{$\begin{array}{l}\text { Objeto pele } \\
\text { média }\end{array}$} & $x$ & 0,40 & 0,14 \\
\hline & y & 0,23 & 0,15 \\
\hline \multirow{2}{*}{$\begin{array}{l}\text { Objeto pele } \\
\text { escura }\end{array}$} & $x$ & 0,56 & 0,24 \\
\hline & $\mathrm{y}$ & 0,20 & 0,20 \\
\hline \multirow{2}{*}{$\begin{array}{c}\text { Objeto } \\
\text { vermelho }\end{array}$} & $x$ & 0,26 & 0,26 \\
\hline & y & 0,10 & 0,10 \\
\hline \multirow{6}{*}{$\begin{array}{l}\text { Objeto } \\
\text { lesões }\end{array}$} & $1 x$ & 0,25 & 0,25 \\
\hline & $1 y$ & 0,24 & 0,24 \\
\hline & $2 x$ & 0,63 & 0,16 \\
\hline & $2 y$ & 0,16 & 0,16 \\
\hline & $3 x$ & 0,13 & 0,13 \\
\hline & $3 y$ & 0,28 & 0,28 \\
\hline \multirow{2}{*}{$\begin{array}{l}\text { Lesão em mão } \\
\text { de borracha }\end{array}$} & $x$ & 0,07 & 0,02 \\
\hline & $y$ & 0,19 & 0,09 \\
\hline
\end{tabular}

Nas últimas seções verificou-se que, com a Técnica de Projeção de Franjas, é possível obter topografias de objetos regulares de diferentes geometrias e cores, construídos para simular características e propriedades de lesões na pele. Além disso, estudaram-se as limitações e a precisão da técnica, chegando-se à conclusão de que é possível utilizá-la para obter topografias de objetos que não apresentem sombra, brilho e bordas abruptas e que, nesses casos, as discrepâncias são sempre inferiores a $0,30 \mathrm{~cm}$, para as configurações e equipamentos do arranjo experimental utilizado. Nos casos em que os objetos apresentam essas características, a precisão da técnica fica comprometida e as discrepâncias em relação às medidas reais podem ser mais elevadas.

Dentro dessas condições, foi possível validar a técnica como um método de medição de topografias e dimensões de objetos e, com isso, conclui-se que ela pode ser utilizada para medir topografias e dimensões de lesões na pele de pacientes. Nas próximas seções, são mostrados os resultados obtidos na medição de lesões de pacientes e a sugestão de 
um protocolo de procedimento para a utilização da técnica na medida de dimensões de lesões na pele.

\subsection{Lesões de pacientes}

Paciente 1

O mapa de fases moduladas da lesão do paciente 1 , o MDT e o perfil obtido com a Técnica de Projeção de Franjas ao longo da linha traçada no principal eixo desta, são mostrados na Figura 88. No perfil de todas as lesões não se estimou a incerteza de posicionamento da linha, pois não havia motivo para isso, uma vez que, como dito anteriormente, não foi possível medir a altura e a profundidade das lesões dos pacientes com algum método de medição direto, e não havia com que comparar as medidas do perfil. Assim, considerou-se apenas a incerteza do próprio método que, conforme obtido no processo de validação da técnica, é de $0,30 \mathrm{~cm}$. Essa incerteza é a mesma para todos os pontos e não foi colocada nos gráficos para não sobrecarregá-los.

Na Figura 88, observa-se que foi bem difícil de obter contraste entre as franjas nessa lesão, pois ela estava necrosada, apresentava uma coloração escura, praticamente da cor das franjas projetadas, superfície irregular que prejudicava a visualização da deformação destas devido às variações de altura na topografia e era pouco elevada, com elevação próxima à precisão da técnica, conforme pode ser visto na Figura 19. Isso dificultou a análise, causando deformações e ruídos no mapa de fases moduladas, e prejudicou a identificação da frequência das franjas no processo de desmodulação da fase, causando artefatos verticais no MDT, conforme observado na Figura 88.

Porém, ainda assim, foi possível obter o perfil ao longo da linha x sobre o eixo principal da lesão, do qual se nota que, tomando-se uma linha média entre os picos de ruídos, a altura da lesão era de aproximadamente $0,40 \mathrm{~cm}$ acima da pele saudável, que é um valor razoável, apesar de não ter sido possível a comparação com alguma medida utilizando um método de medição direto. Porém, por se tratar uma lesão com altura próxima à precisão da técnica, a utilização desta com o equipamento experimental utilizado pode não ser a mais adequada para a determinação de suas dimensões.

O MDT 3D e o mapa de intensidades obtidos para essa lesão são mostrados na Figura 89. No MDT 3D, se notam mais claramente os artefatos e ruídos citados anteriormente, e 
no mapa de intensidades são observadas as características da lesão que prejudicaram a análise.

(a)

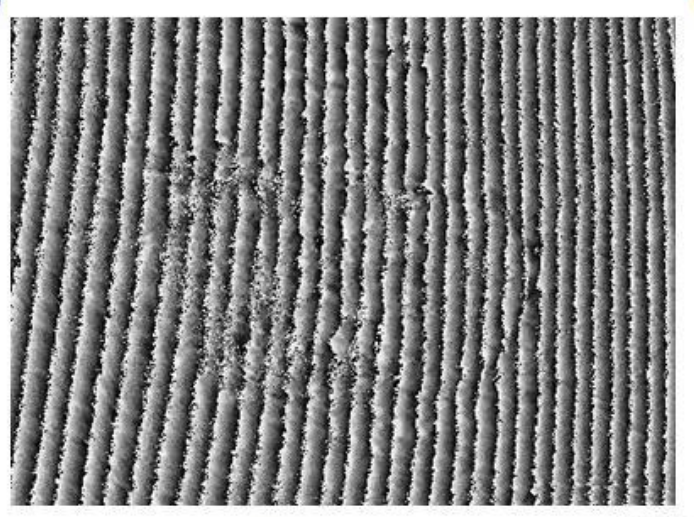

(c) (b)

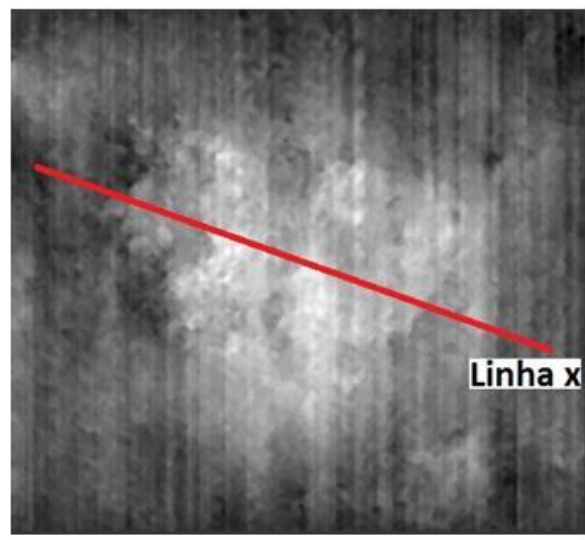

- Projeção de franjas

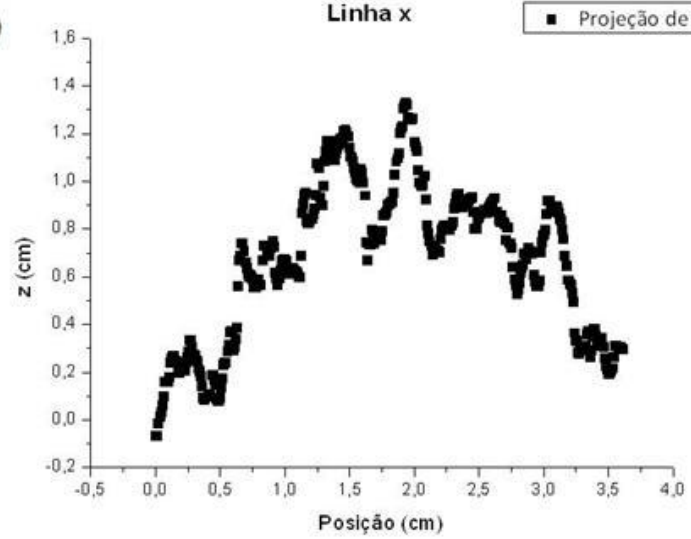

Figura 88: (a) Mapa de fases moduladas da lesão do paciente 1. (b) MDT. (c) perfil obtido com a Técnica de Projeção de Franjas ao longo da linha x.

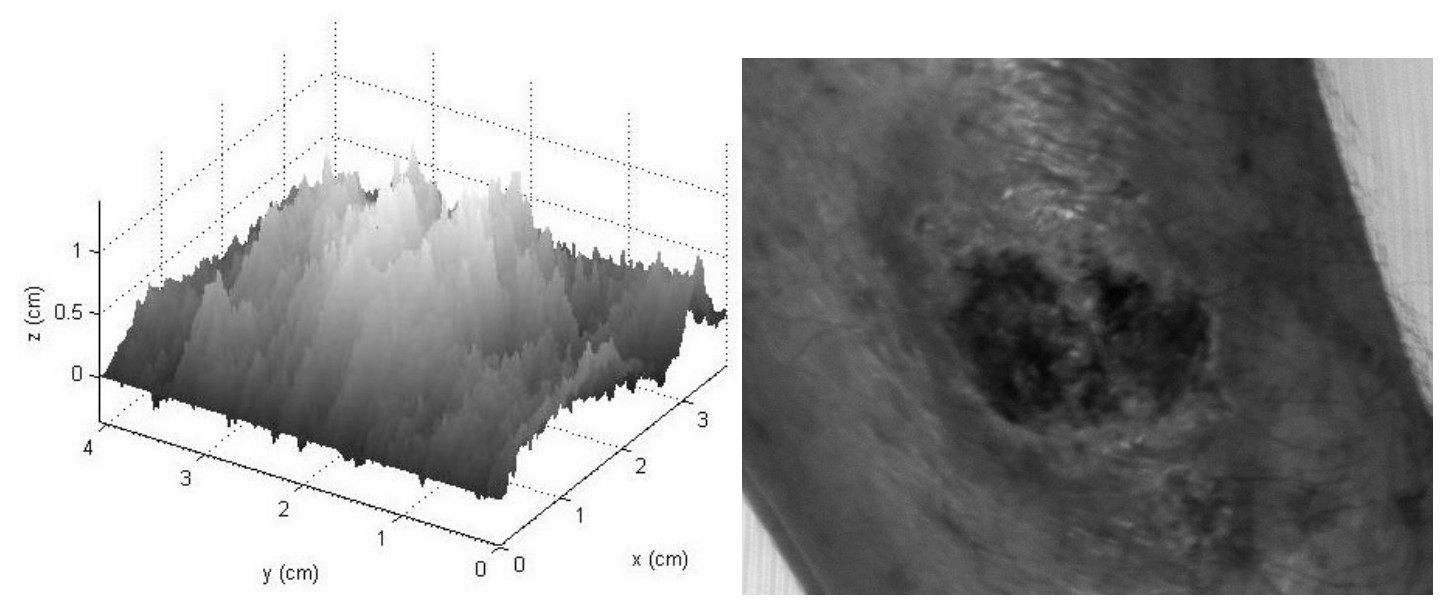

Figura 89: MDT 3D (esquerda) e mapa de intensidades (direita) obtidos para a lesão do paciente 1. 


\section{Paciente 2}

O mapa de fases moduladas da lesão do paciente 2 , o MDT e o perfil obtido com a Técnica de Projeção de Franjas ao longo da linha traçada no eixo principal desta, são mostrados na Figura 90. Observa-se que, apesar da lesão apresentar uma parte necrosada e partes com bordas abruptas (conforme pode ser visto na Figura 20), foi possível resolver bem a topografia, de forma que em apenas uma pequena região as franjas apresentaram ruídos, mas, com a filtragem, a iluminação de fundo e a abertura da lente acoplada à câmera adequadas, foi possível obter um MDT sem artefatos e ruídos. O perfil ao longo do eixo principal da lesão (linha $\mathrm{x}$ ) também apresentou um formato coerente com o real e a profundidade obtida foi de aproximadamente $0,60 \mathrm{~cm}$, que é um valor razoável. O MDT 3D e o mapa de intensidades obtidos para essa lesão são mostrados na Figura 91, ambos representaram bem as características desta.

(a)

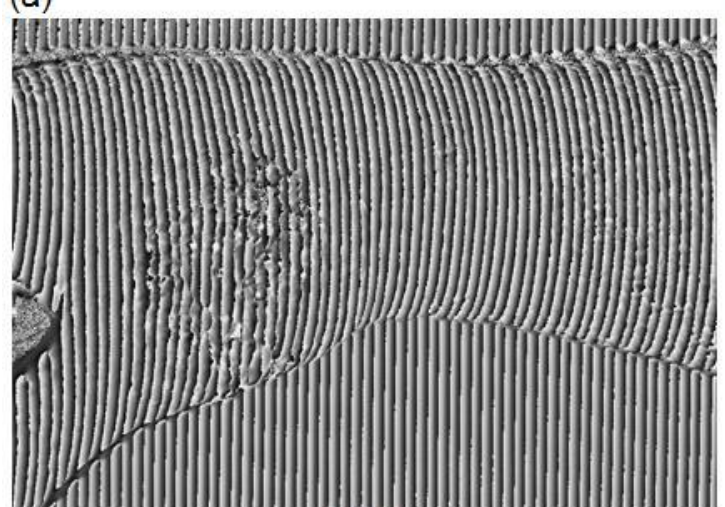

(b)

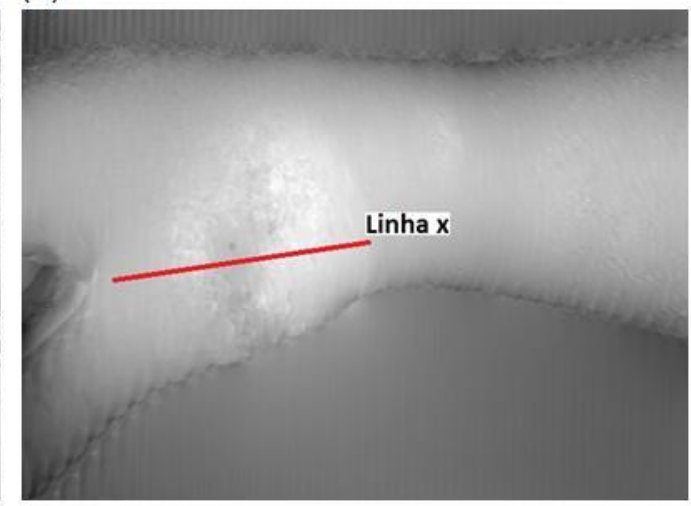

Linha $x$

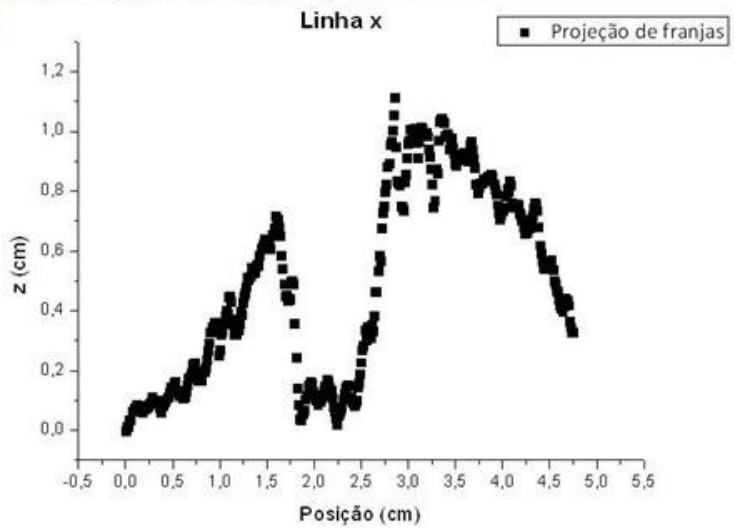

(c)

Figura 90: (a) Mapa de fases moduladas da lesão do paciente 2. (b) MDT. (c) perfil obtido com a Técnica de Projeção de Franjas ao longo da linha x. 

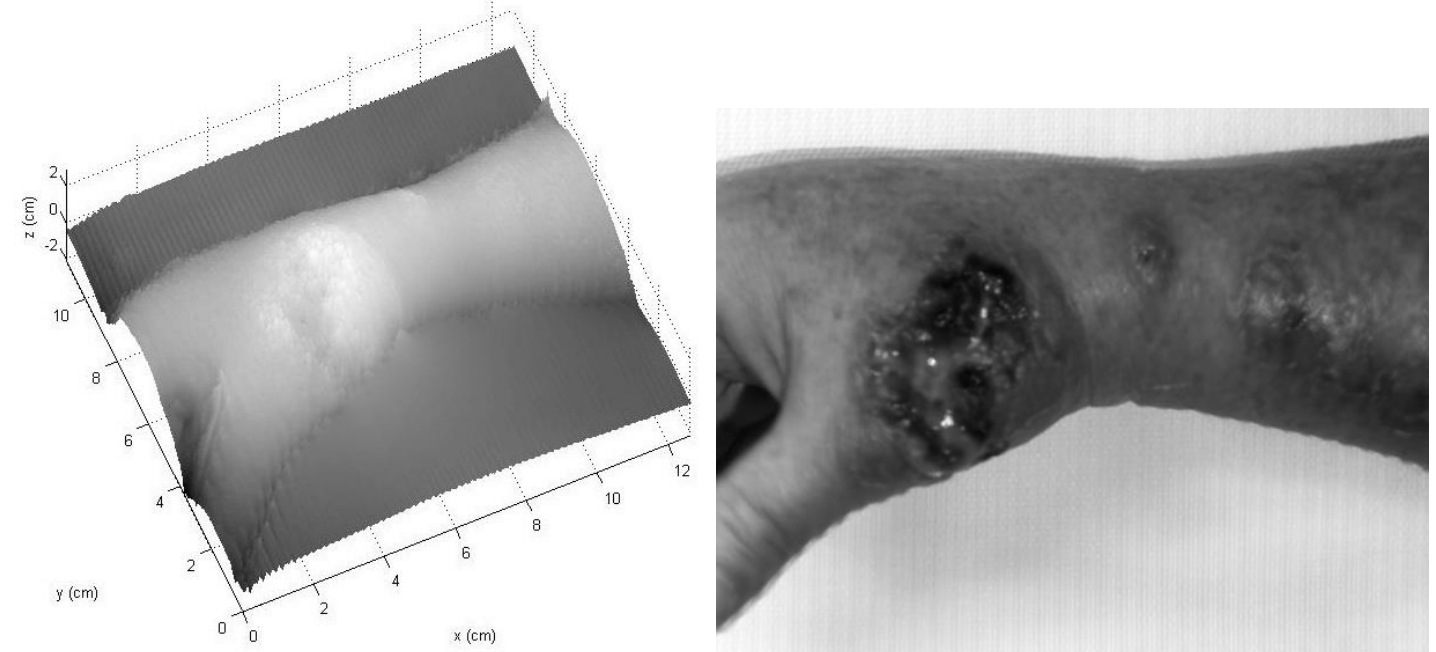

Figura 91: MDT 3D (esquerda) e mapa de intensidades (direita) obtidos para a lesão do paciente 2.

\section{Paciente 3}

O mapa de fases moduladas da lesão do paciente 3 , o MDT e o perfil obtido com a Técnica de Projeção de Franjas ao longo da linha traçada no principal eixo desta, são mostrados na Figura 92.

$\mathrm{Na}$ obtenção das imagens deste paciente, não foi possível posicionar a lesão exatamente de frente para a câmera, pois o suporte e a localização da cama hospitalar (que estava encostada na parede do lado esquerdo da cama, mesmo lado da lesão do paciente) não permitiam um bom posicionamento para a tomada de dados, de forma que as imagens apresentaram uma região de sombra que causou ruídos na região superior do mapa de fases moduladas e do MDT, conforme observado na Figura 92. Apesar disso, por ser uma lesão com uma topografia de análise simples e coloração clara, de fácil obtenção de contraste entre as franjas, o MDT e o perfil ao longo do eixo principal representaram bem as características da lesão e não apresentaram muitos ruídos e artefatos. No perfil obtido, se nota que a altura da lesão foi de aproximadamente $0,50 \mathrm{~cm}$, que é um valor razoável. O MDT 3D e o mapa de intensidades obtidos para essa lesão são mostrados na Figura 93, ambos representaram bem as características dela. 
(a)

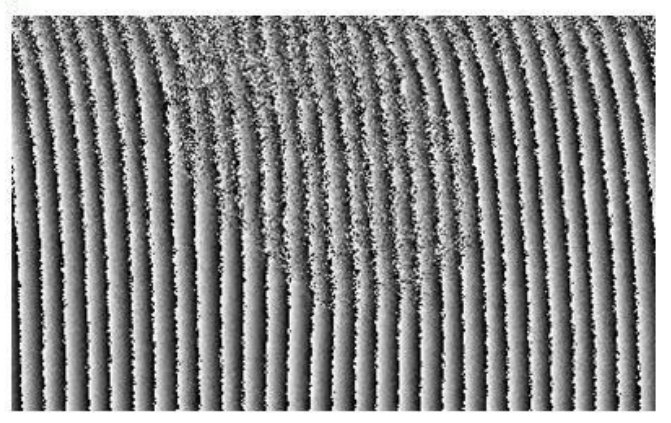

(b)

(c)

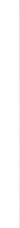

(c)

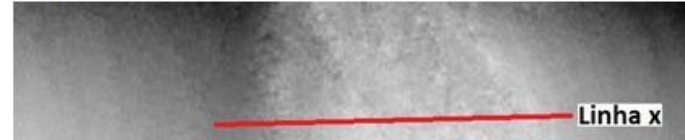

inha $x$

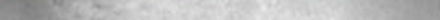
Linha $\mathrm{x}$ - Projeção de franjas

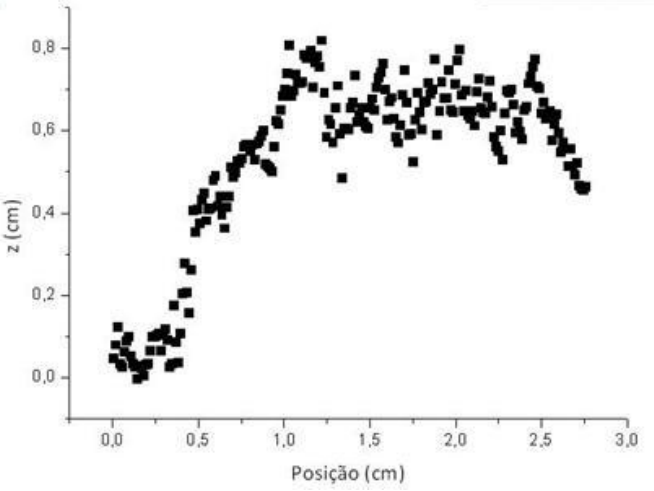

Figura 92: (a) Mapa de fases moduladas da lesão do paciente 3. (b) MDT. (c) perfil obtido com a Técnica de Projeção de Franjas ao longo da linha x.
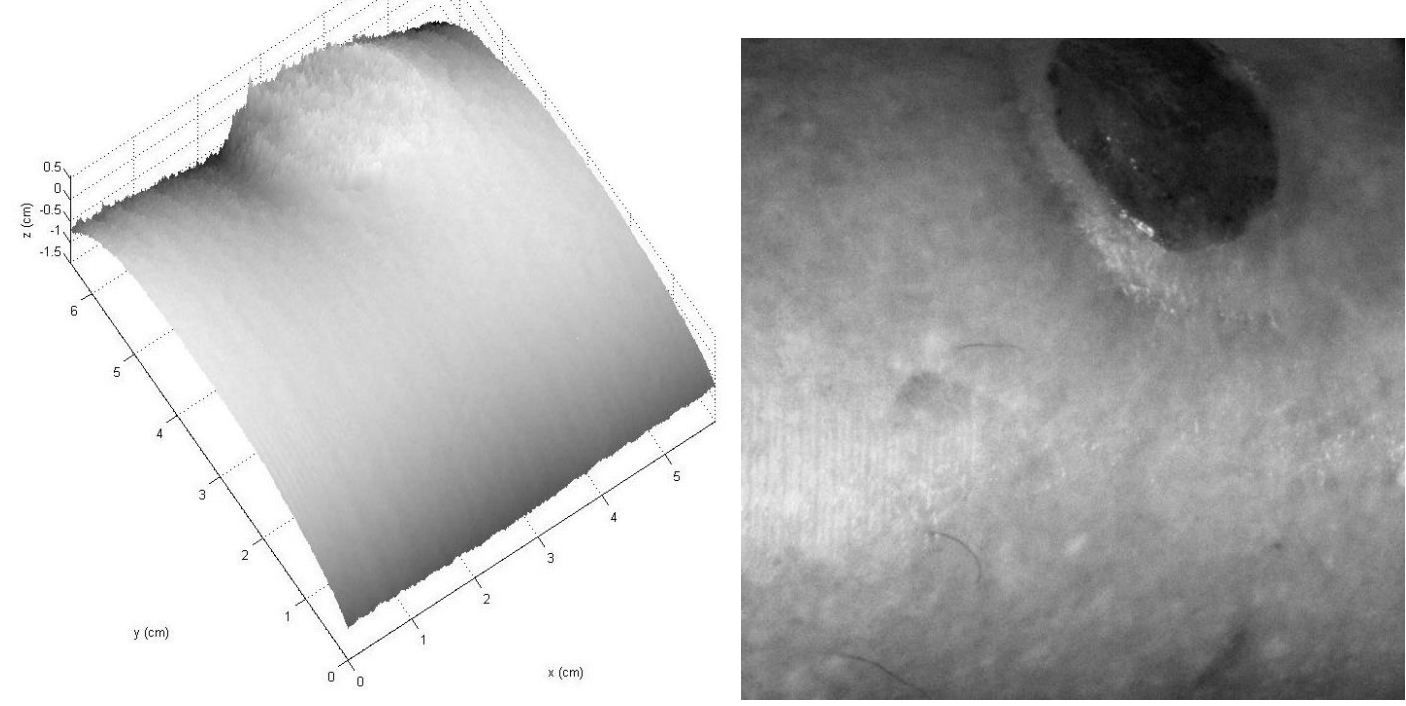

Figura 93: MDT 3D (esquerda) e mapa de intensidades (direita) obtidos para a lesão do paciente 3.

Nesta última seção, observou-se que foi possível utilizar a Técnica de Projeção de Franjas para obter a topografia de lesões em pacientes com sucesso. Porém, conforme já 
se havia estudado anteriormente com os objetos regulares, nos casos em que a lesão apresenta sombra, bordas abruptas, brilho e uma coloração que impede que as franjas e sua frequência sejam bem distinguidas, a técnica apresenta uma limitação. Nas seções anteriores, também se observou que a maior discrepância entre os dados obtidos com a técnica e os medidos com o paquímetro, para os objetos que não apresentavam essas características, foi sempre inferior a $0,30 \mathrm{~cm}$, portanto, essa foi a incerteza utilizada.

Além disso, na tomada de dados das lesões de pacientes, notou-se uma dificuldade em obter as imagens do objeto de calibração posicionado em um plano de referência adequado, pois era necessário pedir para que o paciente segurasse o objeto próximo à superfície da lesão ou apoiá-lo sobre ela. Por isso, se sugere uma adaptação ao suporte portátil utilizado no arranjo experimental no ambiente hospitalar, que consiste em acoplar uma ponteira de tamanho $L$ (Figura 11 ) retrátil, que permite ajustar a posição do objeto de calibração apoiado em um plano de referência para a obtenção das imagens deste e retirá-lo para a obtenção das imagens da lesão.

Ao longo de todo esse estudo, se observou que a principal limitação da técnica se deve à presença de sombra e brilho na imagem ou à presença de bordas abruptas nos objetos, pois todos esses fatores prejudicam a identificação da frequência do padrão e a distinção entre as franjas ou causam descontinuidades nelas.

Uma primeira alternativa para se tentar contornar esses problemas seria testar outros métodos de reconstrução dos padrões (como a Transformada de Fourier Selecionada [Kemao, 2004], a Transformada de Ondulações Contínuas [Dursun et al., 2004], a Transformada S [Ozder, 2007], o Método de Dupla Propagação [Brito et al., 2013], entre outros.) e compará-los com os resultados obtidos com a Técnica de Projeção de Franjas. Também se poderiam testar outros métodos de desmodulação da fase (como o método de desmodulação de fase temporal [Huntley e Saldner, 1993], o método de confiabilidade guiada [Su e Chen, 2004], o método de desmodulação da fase espaço-temporal [Zhang et al., 1999], entre outros.) e compará-los com os resultados obtidos com o Método de Deslocamento de Fase. Essas alternativas de análise seriam interessantes, pois buscam eliminar de forma mais efetiva a presença de ruídos na imagem. 
Outra proposta interessante para eliminar ou contornar principalmente o problema da sombra e do brilho nas imagens seria a utilização de múltiplos projetores [Cai e Su, 2007], cada um iluminando o objeto de estudo de um ângulo diferente, ou a utilização de tomografia óptica [Srivastava et al., 2010], que fotografa o objeto de vários ângulos diferentes e reconstrói o padrão através das várias imagens obtidas.

Além desses principais problemas observados, também existe a limitação tecnológica dos equipamentos utilizados que, conforme estudado no processo de calibração e teste do arranjo experimental, a partir de uma determinada densidade de franjas, produziam deformações nos padrões senoidais a serem projetados e adquiridos. Dessa forma, para tentar melhorar a limitação e a precisão da técnica se poderia utilizar uma câmera e um projetor com melhor resolução, capaz de adquirir e projetar imagens com um padrão de franjas senoidal de maior frequência, sem causar deformações nestas, já que a técnica aumenta a sua precisão conforme aumenta a densidade de franjas projetadas.

Dessa forma, observando e respeitando as limitações da Técnica de Projeção de Franjas utilizada com os métodos e equipamentos descritos nessa dissertação, estabeleceu-se um protocolo de procedimento para a utilização desta na medida de dimensões de lesões na pele de pacientes no hospital. Esse protocolo está descrito na seção seguinte.

\subsection{Sugestão de um protocolo de procedimento para a utilização da técnica na medida de lesões na pele}

1. Primeiramente, analise as características da lesão:

a) Caso a lesão apresente necrose ou tecido de coloração escura (praticamente da cor das franjas projetadas), não será possível a utilização da técnica ou os resultados apresentarão muitos ruídos e artefatos;

b) Caso a lesão apresente regiões de sombra, brilho e bordas abruptas muito grandes em relação ao tamanho da lesão, os resultados também apresentarão ruídos e artefatos;

c) Caso essas regiões sejam pequenas em relação ao tamanho da lesão, esses problemas podem ser contornados com ajuste da iluminação e filtragem adequada das imagens; 
2. Posicione o suporte com a câmera e o projetor de forma que a imagem do padrão senoidal seja projetada sobre a lesão e, ao mesmo tempo, a câmera consiga captar essa imagem;

3. Ajuste a iluminação de fundo e a abertura da lente acoplada à câmera de modo que as franjas apareçam sem saturação e nitidamente na imagem;

4. Adquira as quatro imagens da lesão;

5. Posicione o objeto de calibração, através da ponteira retrátil, a uma distância bem próxima da lesão, adequada para ser tomada como plano de referência:

a) O objeto e o plano de referência deste devem ser esterilizados previamente;

b) Deve-se utilizar um objeto e um plano de referência para cada paciente;

6. Ajuste novamente a iluminação de fundo e a abertura da lente acoplada à câmera de modo que as franjas apareçam sem saturação e nitidamente na imagem;

7. Adquira as quatro imagens do objeto de calibração;

8. A análise das imagens pode ser feita posteriormente. 


\section{CONCLUSÕES E PERSPECTIVAS FUTURAS}

Sabendo do problema e da importância de medir dimensões de lesões crônicas na pele de pacientes, como úlceras por pressão e lesões em pacientes com dificuldade de cicatrização, para o acompanhamento do processo de cicatrização e a escolha do tratamento adequado, o objetivo deste trabalho foi desenvolver uma técnica capaz de medir as dimensões de lesões na pele de forma não invasiva, rápida, exata e de baixo custo.

Para isso, primeiramente calibrou-se o arranjo experimental, escolhendo as distâncias a serem utilizadas e o melhor período das franjas projetadas. As distâncias foram escolhidas de forma a possibilitar uma precisão adequada da técnica para a medição do tamanho típico de lesões crônicas e úlceras, mas que ao mesmo tempo fossem possíveis de serem reproduzidas em um ambiente hospitalar, essas distâncias foram de $d \cong 10 \mathrm{~cm}$, entre a câmera CCD e o projetor, e de $L \cong 50 \mathrm{~cm}$, entre o plano de referência e a câmera. Já o período das franjas foi escolhido como sendo o com maior frequência, mas que ao mesmo tempo fosse capaz de ser reproduzido pelo projetor e adquirido pela câmera sem sofrer deformação, esse período foi de $p=(0,33 \pm 0,01) \mathrm{cm} /$ franja.

Em seguida, compararam-se duas técnicas diferentes de análise de franjas: a Técnica Moiré de Projeção e a Técnica de Projeção de Franjas, e chegou-se a conclusão de que a Técnica de Projeção de Franjas era a mais adequada para o propósito estabelecido, já que, além de reproduzir melhor a topografia do objeto estudado, também apresentava a vantagem da análise ser mais simples, com menos passos, e de necessitar da aquisição de menos imagens. Também se compararam dois métodos diferentes de reconstrução dos padrões: o método de Deslocamento de Fase e o de Projeção Ortogonal, o método de Deslocamento de Fase apresentou melhores resultados, uma vez que o método de Projeção Ortogonal requer uma densidade de franjas maior a ser projetada sobre o objeto, para que haja uma separação e uma definição maior entre os termos de ordem zero e de primeira ordem, e os equipamentos utilizados no arranjo experimental não possuíam resolução suficiente para isso.

Estudou-se também a possibilidade de projetar franjas coloridas com o intuito de obter melhor contraste entre elas em superfícies com cores que simulavam diferentes tons de pele e a cor das lesões. Porém, provavelmente devido à utilização de uma câmera CCD 
monocromática no arranjo experimental, o padrão que apresentou melhores resultados foi o padrão preto e branco.

Então, aplicou-se a Técnica de Projeção de Franjas com Deslocamento de Fase para a obtenção de topografias e dimensões de objetos com diferentes geometrias e cores, chegando-se a conclusão de que a técnica não resolve bem objetos que apresentem grandes regiões (em relação ao tamanho da região de interesse) de sombra, brilho ou que apresentam bordas abruptas ou descontínuas, onde as franjas não se deformam acompanhando as variações de altura na topografia, pois, nesses casos, os resultados apresentaram artefatos e ruídos. Também se observou que os planos de referência devem ocupar a imagem toda, para que não haja ruídos por conta disso.

Nos casos em que os objetos não apresentam as características citadas, ou as regiões que as apresentam são muito pequenas em relação ao tamanho da região de interesse, a técnica pode ser utilizada e apresenta bons resultados. Nesses casos, os ruídos e artefatos podem ser tratados com filtros adequados ou pode-se ajustar a iluminação de fundo e a abertura da lente acoplada à câmera, de modo a obter uma maior distinção entre as franjas. Nessas condições, as dimensões dos objetos obtidas com a técnica foram compatíveis com as medidas com um paquímetro, sendo que a máxima discrepância entre os valores foi sempre inferior a $0,30 \mathrm{~cm}$. Essa foi, portanto, a precisão adotada para a utilização da técnica com o arranjo experimental utilizado.

Observou-se também que a precisão obtida para a técnica está relacionada com o período espacial de padrão de franjas projetado, uma vez que a precisão encontrada para a técnica, de $0,30 \mathrm{~cm}$, foi muito próxima ao tamanho das franjas utilizadas, de $(0,33 \pm 0,01) \mathrm{cm}$.

Na aplicação da Técnica de Projeção de Franjas com Deslocamento de Fase para a obtenção de topografias e dimensões de lesões de pacientes, novamente houve dificuldade em reconstruir imagens em que as lesões apresentavam regiões de sombra, brilho, bordas abruptas ou coloração escura. Já para as lesões cujas regiões que apresentavam essas características eram pequenas ou não afetavam a visibilidade e a distinção entre as franjas, a topografia e as dimensões destas foram obtidas com sucesso.

Com isso, concluiu-se que é possível utilizar a Técnica de Projeção de Franjas com Deslocamento de Fase para a medida de dimensões de lesões na pele e, observando e 
respeitando as limitações dela com os métodos e equipamentos utilizados, pôde-se estabelecer um protocolo de procedimento para a utilização da técnica na medida de dimensões de lesões na pele de pacientes na clínica.

Como perspectivas futuras para este trabalho, pode-se tentar melhorar a precisão e contornar os problemas citados anteriormente, utilizando uma câmera e um projetor com melhor resolução, testando outros métodos de reconstrução dos padrões, outros métodos de desmodulação da fase, além de melhoras na utilização da técnica em si, propostas na literatura. 


\section{REFERÊNCIAS BIBLIOGRÁFICAS}

BRITO IV; GESUALDI MRR; RICARDO J; PALACIOS F; MURAMATSU M; VALIN JL Photorefractive digital holographic microscopy applied in microstructures analysis. Optics Communications 286 103-110, 2013.

CAI Y; SU X - Inverse projected-fringe technique based on multi projectors. Optics and lasers in Engineering 45(10) 1028-1034, 2007.

CHEN L; HUANG C - Miniaturized 3D surface profilometer using digital fringe projection. Measurement Science and Technology 16 (5) 1061-1068, 2005.

CHING N; ROSENFELD D; BRAUN M - Two-dimensional phase unwrapping using a minimum spanning tree algorithm, IEEE Transactions on Image Processing 1 355-365, 1992.

COOPER DM - Clinical Assessment/Measurement of Healing: Evolution and Status. Clinical Materials 8 263-271, 1991.

COSTA RM; BRAGA RA; OLIVEIRA BS; SILVA E; YANAGI T; LIMA JT - Sensitivity of the moiré technique for measuring biological surfaces. Biosystems Engineering 100 321-328, 2008.

DASS A - Projeto Humanae. http://humanae.tumblr.com, acessado em 01/10/2012.

DURSUN A; OZDER S; ECEVIT FN - Continuous wavelet transform analysis of projected fringe patterns. Measurement Science and Technology 15(9) 1768-1772, 2004.

EDSBERG LE - Pressure Ulcer Tissue Histology: An Appraisal of Current Knowledge. Ostomy Wound Management 53(10) 40-49, 2007.

FERRAQ Y; BLACK D; LAGARDE JM; SCHMITT AM; DAHAN S; GROLLEAU JL; MORDON S - Use of a 3-D imaging technique for non-invasive monitoring of the depth of experimentally induced wounds. Skin Research and Technology 13 399-405, 2007.

FERREIRA MC; DE CARVALHO VF; JUNIOR PT; ALVES HR; NAKAMOTO HA; MICHELSKI DA - Tratamento cirúrgico da úlcera por pressão como complicação do tétano. Revista Brasileira de Cirurgia Plástica 23(4) 337-342, 2008. 
GASVIK KJ - Optical Metrology. John Wiley \& Sons, Ltd. Chichester, England, 2002.

GORTHI SS; RASTOGI P - Fringe Projection Techniques: Whither we are? Optics and lasers in Engineering 48(2) 133-140, 2010.

HAGHPANAH S; BOGIE K; WANG X; BANKS PG - Reliability of electronic versus manual wound measurement techniques. Archives of Physical Medicine and Rehabilitation 87 1396-1402, 2006.

HOBSON CA; ATKINSON JT; LILLEY $\mathrm{F}$ - The application of digital filtering to phase recovery when surface contouring using fringe projection techniques. Optics and Lasers in Engineering 27 355-368, 1997.

HUANG PS; JIN F; CHIANG F - Quantitative evaluation of corrosion by a digital fringe projection technique. Optics and Lasers in Engineering 31(5) 371-380, 1999.

HUMBERT P; MEAUNE S; GHARBI T - Wound healing assessment. Phlebolymphology 47 312-319, 2004.

HUNTLEY JM; SALDNER H - Temporal phase-unwrapping algorithm for automated interferogram analysis. Applied Optics 32(17) 3047-3052, 1993.

KAUFMANN G; GALIZZI G; RUIZ P - Evaluation of a preconditioned conjugate-gradient algorithm for weighted least-square unwrapping of digital speckle-pattern interferometry phase maps, Applied Optics 37(14) 3076-3084, 1998.

KEMAO Q - Windowed Fourier transform for fringe pattern analysis. Applied Optics 43(13) 2695-2702, 2004.

LAGAN KM; DUSOIR AE; MCDONOUGH SM; BAXTER D - Wound Measurement: The Comparative Reliability of Direct Versus Photographic Tracings Analyzed by Planimetry Versus Digitizing Techniques. Archives of Physical Medicine and Rehabilitation 81 11101116, 2000.

LI JL; SU XY; SU HJ; CHA SS - Removal of carrier frequency in phase-shifting techniques. Optics and Lasers in Engineering 30 107-115, 1998.

LILLEY F; LALOR MJ; BURTON DR - Robust fringe analysis system for human body shape measurement. Optical Engineering 39(1) 187-195, 2000. 
LINO ACL - Aplicação de Moiré de Projeção com Deslocamento de Fase na Construção de Modelos Digitais Topográficos de Órgãos Vegetais. Dissertação (Doutorado em Engenharia Agrícola). Universidade Estadual de Campinas, 2008.

MARTÍNEZ A; RAYAS JA; CORDERO RR; BALIEIRO D; LABBE F - Leaf cuticle topography retrieved by using fringe projection. Optics and Lasers in Engineering 50 31-235, 2012.

MIAO H; QUAN C; TAY CJ; FU Y - Analysis of phase distortion in phase-shifted fringe projection. Optics and Lasers in Engineering 45 318- 325, 2007.

MICHALSKI M; RABAL HJ; GARAVAGLIA MJ - Operations using fringe projection. Applied Optics 25(23) 4338-4342, 1986.

NPUAP - National Pressure Ulcer Advisory Panel. http://www.npuap.org/, acessado em $15 / 02 / 2013$

OZDER S; KOCAHAN O; COSKUN E; GOKTAS H - Optical phase distribution evaluation by using S-transform. Optics Letters 32(6) 591-593, 2007.

PATORSKI, K. - The Moiré Fringe Technique. Elsevier Science Publishes. Amsterdam, Netherlands, 1993.

QUAN C; TAY CJ; CHEN LJ - A study on carrier-removal techniques in fringe projection profilometry. Optics \& Laser Technology 39 1155-1161, 2007.

RAJSHEKHAR G; RASTOGI P - Fringe analysis: Premise and perspectives. Optics and Lasers in Engineering 50(8) iii-x, 2012.

SOGA, D - Medida de Topografia de superfície usando a Técnica de Deslocamento de Fase. Dissertação de Mestrado em Física. Universidade de São Paulo, 2000.

SOURCE - Source ${ }^{\circledR}$ Werbeartikel. http://www.source-werbeartikel.com/PANTONE/, acessado em 19/02/2013.

SRIVASTAVA A; TSUKAMOTO K; YOKOYAMA E; MURAYAMA K; FUKUYAMA M - Fourier analysis based phase shift interferometric tomography for three-dimensional reconstruction of concentration field around a growing crystal. Journal of Crystal Growth 312 2254-2262, 2010. 
SU X; CHEN W - Reliability-guided phase unwrapping algorithm: a review. Optics and Lasers in Engineering 42 245-261, 2004.

TAKEDA M; INA H; KOBAYASHI S - Fourier-transform method of fringe-pattern analysis for computer-based topography and interferometry. Journal of the Optical Society of America 72(1), 1982.

TAVARES PJ; VAZ MA - Orthogonal projection technique for resolution enhancement of the Fourier transform fringe analysis method. Optics Communications 266 465-468, 2006.

VOLKOV VV; ZHU Y - Deterministic phase unwrapping in the presence of noise. Optics Letters 28(22) 2156-2158, 2003.

WANG Y; GU Y; LIAO X; CHEN R; DING H - Fluorescence monitoring of a photosensitizer and prediction of the therapeutic effect of photodynamic therapy for port wine stains. Experimental Biology and Medicine 235 175-180, 2010.

YERAS AM - El Moiré de Sombra y la lluminación Estructurada en el diagnóstico y seguimiento de enfermedades del sistema óseo-muscular del cuerpo humano. Tesis de Doctorado en Ciencias Técnicas. Instituto Superior Politécnico “José A. Echeverría”, 2004.

YERAS AM - Moiré topography in odontology. Optics and Lasers in Engineering 40 143152, 2003.

ZHANG H; LALOR MJ; BURTON DR - Spatiotemporal phase unwrapping in the measurement of shape. Applied Optics 38(16) 3534-3541, 1999.

ZHANG Q; SU X - High-speed optical measurement for the drumhead vibration. Optics Express 13(8) 3110-3116, 2005.

ZHANG Q; SU X - An optical measurement of vortex shape at a free surface. Optics \& Laser Technology 34(2) 107-113, 2002.

ZHOU G; LI Z; WANG C; SHI Y - A Novel Method for Human Expression Rapid Reconstruction. Tsinghua Science and Technology 14 62-65, 2009. 


\section{ANEXOS}

\subsection{Anexo I}

\section{INSTITUTO DE FÍSICA DA UNIVERSIDADE DE SÃO PAULO}

\section{INSTITUTO DE INFECTOLOGIA EMILIO RIBAS}

TERMO DE CONSENTIMENTO LIVRE E ESCLARECIDO

I - DADOS DE IDENTIFICAÇÃO DO SUJEITO DA PESQUISA OU RESPONSÁVEL LEGAL

1. NOME DO PACIENTE:

DOCUMENTO DE IDENTIDADE №:

SEXO: $\square \quad F \square$

DATA DE NASCIMENTO:

ENDEREÇO:

№ APTO:

BAIRRO: CIDADE:

CEP: TELEFONE: DDD

2. RESPONSÁVEL LEGAL:

NATUREZA (grau de parentesco, tutor, curador, etc.):

DOCUMENTO DE IDENTIDADE №.

SEXO: $\square \quad F \square$

DATA DE NASCIMENTO:

ENDEREÇO: № APTO:

BAIRRO: CIDADE:

CEP: TELEFONE: DDD 
II - DADOS SOBRE A PESQUISA CIENTÍFICA

1. TÍTULO DA PESQUISA: Utilização da Técnica de Projeção de Franjas para a avaliação de dimensões de lesões de pele e sua evolução durante a cicatrização

RESPONSÁVEL PELA PESQUISA: Marcia Tiemi Saito

CARGO/FUNÇÃO: Estudante de mestrado do Instituto de Física da Universidade de São Paulo

2. AVALIAÇÃO DO RISCO DA PESQUISA:

SEM RISCO

RISCO MINIMO $\square \quad$ RISCO MÉDIO

RISCO BAIXO

RISCO MAIOR $\square$

(Probabilidade de que o indivíduo sofra algum dano como consequência imediata ou tardia do estudo)

3. DURAÇÃO DA PESQUISA: 01 sessão 
III - REgISTRO DAS EXPLICAÇÕES do PESQUisAdor AO PACIENTE OU SEU REPRESENTANTE LEGAL SOBRE A PESQUISA CONSIGNANDO:

1. Justificativa e os objetivos da pesquisa

2. Procedimentos que serão utilizados e propósitos, incluindo a identificação dos procedimentos que são experimentais

3. Desconfortos e riscos esperados

4. Benefícios que poderão ser obtidos

5. Procedimentos alternativos que possam ser vantajosos

Neste hospital você realiza um tratamento dermatológico para a cicatrização das lesões na sua pele. Como parte do acompanhamento do seu tratamento, os médicos precisam realizar medidas das dimensões da sua lesão, para avaliar se o tratamento está sendo eficaz ou não.

Esta pesquisa tem o objetivo de desenvolver uma nova técnica de medida das dimensões das lesões, como a profundidade e o volume, de forma não invasiva e precisa. A fim de melhor avaliar a eficácia do tratamento médico e a evolução do processo de cicatrização das lesões.

As medidas das dimensões da sua lesão consistem em projetar uma imagem na sua lesão, com um projetor e fotografá-la com uma câmera. Esse procedimento não causará nenhum desconforto, dor ou qualquer outro risco ao seu tratamento, por se tratar basicamente de tirar uma foto da lesão.

Os resultados dessa pesquisa poderão beneficiar outros pacientes no futuro, por desenvolver uma forma de medir as dimensões de lesões de forma precisa e não invasiva, sem causar dor ou qualquer risco. 
1. Acesso, a qualquer tempo, às informações sobre procedimentos, riscos e benefícios relacionados à pesquisa, inclusive para dirimir eventuais dúvidas.

2. Liberdade de retirar seu consentimento a qualquer momento e de deixar de participar do estudo, sem que isto traga prejuízo à continuidade da assistência.

3. Salvaguarda da confidencialidade, sigilo e privacidade.

O Sr(a) terá acesso a qualquer momento às informações sobre os procedimentos, riscos e benefícios relacionados à pesquisa, inclusive para solucionar dúvidas que não tenham Ihe ocorrido anteriormente.

O Sr(a) tem a liberdade de retirar o seu consentimento a qualquer momento e de deixar de participar do estudo, sem qualquer prejuízo ao tratamento.

Todos os dados obtidos serão conservados sob sigilo, sendo sua identidade preservada. Os dados obtidos estarão a sua disposição e/ou do representante legal devidamente credenciado, de acordo com as normas vigentes. 
V - INFORMAÇÕES DE NOMES, ENDEREÇOS E TELEFONES DOS RESPONSÁVEIS PELO ACOMPANHAMENTO DA PESQUISA, PARA CONTATO EM CASO DE INTERCORRÊNCIAS CLÍNICAS E REAÇÕES ADVERSAS.

Prof. Dr. José Angelo Lauletta Lindoso - Av. Dr. Enéas de Carvalho Aguiar, 450, Prédio II - IMT - Fone: (11) 30617023

Mestranda Marcia Tiemi Saito - Rua do Matão, Travessa R, 187, Laboratório de Dosimetria - IFUSP - Fone: (11) 30916775

VI - OBSERVAÇÕES COMPLEMENTARES

VII - CONSENTIMENTO PÓS-ESCLARECIDO

Declaro que, após convenientemente esclarecido pelo pesquisador e ter entendido o que me foi explicado, consinto em participar do presente Protocolo de Pesquisa.

São Paulo, de de 20 .

Assinatura do sujeito da pesquisa ou responsável legal

Assinatura do pesquisador

(carimbo ou nome legível) 